\author{
UNIVERSIDADE DE SÃO PAULO \\ FACULDADE DE MEDICINA DE RIBEIRÃO PRETO \\ DEPARTAMENTO DE BIOQUÍMICA E IMUNOLOGIA
}

Priscila de Oliveira Coelho

Identificação de genes associados à atrofia muscular induzida pela privação de andrógeno

\title{
RIBEIRÃO PRETO/SP
}




\section{Priscila de Oliveira Coelho}

Identificação de genes associados à atrofia muscular induzida pela privação de andrógeno

Tese apresentada à Faculdade de Medicina de Ribeirão Preto da Universidade de São Paulo, para obtenção do título de Doutor em Ciências. Área de concentração: Bioquímica.

Orientador: Prof. Dr. Marcelo Damário Gomes

\section{RIBEIRÃO PRETO/SP}


Autorizo a reprodução e divulgação total ou parcial deste trabalho, por qualquer meio convencional ou eletrônico, para fins de estudo e pesquisa, desde que citada a fonte.

Coelho, Priscila de Oliveira.

Identificação de genes associados à atrofia muscular induzida pela privação de andrógeno / Priscila de Oliveira Coelho - Ribeirão Preto, 2019. $125 f ., 30 \mathrm{~cm}$.

Tese apresentada à Faculdade de Medicina de Ribeirão Preto da Universidade de São Paulo, para obtenção de título de Doutor em Ciências. Área de Concentração: Bioquímica.

Orientador: Prof. Dr. Marcelo Damário Gomes

1.FBXO32. 2.Atrofia muscular. 3.Atrogenes. 4.Anti-atrogenes. 
Nome: Coelho, Priscila de Oliveira

Título: Identificação de genes associados à atrofia muscular induzida pela privação de andrógeno

Tese apresentada à Faculdade de Medicina de Ribeirão Preto da Universidade de São Paulo, para obtenção do título de Doutor em Ciências. Área de concentração: Bioquímica.

Aprovado em:

BANCA EXAMINADORA

Prof. Dr. Instituição:

Julgamento: Assinatura:

Prof. Dr. Instituição:

Julgamento: Assinatura:

Prof. Dr. Instituição:

Julgamento: Assinatura:

Prof. Dr. Instituição:

Julgamento: Assinatura: 


\section{AGRADECIMENTOS}

Aos meus pais, Wilson e Rosalina, pelo total apoio durante essa longa jornada da pósgraduação. Pelo suporte emocional nas épocas mais difíceis, por não terem me deixado desistir e por sempre apoiarem todos os meus sonhos. E minhas viagens!

Ao professor Marcelo pela oportunidade e confiança em trabalhar em seu laboratório todos esses anos.

À professora Rosely Godinho e seus alunos, Leonardo e Enio, pela parceria e colaboração com os inúmeros experimentos com animais e pela troca de conhecimento.

À professora Flavia Guarnier pelo aprendizado, pela paciência e disponibilidade.

À Livia Zaramela pela paciência e tranquilidade em me explicar, de novo e de novo, os caminhos difíceis da bioinformática.

À professora Isis e seus alunos, Willian e Dawit, muito obrigada pela paciência e pelos ensinamentos toda vez que eu aparecia pedindo inúmeros auxílios, anticorpos e protocolos.

Ao professor Cláudio e seus alunos. Obrigada pelos auxílios e pela parceria na realização de experimentos.

À Ana Carla pela parceria e companhia nesses 6 anos! Pelos dias de alegrias, dias de experimentos de 15 horas, dias normais, alguns difíceis, às vezes sem muita paciência e outros com muitas risadas! Obrigada por dividir milimetricamente a bancada comigo durante todo esse tempo! rs... pelos cafés durante a tarde pra falar da vida... Obrigada pelo auxílio pessoal, experimental e emocional!

À Nichelle por todo o auxílio experimental com os camundongos e com as macerações emocionantes de músculos imersos em nitrogênio líquido. Obrigada pela paciência, pelos ensinamentos "estatísticos" e por não ter me deixado roubar o ratinho Pancetta, cujo apego emocional foi tanto que quase morri de tristeza quando você o destroncou. 
Ao pessoal da secretaria: Maria Ivone, Rose e Ronaldo. Obrigada pelas risadas, pelos conselhos e as ajudas de última hora com as "papeladas" da pós.

À Maria Ivone pelo ouvido amigo, pelas conversas, as puxadas de orelha e seu carinhoso suporte emocional.

À Cacilda pela companhia, pelas inúmeras histórias e por dividir todo esse período de amadurecimento dentro do laboratório. E por não ter explodido o Prédio Central com as autoclaves esquecidas de desligar. Mas só às vezes rs...

Ao Rafael, por todos esses anos juntos. Por sempre me socorrer nos momentos mais difíceis, tanto no Doutorado com os experimentos complicados quanto com as dificuldades pessoais, quando as vezes tudo parecia se perder. Obrigada pelos dias bons e pelos dias incríveis partilhados. Pelas nossas viagens e aventuras! Pelo nosso amor.

À turma da academia Top Fusion: Marcus, Flávia, Rafaela, Marinho e Bruninha. Pelos treinos mortais de Wushu Sanda, pelas conversas e cervejas divididas, as muitas risadas partilhadas, as festas inesquecíveis e pela companhia.... Meu muito obrigado! Sem a amizade de vocês e esse esporte incrível, eu dificilmente teria sobrevivido aos vários períodos estressantes do Doutorado.

Ao meu vitiligo desenvolvido logo no início do Doutorado, por ter me mostrado que ansiedades precisam sim serem olhadas com carinho e entendidas. Obrigada por me ensinar que controlar o psicológico é essencial e também faz parte. E que as manchas não são marcas, são ensinamentos.

À Deus, pelo dom da vida, por me guiar no caminho correto e por decerto, ter colocado algumas pedras no meu caminho. Mas desta forma, por também me fazer entender que as dificuldades servem para serem superadas e que ainda há belas flores à minha espera. 
“Inteligência é a habilidade de se adaptar às mudanças. ” Stephen Hawking 


\section{RESUMO}

Coelho, P.O. Identificação de genes associados à atrofia muscular induzida pela privação de andrógeno. 125 folhas. Tese (Doutorado) - Faculdade de Medicina, Universidade de São Paulo, Ribeirão Preto, 2019.

A perda muscular ou atrofia é uma condição associada a importantes doenças sistêmicas humanas, incluindo diabetes, câncer e insuficiência renal. Há diversos estudos de perfis transcricionais mostrando que um conjunto comum de genes, denominados atrogenes, é modulado nos músculos atrofiados. No entanto, as alterações transcricionais que desencadeiam a reversão ou atenuação da atrofia muscular ainda não foram caracterizadas a nível molecular até o momento. Para identificar os principais genes envolvidos na recuperação da massa muscular esquelética, utilizamos a técnica de microarray e RT-PCR para investigar genes diferencialmente expressos durante a reversão da atrofia do músculo Elevador do ânus (EA) sensível a andrógeno, no modelo de castração e reposição de testosterona. Como esperado, a maioria dos genes expressos de maneira diferencial comportam-se como atrogenes e respondem à atrofia induzida pela castração. Porém, observou-se pela primeira vez um grupo de sete genes (APLN, DUSP5, IGF1, PIK3IP1, KLHL38, PI15 e MKL1) que não responderam à castração, mas exclusivamente à reposição de testosterona. Considerando que quase todas as proteínas codificadas por esses genes estão associadas à reversão da atrofia e podem funcionar como reguladores da proliferação/crescimento celular, nossos resultados abrem novas perspectivas sobre a existência de anti-atrogenes.

Palavras-chave: FBXO32, atrofia muscular, atrogenes e anti-atrogenes. 


\begin{abstract}
Coelho, P.O. Identification of genes associated in androgen deprivation-induced skeletal muscle atrophy. 125 pages. Thesis (Doctorate) Faculty of Medicine, University of São Paulo, Ribeirão Preto, 2019.
\end{abstract}

Muscle wasting or atrophy is a condition associated with major human systemic diseases including diabetes, cancer, and kidney failure. There is accumulating evidence from transcriptional profiles showing that a common set of genes, termed atrogenes, is modulated in atrophying muscles. However, transcriptional changes that trigger reversion or attenuation of muscle atrophy have not been characterized at the molecular level until now. To identify key genes involved in the recovery of skeletal muscle mass, we have used cDNA microarrays and RT-PCR to investigate genes differentially expressed during the atrophy reversion of the androgen-sensitive Levator ani muscle (LA), in the well-established model of castration and testosterone replacement. As expected, most of the differential expressed genes behave as atrogenes and responded to castration-induced atrophy. Strikingly, seven genes (APLN, DUSP5, IGF1, PIK3IP1, KLHL38, PI15, and MKL1) did not respond to castration but exclusively to the testosterone replacement. Considering that almost all proteins encoded by these genes are associated to reversion of atrophy and may function as regulators of cell proliferation/growth, our results open new perspectives on the existence of a new group of genes, determined anti-atrogenes.

Keywords: FBXO32, muscle atrophy, atrogenes, and anti-atrogenes. 


\section{LISTA DE ABREVIATURAS}

ActRIIA Receptores de activina tipo II A

ActRII Receptores de activina tipo II B

Akt/PKB Proteína quinase B

AMD1 Adenosilmetionina descarboxilase 1

AMH Hormônio Anti -Mülleriano

Atrogin-1/ MAFbx/ FBX032 Muscle atrophy F-box

APLN Apelina

ATP Adenosina trifosfato

BSA Albumina sérica bovina

CCK Colecistoquinina

CTGF Fator de crescimento do tecido conjutivo

CXCL14 Chemokine (C X C Motif) Ligand 14

DAVID Database for Annotation, Visualization and Integrated Discovery

DEPC Água milli-Q tratada com dietil-pirocarbonato 0,01\% e

autoclavada

DMEM

DPBS

DUSP5

EAA

E1

E2

E3

EA

Epc1

FDR

FOXO

GO

HEK293T

HOPX

IGF1
Meio de Eagle modificado por Dulbecco

Tampão salina fosfato Segundo Dulbecco

Fosfatase 5 de dupla especificidade

Esteróides androgênicos anabolizantes

Enzima ativadora de ubiquitina

Enzima carreadora de ubiquitina

Enzima ligante de ubiquitina ou ubiquitina-ligase

Músculo Elevador do ânus

Potenciador do Polycomb1

Taxa de falsa descoberta

Forkhead box $\mathrm{O}$

Ontologia gênica

Cultura de células embrionárias renais humanas

Proteína de único homeodomínio

Fator de crescimento semelhante à insulina tipo 1 
insulina

IRS-1

KLF15

KLHL38

LOWESS

MAPK

METTL7A

MKL1

mTOR

MuRF-1

NF-Kb

ODC1

PGF

PI15

PI3K

PIK3IP1

PT

RA

RING

RNs

RPL32

RPL39

RPS6Ka5

RT-PCR

da polimerase

SUP

TGF- $\alpha$

TGF- $\beta$

$\Delta \mathbf{C t}$

$\Delta \mathbf{C t}$
Substrato do receptor de insulina

Fator 15 semelhante à Kruppel

$38^{\circ}$ Membro da família Kelch identificado

LOcally WEighted Scatterplot Smoothing

Proteína quinase ativada por mitógeno

Proteína do tipo metiltransferase (7A)

Leucemia megacarioblastica 1

Complexo do alvo da rapamicina em mamíferos

Muscle RING Finger-1

Fator nuclear Kappa B

Ornitina descarboxilase 1

Fator de crescimento placentário

Inibidor de Peptidase 15

Fosfatidilinositol 3 quinase

Proteína 1 de interação da Fosfatidilinositol 3 quinase

Propionato de testosterona

Receptor de andrógenos

Really interesting new gene

Receptores nucleares

Proteína ribossomal L32

Proteína ribossomal L39

Proteína quinase a5 ribossomal s6

Reação da transcriptase reversa, seguida de reação em cadeia

Sistema Ubiquitina-Proteassoma

Fator de crescimento transformador $\alpha$

Fator de crescimento transformador $\beta$

Ct do Gene alvo menos Ct do gene constitutivo (housekeeping)

$\Delta \mathrm{Ct}$ do grupo de amostras menos $\Delta \mathrm{Ct}$ do grupo controle 


\section{SUMÁRIO}

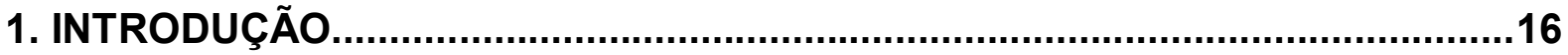

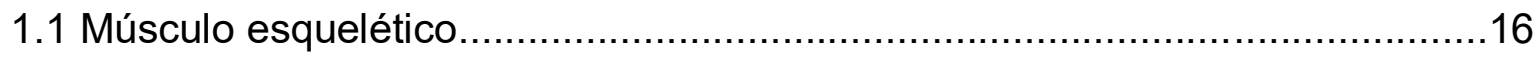

1.2 Reguladores da massa muscular esquelética...............................................18

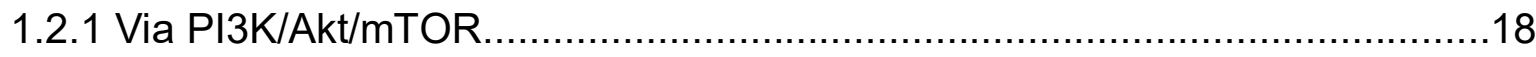

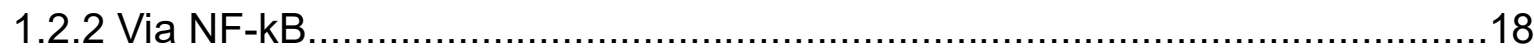

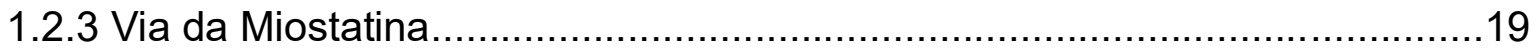

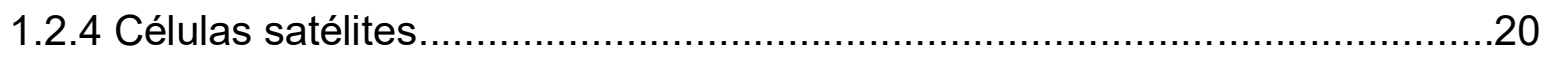

1.2.5 Apoptose e via autofágica/lisossomal ..................................................21

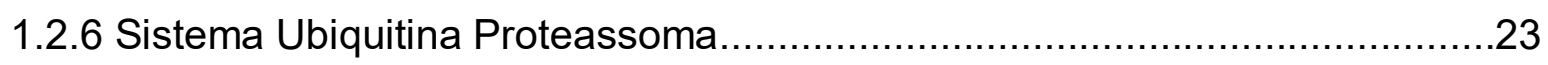

1.3 Modelos experimentais de atrofia em roedores........................................25

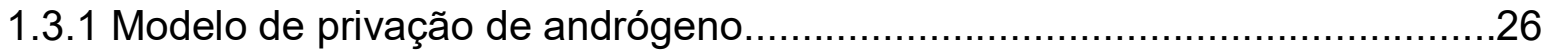

1.3.2 Testosterona e o receptor de andrógeno...............................................27

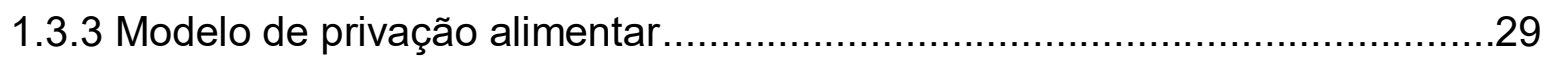

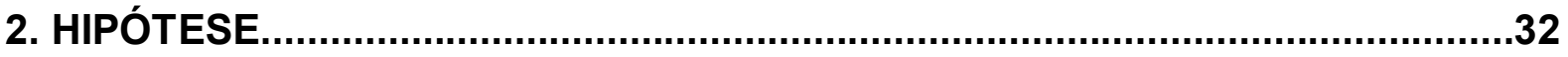

3. JUSTIFICATIVA

4. OBJETIVOS

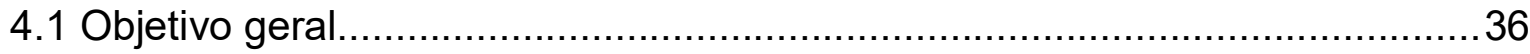

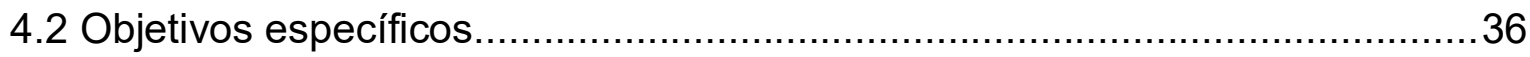

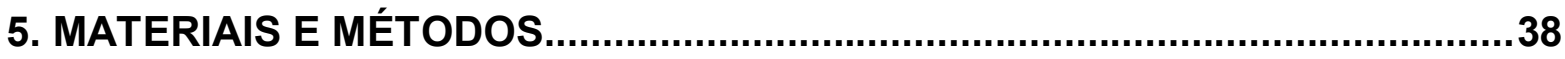

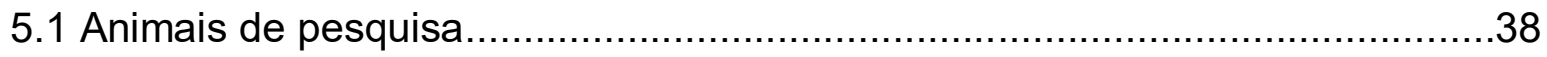

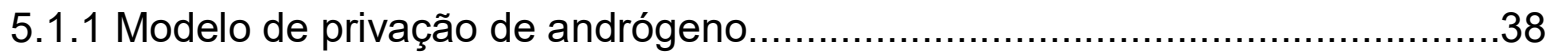

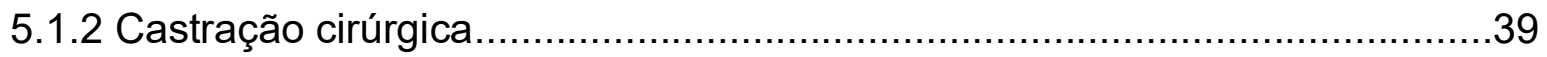




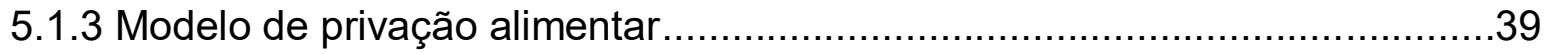

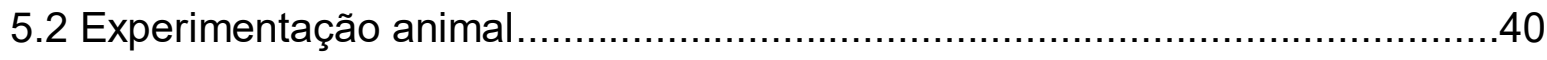

5.3 Extrações de RNA das amostras musculares................................................40

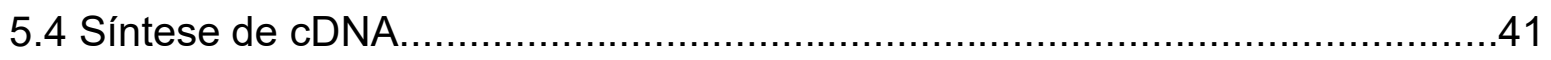

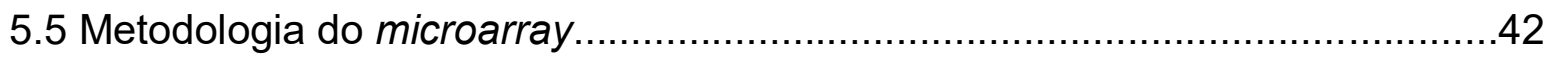

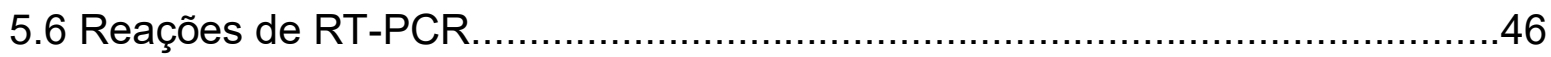

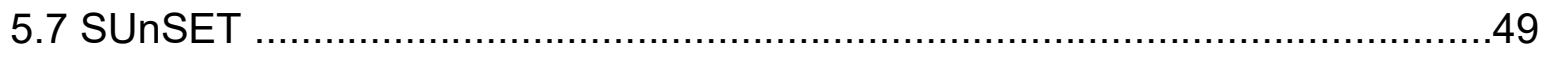

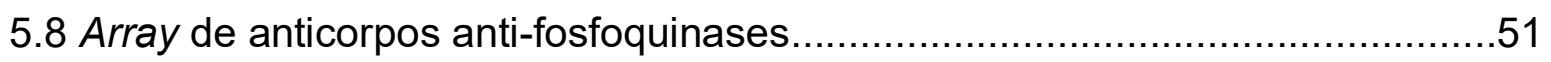

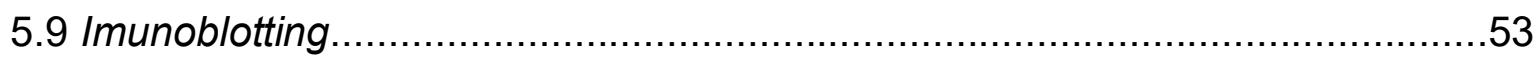

5.9.1 Anticorpos

6. RESULTADOS

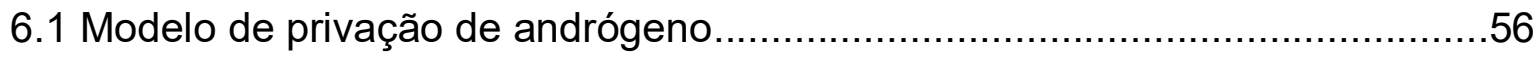

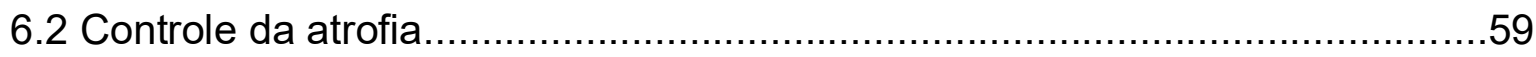

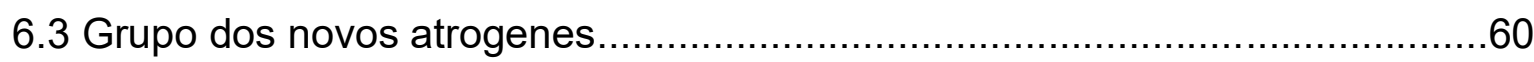

6.4 Grupo dos genes associados à reversão da atrofia.......................................65

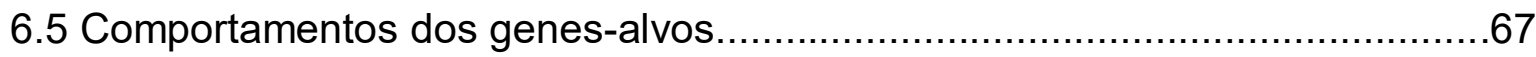

6.6 Modelo de privação alimentar.....................................................................68

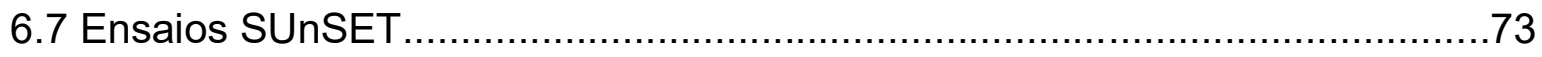

6.8 Array de anticorpos anti-fosfoquinases....................................................

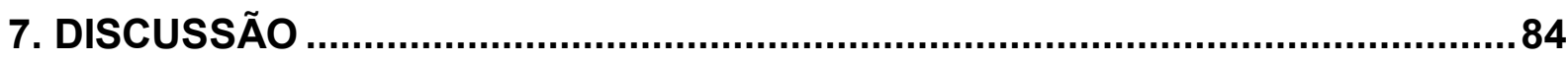

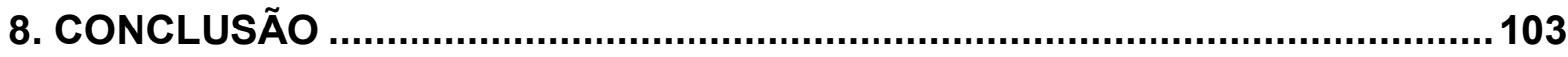

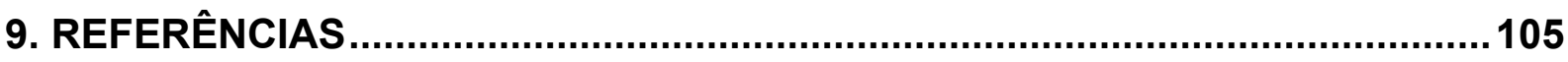

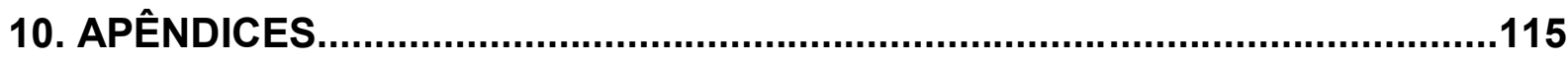

A. Genes diferencialmente expressos em 24 horas.......................................115

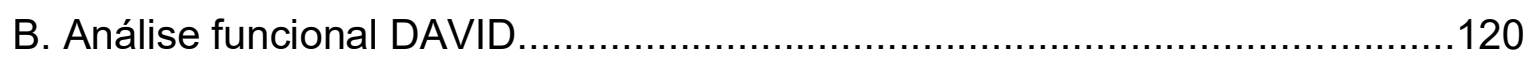


C. Membranas de nitrocelulose para Western blotting.

121

11. ANEXOS.

124

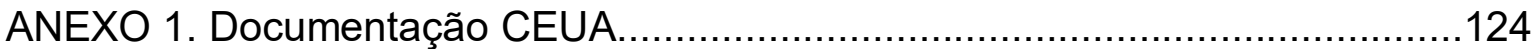

ANEXO 2. Fosfoquinases e sítios de fosforilação............................................125 


\section{INTRODUÇÃO}

\subsection{0 músculo esquelético}

A musculatura esquelética constitui cerca de $40 \%$ a $50 \%$ da massa corporal humana, sendo o principal tecido e a principal fonte de proteínas dos mamíferos, durante períodos catabólicos em situações de estresse metabólico, bem como um dos principais órgãos envolvidos na disponibilidade e manutenção de energia. Os músculos executam as funções locomotoras e posturais/tônicas, bem como desempenham um importante papel metabólico (Lee, Wang et al. 2000, Izumiya, Hopkins et al. 2008). Portanto, a manutenção da massa muscular é essencial para prevenir doenças e melhorar a qualidade de vida de um indivíduo.

Durante processos catabólicos, como no jejum, desequilíbrio hormonal ou doenças sistêmicas, os aminoácidos disponibilizados pelo músculo servem como fonte de energia para vários órgãos. A massa muscular e o tamanho das fibras respondem muito rapidamente a diferentes desafios, sejam eles anabólicos ou catabólicos. Foi descrito anteriormente que $30 \%$ de perda de peso representa $75 \%$ de queda na massa protéica. (Tisdale 2010, Sandri 2013). É de amplo conhecimento que o músculo esquelético possui uma plasticidade pronunciada e que é capaz de modular o seu metabolismo dependendo da tensão mecânica e do caráter da atividade contrátil.

As fibras musculares podem sofrer um processo de reparo de células danificadas quando o estresse (por exemplo, exercício ou trauma) ativa células satélites quiescentes da vizinhança, levando-as a proliferar, migrar e substituir/reparar as miofibrilas que sofreram injúrias (Shortreed K. 2008). 
Existem várias vias envolvidas no processo de perda muscular. O seu curso envolve um desequilíbrio no balanço entre a taxa de síntese e a degradação proteica, com a diminuição de massa em última instância (Hallows, Yu et al. 2011). Os fatores endócrinos e inflamatórios são os mediadores gerais desse equilíbrio (Lang, Streeper et al. 2010). O processo de atrofia envolve uma diminuição no tamanho/volume do tecido bem como a diminuição no volume celular, causada pela perda de proteínas, citoplasma e organelas, simultânea à diminuição de força e performance muscular. A atrofia muscular esquelética pode ocorrer em um indivíduo por vias naturais, no caso a senescência (sarcopenia) a partir da quinta década de vida; por períodos prolongados de jejum, doenças como câncer e diabetes, pacientes acamados, danos por queimaduras graves, doenças neurodegenerativas, AIDS ou estimulação hormonal catabólica com o uso de corticoesteroides (Thomas 2007, Cruz-Jentoft, Baeyens et al. 2010, Schiaffino, Dyar et al. 2013).

Já a síntese proteica no músculo esquelético é impulsionada pelo hormônio do crescimento IGF-1 (Glass 2005), a insulina e a testosterona (Fanzani, Conraads et al. 2012) sendo fortalecidos por nutrição e exercício adequados (Shavlakadze and Grounds 2006).

Assim, identificar os mecanismos moleculares que regulam a degradação e a síntese proteica é fundamental para o desenvolvimento de programas de exercícios eficazes e intervenções farmacológicas potenciais que possam inibir a atrofia muscular e/ou promoverem a hipertrofia. 


\subsection{Reguladores da massa muscular esquelética}

\subsubsection{Via PI3K/Akt/mTOR}

Uma das vias centrais para o controle do tamanho das fibras musculares é a via $\mathrm{PI3K} / \mathrm{Akt} / \mathrm{mTOR}$ (fosfatidilinositol 3 quinase/ proteína quinase $\mathrm{B}$ / alvo de rapamicina em mamíferos), uma via modulada por IGF-1 e a insulina (Rommel, Bodine et al. 2001). A estimulação da síntese de proteínas envolve esses hormônios interagindo com seus respectivos receptores de tirosina quinase para fosforilar o IRS-1 (substrato do receptor de insulina) e ativar a sinalização PI3K/Akt (Vivanco and Sawyers 2002), que ativa mTOR (Pallafacchina, Calabria et al. 2002) e por sua vez, fosforila downstream os alvos p70S6K e 4E-BP1 (Bodine, Stitt et al. 2001, Pallafacchina, Calabria et al. 2002) levando ao aumento da síntese proteica. A ativação de Akt possui duas funções simultâneas: resiste à atrofia fosforilando fatores de transcrição FOXO, impedindo assim sua translocação para o núcleo onde, de outra forma, promoveriam a transcrição dos atrogenes MuRF-1 e FBXO32 (ou MAFbx) associados à atrofia (Sandri, Sandri et al. 2004), ambas ubiquitinas ligases que catalisam a degradação de proteínas através do Sistema Ubiquitina Proteassoma (SUP). A inibição da fosforilação da Akt promove atrofia muscular, prevenindo a fosforilação dos fatores de transcrição da FoxO, impulsionando a transcrição dos atrogenes de atrofia MuRF-1 e FBXO32 (Sandri, Sandri et al. 2004, Skurk, Izumiya et al. 2005). Ambas E3 ligases também podem ser ativadas por uma via independente da sinalização de Akt, a via do NF-kB.

\subsubsection{Via NF-kB}

O NF-kB é um fator de transcrição ativado em atrofia por desuso (Hunter, Stevenson et al. 2002) e condições caquéticas (Remels, Gosker et al. 2010, Wysong, Couch et 
al. 2011). Quando não estimulado, o fator NF-kB encontra-se no citoplasma ligado a uma proteína inibitória: o lkB. Esse complexo impede a translocação do NF-kB para o núcleo. Quando estimulado, ocorre ativação de NF-KB, levando à sua translocação para o núcleo, onde então ele pode se ligar ao promotor de MuRF-1 e iniciar a degradação muscular induzida pelo proteassoma (Cai, Frantz et al. 2004). Os promotores de MuRF-1 e FBXO32 têm sítios putativos de ligação para outros fatores de transcrição, como os fatores de transcrição NF-kB, CCAAT/proteína potenciadora de ligação $\beta$ (C/EBPß) e Smad3, que podem ativar MuRF-1 ou FBXO32 individualmente ou em combinação com outros fatores. Numerosos estudos demonstraram um papel para os fatores de transcrição NF-kB (p65, c-Rrel, RelB, p52, p50) na indução de atrofia muscular sob condições como desuso (Judge, Koncarevic et al. 2007, Van Gammeren, Damrauer et al. 2009), desnervação (Mourkioti, Kratsios et al. 2006), envelhecimento (Bar-Shai, Carmeli et al. 2008) e caquexia (Cai, Frantz et al. 2004, Rhoads, Kandarian et al. 2010). A atrofia muscular induzida por níveis elevados dos fatores de transcrição NF-kB é frequentemente associada ao aumento da expressão das E3 ligases MuRF-1 e FBXO32. (Cai, Frantz et al. 2004, Wu, Kandarian et al. 2011).

\subsubsection{Via da Miostatina}

Nos últimos anos, a miostatina, membro da superfamília do fator de crescimento transformador $\beta$ (TGF- $\beta$ ), surgiu como um regulador chave da massa muscular esquelética. Sua deleção ou perda de função induz o crescimento excessivo do músculo, enquanto sua superexpressão ou administração sistêmica causa atrofia muscular. O dímero C-terminal maduro da miostatina liga-se a um dos dois receptores de activina tipo II (ActRIIB em maior grau que o ActRIIA), que recruta, 
fosforila e ativa os receptores de activina tipo I (ALK4 e ALK5) que, por sua vez, leva à fosforilação e ativação de Smad2 e Smad3 (Lee and McPherron 2001, Rebbapragada, Benchabane et al. 2003). Smad2 e Smad3 fosforilados formam um complexo heterodimérico com o mediador comum Smad4. Estas proteínas Smads ativadas funcionam como os principais mediadores intracelulares da sinalização da miostatina à medida que se translocam para o núcleo e ativam a transcrição dos genes-alvo através da interação com o DNA e outros fatores nucleares (Derynck, Zhang et al. 1998). Diversos estudos demonstraram que a inibição de diferentes componentes da via miostatina - ActRIIB - ALK4/ALK5 - Smad2/3 promove a hipertrofia muscular na idade adulta. (Sartori, Milan et al. 2009, Trendelenburg, Meyer et al. 2009).

Outros estudos revelaram uma relação entre os efeitos anabólicos dos andrógenos e a miostatina. Andrógenos regulam negativamente a expressão da miostatina no músculo elevador do ânus em ratos, músculo dependente de andrógeno (Mendler, Baka et al. 2007). Além disso, os andrógenos podem regular a expressão da miostatina também de maneira indireta. Por exemplo, a folistatina (FS), um regulador negativo da miostatina, é regulada positivamente após o tratamento com testosterona em células satélites e no músculo, sugerindo que a inibição da miostatina pela FS pode contribuir para o efeito hipertrófico dos andrógenos (Braga, Bhasin et al. 2012).

\subsubsection{Células satélites}

O crescimento muscular em adultos é principalmente devido ao aumento do conteúdo de proteínas celulares através da ativação da via PI3K/Akt/mTOR que regula a síntese de proteínas. No entanto, a adição de novos núcleos fornecidos por células-tronco musculares, chamadas células satélites, também parece ser 
necessária para o crescimento pós-mitótico das miofibrilas. As células satélites fornecem mioblastos para o crescimento pós-natal (Sloper and Partridge 1980, Allbrook 1981) e são fundamentais para a reparação do músculo esquelético (Sambasivan, Yao et al. 2011). Essas células são quiescentes até que um estresse (ex: trauma, exercício) seja imposto.

Após a lesão muscular, as células satélites são estimuladas pelos vários sinais que surgem do ambiente danificado. Elas então migram em direção ao local da lesão e entram novamente no ciclo celular para proliferar. Nesta fase, em resposta a estímulos como crescimento, remodelação ou trauma, as células-satélites são ativadas, proliferam-se e expressam marcadores miogênicos Pax7 e/ou Myf5 e/ou MyoD (Olguin, Yang et al. 2007, Bentzinger, Wang et al. 2013). Neste estado, também são denominadas mioblastos. Essas células fundem-se a fibras musculares já existentes ou a células satélites vizinhas para gerar novas fibras musculares.

Alguns dados sugerem que as células satélites também podem contribuir para a hipertrofia muscular após a perda da miostatina. De fato, o número de células satélites em estado estacionário por unidade de fibra muscular e a proporção de células satélites ativadas são significativamente mais altas em camundongos nocautes para a miostatina (Mstn - /-) do que em animais selvagens (McCroskery, Thomas et al. 2003).

Durante o envelhecimento a resposta proliferativa e capacidade regenerativa para perturbação são reduzidas nas células satélites (Collins, Zammit et al. 2007, van der Meer, Jaspers et al. 2011).

\subsubsection{Apoptose e via autofágica/lisossomal}

A via da apoptose, ou morte celular programada, é um processo importante em organismos multicelulares, mesmo durante o desenvolvimento, onde assegura a 
eliminação de tecidos supérfluos, sendo crítico para a manutenção da homeostase tecidual. Durante a apoptose, as enzimas que clivam as proteínas, as caspases, são ativadas no citosol e são responsáveis pela clivagem proteolítica de um amplo espectro de alvos celulares (Earnshaw, Martins et al. 1999). O músculo esquelético é um tecido único, pois suas células musculares, as miofibrilas, são multinucleadas. Este aspecto do músculo esquelético levou ao conceito do domínio mio-nuclear, que é definido como a quantidade teórica de citoplasma suportada por um único núcleo de fibra muscular, que é chamado de um mionúcleo (proteína/DNA) (Cheek 1985). Portanto, a perda de alguns núcleos não resulta necessariamente na destruição da fibra muscular (Dirks-Naylor and Lennon-Edwards 2011).

Mesmo assim, a apoptose desempenha um papel importante na atrofia do músculo esquelético. Fato este deduzido a partir da observação do seu aumento no músculo esquelético em vários aspectos patológicos e sob algumas circunstâncias fisiológicas. Exemplos: na insuficiência cardíaca crônica, distúrbios do neurônio motor, desnervação do músculo esquelético, lesão da medula espinhal, distrofia muscular e atrofia do músculo esquelético devido à suspensão ou imobilização do membro posterior estão associados a um aumento na taxa de apoptose dos músculos esqueléticos afetados (Allen, Linderman et al. 1997, Tews, Goebel et al. 1997, Podhorska-Okolow, Sandri et al. 1998, Adams, Jiang et al. 1999, DupontVersteegden, Murphy et al. 1999, Borisov and Carlson 2000, Smith, Maxwell et al. 2000).

Já o sistema proteolítico lisossomal, a primeira via proteolítica intracelular descrita, é caracterizado pela degradação de macromoléculas no interior do lisossomo (Blommaart et al. 1997). Esse processo ocorre constitutivamente para manter um equilíbrio anabólico/catabólico dinâmico dentro da célula. Mesmo assim, durante 
estresse oxidativo (Dobrowolny, Aucello et al. 2008, Aucello, Dobrowolny et al. 2009) ou condições catabólicas extremas (Schiaffino and Hanzlikova 1972, Mizushima, Yamamoto et al. 2004) podem regular a autofagia. mTOR está integralmente envolvido em vias de autofagia (Yang and Klionsky 2010), no entanto, nos músculos esqueléticos, o fator de transcrição FOXO3 é o principal indutor de genes da autofagia, como o LC3 e o Bnip3 (Mammucari, Milan et al. 2007). A expressão gênica induzida por FOXO3 bem controlada é a chave para a autofagia balanceada.

\subsubsection{Sistema Ubiquitina Proteassoma}

O Sistema Ubiquitina Proteassoma (SUP) é responsável por até $80-90 \%$ da degradação protéica celular (Lecker, Goldberg et al. 2006) sendo o principal mecanismo de proteólise intracelular. E a atividade proteolítica aumentada é uma marca registrada em vários modelos de atrofia. No caso do músculo esquelético, os aumentos no SUP estão associados à perda de massa muscular. No músculo, ele é necessário para remover proteínas sarcoméricas após alterações na atividade muscular. Uma diminuição na massa muscular está associada a: (1) aumento da conjugação de ubiquitina para proteínas musculares; (2) atividade proteassomal ATP-dependente aumentada; (3) aumento da degradação de proteínas que pode ser eficientemente bloqueada por inibidores do proteassoma; e (4) regulação positiva de transcritos que codificam a ubiquitina, algumas enzimas conjugadoras de ubiquitina (E2), algumas proteínas ubiquitina-ligases (E3) e várias subunidades do proteassoma (Lecker, Goldberg et al. 2006). 


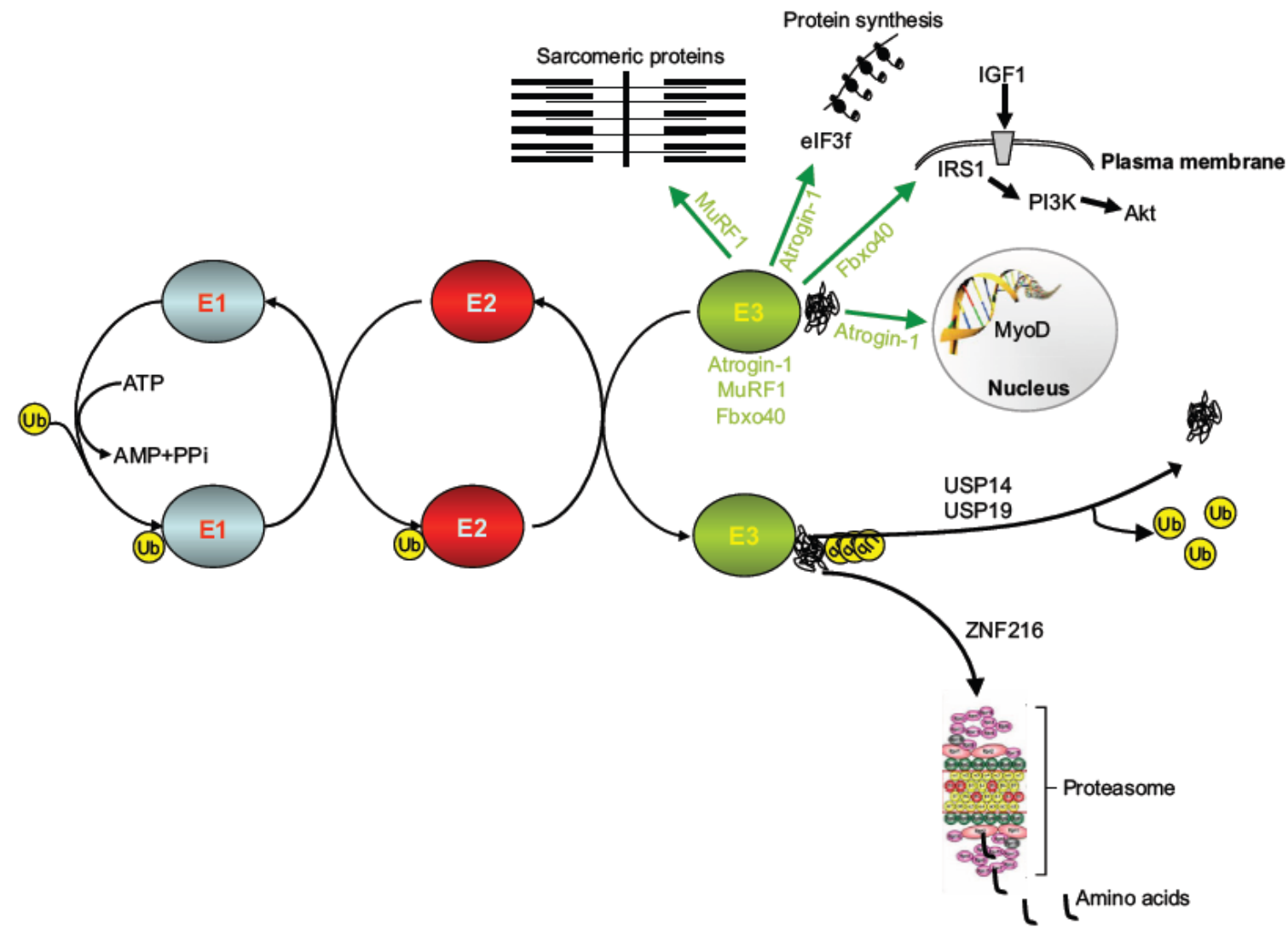

Figura 1. SUP na homeostase muscular. A enzima E1 ativa a ubiquitina numa reação dependente de ATP. A ubiquitina ativada é então encaminhada para enzimas E2 via E1. A reação final de ubiquitinação é catalisada por membros da classe de enzimas E3, induzindo a transferência de ubiquitina de E2 para o substrato. O substrato poliubiquitinado é reconhecido pelo proteassoma. As cadeias de poliubiquitina são removidas por enzimas de deubiquitinases (USPs). Os componentes deste sistema que contribuem para a perda de massa muscular são descritos: (1) O ZNF216 está envolvido no reconhecimento pelo proteassoma de proteínas ubiquitinadas durante a atrofia muscular; (2) Atrogin-1 regula a meia-vida do fator de transcrição MyoD e do elF3f, cruciais para a síntese proteica; (3) Fbxo40 regula a meia-vida do IRS1, um fator essencial para a sinalização de IGF-1/ insulina e (4) MuRF-1 regula a meia-vida de várias proteínas sarcoméricas. (Adaptado de "Cellular and molecular mechanisms of muscle atrophy") (Bonaldo and Sandri 2013).

O genoma humano codifica mais de 600 ubiquitina-ligases (Lee and Goldberg 2011).

Elas estão envolvidas na regulação precisa de diferentes processos celulares e vem sendo feito um grande progresso recente na elucidação dos papéis das diferentes E3s na regulação do metabolismo, transcrição, ciclo celular, oncogênese e tamanho das fibras musculares. Uma contribuição importante para a identificação de ubiquitina ligases envolvidas na atrofia foram fornecidas pelo pioneirismo em estudos de perfil de expressão gênica realizada pelos grupos do Dr. Alfred L. 
Goldberg e Dr. David J. Glass. Estudos esses que culminaram na descoberta das ubiquitina-ligases (E3) Atrogin-1 e MuRF-1, amplamente utilizadas como marcadores da atrofia (Bodine, Latres et al. 2001, Gomes, Lecker et al. 2001).

A análise comparativa de expressão gênica em diferentes modelos de atrofia muscular (incluindo diabetes, câncer-caquexia, insuficiência renal crônica, jejum e desnervação), estabeleceu a existência de um subconjunto de genes relacionados com atrofia ou Atrogenes (Sacheck, Hyatt et al. 2007).

\subsection{Modelos experimentais de atrofia em roedores}

As vantagens claras e bem conhecidas dos modelos animais são sua homogeneidade, geralmente de boa reprodutibilidade, nenhuma interferência com diferentes terapias e uma ampla gama de outros fatores imprevisíveis que afetam o desenvolvimento da doença em condições clínicas.

A maioria dos modelos de perda de massa muscular esquelética citados nos diversos estudos publicados em que se baseiam este trabalho, foram desenvolvidos em roedores, particularmente em ratos e camundongos. A vantagem óbvia dos camundongos é seu pequeno porte, fácil locação e rápida resposta em perda de peso/atrofia. Já os ratos são melhores para modelos cirúrgicos e permitem amostragem seriada de tecido.

Até agora pouco sabemos sobre o conjunto de genes que estão envolvidos na reversão da atrofia. Isso pode ser devido, em parte, aos desafios em intervir para reverter o processo de atrofia nesses modelos experimentais. Um modelo pouco estudado que permite tal estratégia de reversão é o modelo de atrofia por privação de andrógeno, no qual a reposição dos níveis de testosterona pode ser facilmente alcançada com a administração de sintéticos de testosterona. 


\subsubsection{Modelo de privação de andrógeno}

O músculo Elevador do ânus (EA) do rato macho adulto é um modelo particularmente sensível para estudar os efeitos do andrógeno na massa muscular esquelética e na expressão de ubiquitina ligases como Atrogin-1 e MuRF-1 (PiresOliveira, Maragno et al. 2010). Nesse modelo, a atrofia muscular é induzida especificamente pela remoção do androgênio, sem lesão neuromuscular invasiva, como na desnervação, ou distúrbio metabólico sistêmico causado por caquexia ou jejum. Pires-Oliveira e colaboradores (Pires-Oliveira, Maragno et al. 2010), mostraram que a testosterona rapidamente e amplamente inibe a expressão das ubiquitina-ligases Atrogin-1 e Murf-1 in vivo, o que pode ser crítico para a ação anabólica dos hormônios sexuais masculinos (Pires-Oliveira, Maragno et al. 2010).

O músculo EA é considerado altamente responsivo à andrógeno mesmo durante pouco tempo de tratamento (Ferrando, Sheffield-Moore et al. 2002, Giannoulis, Jackson et al. 2008). Em um período curto de 7 dias de castração, o EA apresenta a ativação clássica dos atrogenes e o tratamento desses animais com o sintético propionato de testosterona leva a atenuação do quadro, otimizando o equilíbrio proteico muscular (Pires-Oliveira, Maragno et al. 2010). A sensibilidade acentuada desse músculo às alterações aos níveis androgênicos, podem ser facilmente observados por RNAm de atrogenes clássicos antes e após a reposição de PT (ao invés de ser necessário dosar os níveis de testosterona nesses animais), confirmando a efetiva depleção da testosterona pela orquidectomia bem como a sua reposição após a castração. No entanto, nenhuma investigação adicional do perfil transcricional no músculo EA após o tratamento foi descrita até agora. 


\subsubsection{Testosterona e o receptor de andrógeno}

Andrógenos pertencem a uma classe de hormônios esteróides que servem como ligantes para o receptor de andrógeno (RA). Quando este receptor interage com seus ligantes, ele modula a regulação de genes-alvo através do reconhecimento e ligação aos elementos de resposta ao andrógeno (AREs). Os andrógenos e o RA desempenham um papel essencial no desenvolvimento sexual (Hughes, Lim et al. 2001) e podem influenciar a regulação da composição corporal geral (Mooradian, Morley et al. 1987).

O receptor de andrógeno (RA) pertence à subfamília dos receptores nucleares (RNs)

e possui papel significativo no desenvolvimento e manutenção do sistema reprodutivo, muscular esquelético, cardiovascular, imunológico, dos sistemas neurais e hematopoiéticos ( $\mathrm{Lu}$, Wardell et al. 2006). O RA no seu estado inativo é normalmente ligado à proteínas de choque térmico (como HSP90 e HSP70) e à proteínas chaperonas no citosol. A ligação do andrógeno ao receptor desencadeia a liberação das HSPs e as consequentes mudanças conformacionais do RA necessárias para dimerização que assim iniciam um complexo programa de transcrição nas células alvo (Koryakina, Ta et al. 2014). Centenas de genes, como KLK3 (codifica o antígeno prostático específico/PSA), KLK2, FKBP5, entre outros, podem ser regulados pelo RA (Chen, Welsbie et al. 2004). A manutenção de todo o processo de regulação para manter uma homeostase adequada da expressão dos genes é crucial para o crescimento, desenvolvimento e saúde do estado do corpo humano.

Na via canônica, o esteróide anabolizante se liga ao RA para iniciar uma mudança conformacional e subseqüente associação com o co-ativador da transcrição RA- $\beta$ - 
catenina. O complexo de agonista/RA/ $\beta$-catenina transloca-se para o núcleo e se liga a elementos responsivos ao RA localizados no promotor de genes específicos, incluindo genes nas vias IGF-1 (Ferrando, Sheffield-Moore et al. 2002), Wnt (Singh, Bhasin et al. 2009) e miostatina (Mendler, Baka et al. 2007), para aumentar a transcrição (Singh, Artaza et al. 2006). Não canonicamente, os agonistas androgênicos foram demonstrados ativar diretamente Akt (Kang, Janne et al. 2004), levando a múltiplos efeitos downstream.

Os derivados sintéticos da testosterona são conhecidos como esteróides anabólicos androgênicos (EAA). Existem aproximadamente 60 diferentes compostos EAA que podem ser classificados em três classes (Clark \& Henderson, 2003) (Clark and Henderson 2003) com base em sua estrutura química e metabolismo. A classe I pertence aos compostos injetáveis derivados da esterificação do grupo 17ß-hidroxila de testosterona, que pode ser aromatizado para estrogênios, reduzido a diidrotestosterona (DHT), ou hidrolisado em testosterona. A classe II de EAA são compostos derivados de 19-nortestosterona injetáveis, que têm uma meia-vida mais longa e menos atividade androgênica do que os de Classe I. Semelhante à Classe I, a Classe II pode ser aromatizado para estrogênios ou reduzido a DHT. A alquilação no carbono 17 distingue classe III dos EAA (Clark and Henderson 2003) 4. O Propionato de testosterona (PT) pertence a Classe I dos AAS.

Hormônios sexuais masculinos regulam positivamente a massa muscular (Bhasin, Storer et al. 1996). A ativação dos receptores androgênicos nos tecidos-alvo pela testosterona leva ao aumento dos níveis de vários fatores de transcrição que modulam a expressão dos genes-alvo dos andrógenos (Gobinet, Poujol et al. 2002). De fato, é amplamente sabido que os andrógenos são capazes de aumentar a síntese de proteína muscular, enquanto a deficiência androgênica em homens está 
associada à perda de massa muscular esquelética (Mayer and Rosen 1977). Estes fenômenos têm sido extensivamente estudados no músculo EA de roedores machos.

\subsubsection{Modelo de privação alimentar}

Os modelos de atrofia por privação alimentar, que variam de seis horas até 72 horas de jejum, são amplamente utilizados e estão presentes em diversos e importantes estudos de atrofia muscular (Gomes, Lecker et al. 2001, Jagoe, Lecker et al. 2002, Allen, Cleary et al. 2010).

Durante períodos de privação alimentar, a manutenção dos níveis de glicose no sangue é de suma importância para a função cerebral normal. Portanto, os organismos privados de alimentos iniciam uma série de mecanismos fisiológicos designados para permitir que eles mantenham os níveis de glicose no sangue em uma situação de zero ingestão de nutrientes. Além disso, os estoques de energia são mobilizados a partir de vários tecidos para fornecer uma fonte contínua de nutrientes para a produção de energia. Nesse caso, o músculo esquelético exerce papel crítico no metabolismo, armazenando glicogênio e desempenhando função de fonte de aminoácidos que podem ser solicitados em condições de extrema demanda metabólica como durante a privação alimentar (Richard 2002). As proteínas do músculo esquelético são decompostas em aminoácidos livres (Daniel 1977), que podem então ser convertidos em glicose no fígado pela gliconeogênese (Mlekusch, Paletta et al. 1981). Esse processo resulta em uma rápida e dramática atrofia do músculo esquelético durante o estado de privação alimentar e essa atrofia é fundamental para a manutenção da homeostase da glicose durante o jejum (Orngreen, Zacho et al. 2003). 
Em roedores, durante o jejum, a testosterona diminui significativamente após 24 horas e 48 horas. Os níveis também caem após 16 horas de jejum, quando comparado com apenas 4 horas (Ahima, Prabakaran et al. 1996, Gavrilova, Leon et al. 1999, Champy, Selloum et al. 2004). Porém, o peso dos testículos não é afetado nos animais durante esse período (Gavrilova, Leon et al. 1999). 
HIPOTESE 


\section{HIPÓTESE}

Vários estudos na literatura utilizam modelos experimentais em roedores para estudar as vias de sinalização reguladas no músculo atrofiado. No entanto, nenhum estudo similar foi realizado no processo de reversão, principalmente, pelo fato da maioria dos modelos experimentais não permitirem tal reversão. Para abordar essa problemática, foi empregado um modelo bem estabelecido de privação/reposição de andrógeno no músculo Elevador do ânus de ratos machos adultos. A hipótese deste estudo é que existe uma resposta anti-atrófica no músculo EA que pode ser aplicada aos demais músculos esqueléticos. 
JUSTIFICATIVA 


\section{JUSTIFICATIVA}

O estudo de Pires-Oliveira em 2010, mostrou que a castração dos animais por três dias, insuficiente para o estabelecimento de um quadro de atrofia, induz a expressão de marcadores clássicos de atrofia no músculo EA de ratos machos adultos. Este modelo, com ativação aguda de atrofia/reversão, pode ser empregado para estudar a resposta transcricional ainda não caracterizada nos modelos de atrofia. A caracterização molecular do processo de reversão pode oferecer novas estratégias para intervenções farmacológicas/nutrição e protocolos de exercícios físicos objetivando a melhora/atenuação de casos clínicos de atrofia imposta por doenças ou injúrias graves. 


\section{OBJETIVOS}

\subsection{Objetivo geral:}

O principal objetivo deste trabalho foi investigar genes responsivos à reversão da atrofia no músculo Elevador do ânus de camundongos machos adultos, no modelo bem estabelecido de privação androgênica.

\subsection{Objetivos específicos:}

- Empregar a análise por microarray de cDNA para identificar genes responsivos na reversão de atrofia do EA em um modelo de privação androgênica. Para isto, foi comparado os perfis de expressão gênica de músculos de ratos castrados pelo período de 3 dias versus os animais que ficaram o mesmo tempo castrados e tiveram reposição de testosterona por períodos de 8 horas e 24 horas.

- Validar os genes-alvos identificados através da técnica de RT-PCR.

- Analisar os genes-alvos em músculo esquelético de menor responsividade aos andrógenos.

- Investigar a síntese proteica, com experimentos de marcação com Puromicina (SUnSET) em células HEK293T hiperexpressando genes-alvos.

- Investigar o perfil de fosforilação de fosfoquinases, com array de anticorpos anti-fosfoquinases, em músculo EA castrados por 3 dias e castrados por 3 dias e tratados com PT por 8 horas. 


\section{MATERIAIS E MÉTODOS}




\section{MATERIAIS E MÉTODOS}

\subsection{Animais de pesquisa}

\subsubsection{Modelo de privação de andrógeno}

O modelo em rato dos procedimentos de privação/reposição de testosterona foi aprovado pelo Comitê de Ética em Pesquisa da Universidade Federal de São Paulo - Escola Paulista de Medicina (1604/2007 e 0034/2012). Trinta e dois ratos Wistar machos adultos pesando entre 363 e $390 \mathrm{~g}$ do Laboratório de Experimentação Animal do Instituto Nacional de Farmacologia e Biologia Molecular (LEA-INFAR, UNIFESP) foram utilizados no estudo. Os animais foram divididos igualmente em três grupos:

- Grupo Sham (grupo S)

- Grupo Castrado (grupo C3)

- Grupo Castrado/tratado com propionato de testosterona (grupo C3pt).

Ratos dos grupos Sham $(n=8)$, C3 $(n=8)$ e C3pt- $(n=16)$ foram submetidos a cirurgia aberta. O grupo Sham sofreu apenas anestesia e a incisão.

Para C3 e C3pt, a cirurgia envolveu orquidectomia sob anestesia com 75 mg/kg de cetamina e $12 \mathrm{mg} / \mathrm{kg}$ de xilazina. Após a cirurgia, todos os animais foram monitorados durante todo o período experimental adicional. Após 3 dias de castração, os animais destinados ao grupo C3pt foram tratados com uma dose única de propionato de testosterona (PT - $4 \mathrm{mg} / \mathrm{kg}$, em $1 \mathrm{~mL} / \mathrm{kg}$ de óleo de milho) e eutanasiados após 8 horas $(n=8$; denominado grupo C3pt8) ou 24 horas $(n=8$; denominado grupo C3pt24). 


\subsubsection{Castração cirúrgica}

Os ratos foram anestesiados com cetamina $75 \mathrm{mg} / \mathrm{kg}$ e xilazina $12 \mathrm{mg} / \mathrm{kg}$ e castrados por via escrotal através de uma incisão longitudinal na região média do escroto. Após a incisão na túnica albugínea e expulsão dos testículos, os pedículos vasculares foram ligados acima da cabeça do epidídimo e seccionados. As estruturas restantes foram recolocadas na cavidade; o escroto foi suturado e a antissepsia foi feita com etanol $70 \%$ na área operada. Os ratos destinados ao grupo Sham foram somente expostos a incisão cirúrgica.

\subsubsection{Modelo de privação alimentar}

Para outro modelo experimental de atrofia, utilizou-se o modelo murino submetido ao procedimento de privação alimentar (jejum) de 48 horas, aprovado pelo Comitê de Ética em Pesquisa da Faculdade de Medicina de Ribeirão Preto da Universidade de São Paulo (161/2017) - disponível no Anexo 1. Foram utilizados 16 camundongos C57BL/6 machos adultos pesando 22 - $25 \mathrm{~g}$ do Laboratório de Experimentação Animal da Faculdade de Medicina de Ribeirão Preto. Os animais foram divididos igualmente em dois grupos:

- Controle (grupo controle);

- Privação alimentar de 48 horas (grupo FD48).

Os animais foram alimentados com água e ração padrão ad libitum por duas semana para aclimatação ao biotério. No início do experimento, os pellets de alimento foram removidos das gaiolas dos animais do grupo submetido ao jejum. 


\subsection{Experimentação animal}

Os métodos experimentais de ambos os modelos estão dispostos na forma de algorítimo representado esquematicamente na Figura 4.

Durante todo o período experimental (privação/reposição de testosterona e privação de alimento), os animais (ratos e camundongos) foram mantidos em um ciclo claroescuro de 12:12 horas, com água e ração ad libitum (exceto durante o momento de privação alimentar) e em todos os aspectos, todos os protocolos foram realizados de acordo com o Guia para o Cuidado e Uso de Animais de Laboratório [Publicação DHEW No. (NIH) 86-23, Revisado 1985, Escritório de Ciência e Relatórios de Saúde, DRR / NIH, Bethesda, MD 20892].

Todos os animais, no momento apropriado, foram mortos por decapitação e os músculos dos ratos e camundongos foram dissecados, pesados, rapidamente congelados em nitrogênio líquido, pulverizados e armazenados a $-80^{\circ} \mathrm{C}$. No momento da utilização, cada músculo EA e Gastrocnêmio foram transferidos para microtubos livres de RNAse. O RNA foi isolado usando o método TRIzol TM (Invitrogen, Carlsbad, CA) para hibridização por microarray e análise de RT-PCR.

\subsection{Extrações de RNA das amostras musculares}

Tanto os músculos EA quanto o Gastrocnêmio de cada um dos grupos de ratos e camundongos foram rapidamente macerados em cadinhos autoclavados, com uma pequena quantidade de nitrogênio líquido e rapidamente transferidos para microtubos de $1,5 \mathrm{~mL}$ livres de RNAse.

A extração de RNA total das amostras foi feita pelo método do TRIzol ${ }^{\mathrm{TM}}$ (Invitrogen Life Technologies, CA), adicionando $1 \mathrm{~mL}$ de TRIzol ${ }^{\mathrm{TM}}$ em cada amostra. Adicionouse à cada amostra uma pequena esfera de metal para lise mecânica realizada com o 
aparelho TissueLyser II (Qiagen, Alemanha) seguindo programação de dois minutos a $30 \mathrm{~Hz}$ (Hertz), mantido os tubos refrigerados durante todo processo. Após a homogeneização, as amostras foram incubadas por 15 minutos em temperatura ambiente, seguido da adição de $200 \mu \mathrm{L}$ de clorofórmio (Baker, EUA) em cada tubo, agitação vigorosa por 15 segundos e incubação por 10 minutos em temperatura ambiente. As amostras foram centrifugadas a $12000 \mathrm{xg}$ por 15 minutos a $4^{\circ} \mathrm{C}$, onde foi possível a visualização de uma fase aquosa onde o RNA permanece, exclusivamente. Essa fase foi totalmente transferida para outros microtubos de 1,5 $\mathrm{mL}$ livres de RNAse.

Para a precipitação do RNA, foi adicionado às amostras $500 \mu \mathrm{L}$ de isopropanol $100 \%$, as amostras foram incubadas em temperatura ambiente por 10 minutos e então centrifugadas a $12000 \mathrm{xg}$ por 10 minutos a $4^{\circ} \mathrm{C}$ sendo possível a visualização de um pellet semelhante a um gel no fundo de cada tubo. Para a lavagem do RNA, o sobrenadante foi descartado, o pellet foi lavado com $1 \mathrm{~mL}$ de etanol $75 \%$ e as amostras foram brevemente agitadas em vortex e então centrifugadas a 7500 xg por cinco minutos a $4^{\circ} \mathrm{C}$. O sobrenadante foi cuidadosamente descartado e após a secagem dos pellets, estes foram ressuspendidos em 20-30 $\mu$ l de água DEPC (água milli-Q tratada com dietil-pirocarbonato $0,01 \%$ e autoclavada), incubados em banhomaria a $55^{\circ} \mathrm{C}$ por 10 minutos e então quantificados por densidade óptica em espectrofotômetro $(260 \mathrm{~nm})$.

\subsection{Síntese de cDNA}

O cDNA foi sintetizado utilizando o kit ImProm-I/ TM Reverse Transcription System (Promega, EUA) e com o iniciador oligo (dT). Porém, antes da síntese, as amostras de RNA foram tratadas com DNAse, utilizando $1 \mu \mathrm{g}$ de RNA total, $1 \mu \mathrm{L}$ de tampão 
10x da enzima, $1 \mu \mathrm{L}$ de DNAse e água tratada com DEPC completando para um volume final de $10 \mu \mathrm{L}$. As amostras foram incubadas a $37^{\circ} \mathrm{C}$ por 30 minutos, seguido da adição de $1 \mu \mathrm{L}$ de solução de parada da reação e novamente incubadas a $65^{\circ} \mathrm{C}$ por 10 minutos. Para a realização da transcrição reversa, foram utilizados os $11 \mu \mathrm{L}$ das amostras tratadas e $1 \mu \mathrm{L}$ de iniciador oligo (dT). Para o anelamento do oligo (dT) as amostras foram incubada por 10 minutos a $70^{\circ} \mathrm{C}$ e, em seguida, por cinco minutos a $4^{\circ} \mathrm{C}$. Em sequência foram adicionados $4 \mu \mathrm{L}$ do tampão $5 x$ da enzima, $2 \mu \mathrm{L}$ da enzima transcriptase reversa, $2 \mu \mathrm{L}$ de dNTP "mix" (10 mM) e água DEPC para um volume final de $20 \mu \mathrm{L}$. Após a adição do "mix", as amostras foram incubadas a $25^{\circ} \mathrm{C}$ por cinco minutos, $42^{\circ} \mathrm{C}$ por 60 minutos e $70^{\circ} \mathrm{C}$ por 15 minutos. Após a síntese completa as amostras foram devidamente mantidas refrigeradas a $-20^{\circ} \mathrm{C}$.

\subsection{Metodologia do microarray}

Para identificar genes diferencialmente expressos em músculo EA de ratos em resposta ao tratamento com propionato de testosterona, realizou-se um ensaio de microarray utilizando lâminas de oligonucleotideos de rato 4 x 44K (Kit de microarray de GE4x44k v3 de rato, Agilent Technologies, G2519F, design ID 028282). Amostras do grupo Castrado $(C 3, n=4)$ foram tomados como referência e as lâminas foram empregadas para estabelecer a razão de expressão gênica entre C3 x C3pt8 (8 h tratamento; $n=4)$, e C3 x C3pt24 (24 h tratamento; $n=4)$.

Neste sentido, os RNAs de C3 e amostras tratadas com PT foram marcados com Cyanin 3 (Сy3) e Cyanin 5 (Cy5) dUTP, respectivamente. Como controle interno, 200 ng de RNA total foram incubados com RNA Spike-In A ou B. A síntese de cDNA e a seguinte marcação e síntese de cRNA a partir do cDNA foram realizadas usando o kit Quick Amp Labeling (Agilent Technologies), de acordo com as instruções do 
fabricante. O cRNA resultante foi purificado em colunas conforme instruído no kit RNeasy Plus (Qiagen, Alemanha) e quantificado em um equipamento NanoDrop 2000 (Thermo Scientific, CA). Alvos marcados com fluorescência de ratos castrados (controle) e ratos castrados tratados com propionato de testosterona (8 h ou $24 \mathrm{~h}$ ) foram hibridizados para a mesma lâmina de microarray com sondas de $60 \mu \mathrm{m}$ (4 réplicas). Um procedimento de rotulagem flip (troca de corante) foi seguido para anular o viés de corante associado à incorporação desigual dos dois corantes Cy em cDNA (Martin-Magniette, Aubert et al. 2005). As lâminas foram escaneadas no GenePix 4000B (Molecular Devices) que escaneia simultaneamente os canais Cy3 e Cy5 com uma resolução de $5 \mu \mathrm{m}$. As imagens TIFF Cy3 e Cy5 mescladas geradas pelo Gene-Pix foram analisadas usando o Software de extração de recursos Agilent v.9.5.3.1 (Agilent Technologies).

O trabalho descrito teve seu início em 2013 no projeto de mestrado com a descrição dos dados obtidos apresentados na Dissertação. No desenvolvimento do doutorado, foi dado continuidade ao trabalho, porém com várias modificações de análises dos dados primários obtidos no microarray.

Na primeira análise de 2013, para um gene ser considerado diferencialmente expresso, foi utilizado dois critérios: valor de $p<0,1$ obtido com o teste $t$ de Student e fold-change $\left(\log _{2}\right)>1$ ou $<-1$. Dessa maneira, em 8 horas de tratamento com propionato de testosterona 113 genes foram selecionados por esses parâmetros enquanto em 24 horas de tratamento, o número foi de 303 genes diferencialmente expressos. Os alvos que foram escolhidos para validação pela técnica de RT-PCR estavam dentro do grupo tratado por 24 horas com PT. Eles foram selecionados a partir de buscas em banco de dados sobre suas funções e relevância. 
Para publicação do trabalho, uma segunda análise foi realizada, de forma a aplicar métodos consolidados no processamento de dados de microarray. Para isso, as intensidades de sinal bruto de quimioluminescência das lâminas de microarray foram corrigidas e normalizadas usando uma técnica de regressão local LOWESS (Leachly Screening Scotter Plot Weighted) (Cleveland 1988).

O pacote de dados Limma em R/Biocondutor foi utilizado para identificar os genes diferencialmente expressos. Limma (Ritchie, Phipson et al. 2015) ajusta um modelo linear para a expressão de cada gene. Isso permite estimar a variância residual de cada gene e a aplicação do teste t moderado o que é vantajoso para um pequeno ' $n$ ' de repetições do experimento (4 repetições biológicas) (Smyth 2005, Ritchie, Phipson et al. 2015). O test t moderado utiliza a informação de vários genes para o cálculo da variância, enquanto que o teste $t$ de Student calcula a variância usando os valores disponíveis para cada gene, em cada réplica. Dessa forma, reduz-se o número de falsos positivos. Nessa segunda análise, os valores de $\mathrm{p}$ foram ajustados para múltiplos testes controlando-se a taxa de falsa descoberta (FDR) pelo método de Benjamini-Hochberg. Os genes com um FDR $<0,05$ e um fold change $\geq 1,5$ foram considerados significativamente diferentes entre os grupos de tratamentos com PT e o grupo castrado 3 dias. Dentro desses parâmetros, em 24 horas de tratamento com PT foram observados 241 genes diferencialmente expressos. Em 8 horas de tratamento apenas 1 gene (adenosilmetionina descarboxilase 1, Amd1) apresentou-se diferencialmente expresso. A expressão dos top 50 genes diferencialmente expressos em 24 horas foram representados usando um mapa de calor (heatmap). Para tanto, foi utilizado o algoritmo de agrupamento hierárquico (HCL - distância euclidiana) que orderna os genes em função da similaridade do perfil de expressão dos genes e das amostras. Análise de enriquecimento funcional 
foi realizada com os 241 genes diferencialmente expressos em 24 horas e a análise de agrupamento foi realizada usando o pacote gplots na linguagem $R$ (https://www.rdocumentation.org/packages/ gplots).

Os genes foram anotados quanto a sua ontologia (Gene Ontology - GO) utilizando o banco de Dados de Anotação, Visualização e Descoberta Integrada (DAVID) (Huang da, Sherman et al. 2009). O teste exato de Fisher foi aplicado para identificar categorias funcionais enriquecidas. Os valores de $p$ foram novamente ajustados para múltiplos testes controlando para taxa de falsa descoberta pelo método de Benjamini-Hochberg, selecionando um FDR $<0,05$ foi como critério de corte.

Os dados do microarray foram depositados no Centro Nacional de Informações sobre Biotecnologia GEO (NCBI GEO; http://www.ncbi.nlm.nih.gov/geo) e estão disponíveis sob o número de acesso GSE97740.

Todas as análises obtidas com os dados do microarray, e suas posteriores mudanças descritas previamente, tiveram a colaboração da Dra. Livia Soares Zaramela (Departamento de Pediatria, Universidade da Califórnia, San Diego).

\begin{tabular}{|c|c|c|c|c|c|c|}
\hline Gene & NCBI RefSeq & Anotação & $\begin{array}{c}\text { Log2 } \\
\text { (fold } \\
\text { change) }\end{array}$ & $\begin{array}{c}\text { Mudança } \\
\text { absol. }\end{array}$ & $\begin{array}{c}p- \\
\text { valor }\end{array}$ & $\begin{array}{c}p- \\
\text { valor.ajust } \\
(\mathrm{BH})\end{array}$ \\
\hline & & F-box only protein & & & & \\
\hline Fbxo32 & NM_133521 & 32/Atrogin-1 & -2.826 & 7.090 & 0.0000 & 0.0001 \\
\hline KIhl38 & NM_001025008 & Kelch-like protein 38 & -2.301 & 4.928 & 0.0000 & 0.0002 \\
\hline Pik3ip1 & NM_001017453 & $\begin{array}{c}\text { Phosphoinositide-3- } \\
\text { kinase interacting } \\
\text { protein } 1\end{array}$ & -2.029 & 4.082 & 0.0000 & 0.0002 \\
\hline & & Methyltransferase like & & & & \\
\hline Mettl7a & NM_001037355 & $7 A$ & -2.020 & 4.055 & 0.0000 & 0.0000 \\
\hline Igfbp3 & NM_012588 & $\begin{array}{c}\text { Insulin-like growth } \\
\text { factor binding protein } 3\end{array}$ & -1.975 & 3.930 & 0.0000 & 0.0002 \\
\hline & & C-X-C motif chemokine & & & & \\
\hline CXLX14 & NM_001013137 & 14 & -1.579 & 3.006 & 0.0000 & 0.0002 \\
\hline $\operatorname{lgf}-1$ & NM_001082479 & $\begin{array}{c}\text { Insulin-like growth } \\
\text { factor } 1\end{array}$ & 1.758 & 3.383 & 0.0000 & 0.0001 \\
\hline KIf15 & NM_053536 & Kruppel-like factor 15 & -1.403 & 2.644 & 0.0000 & 0.0003 \\
\hline & & $\begin{array}{c}\text { S-adenosylmethionine } \\
\text { decarboxylase }\end{array}$ & & & & \\
\hline Amd1 & NM_031011 & proenzyme & 1.626 & 3.087 & 0.0000 & 0.0006 \\
\hline Cck & NM_012829 & Cholecystokinin & 1.228 & 2.343 & 0.0000 & 0.0011 \\
\hline
\end{tabular}




\begin{tabular}{|c|c|c|c|c|c|c|}
\hline Hopx & NM_133621 & HOP homeobox & 1.100 & 2.143 & 0.0000 & 0.0011 \\
\hline Odc1 & NM_012615 & $\begin{array}{c}\text { Ornithine } \\
\text { decarboxylase }\end{array}$ & 1.241 & 2.364 & 0.0000 & 0.0025 \\
\hline Mkl1 & XM_235497 & $\begin{array}{c}\text { Megakaryoblastic } \\
\text { leukemia } \\
\text { (translocation) } 1\end{array}$ & 0.991 & 1.988 & 0.0000 & 0.0034 \\
\hline Pgf & NM 053595 & Placental growth factor & 0.796 & 1.736 & 0.0000 & 0.0122 \\
\hline Pi15 & NM_001106917 & Peptidase inhibitor 15 & 0.642 & 1.560 & 0.0002 & 0.0330 \\
\hline Apln & NM_031612 & Apelin & 0.224 & 1.168 & 0.0728 & 0.4866 \\
\hline Dusp5 & NM_133578 & $\begin{array}{l}\text { Dual specificity } \\
\text { phosphatase } 5\end{array}$ & 0.111 & 1.080 & 0.3182 & 0.7624 \\
\hline
\end{tabular}

Tabela 1. FDR e log2 (razão de fold-change) de genes diferencialmente expressos selecionados para validação por RT-PCR. O ensaio de microarray foi realizado utilizando quatro replicatas biológicas. A expressão diferencial dos genes foi avaliada com o pacote Limma em R/Biocondutor. Os genes foram considerados diferencialmente expressos se seus valores de $p$, ajustados para o teste de hipóteses múltiplas, fossem $<0,05$ e fold-change $\geq 1,5$.

\subsection{Reações de RT-PCR}

O cDNA das amostras foram submetidos à reação de PCR em tempo real utilizando o kit SsoFast ${ }^{\mathrm{TM}}$ EvaGreen $^{\circledR}$ Supermix (Bio-Rad Laboratories, CA) e os primers forward e reverse com sequências específicas para amplificação dos genes alvos escolhidos (na Tabela 2), sendo o gene constitutivo (housekeeping) RPL39 ou RPL32 escolhido para a normalização dos dados. O gene Atrogin-1 também foi utilizado como controle.

Os resultados foram obtidos com o aparelho da CFX96 ${ }^{\text {TM }}$ Real-time PCR Detection System (Bio-Rad, EUA) a partir da ciclagem: 2 minutos a $50^{\circ} \mathrm{C}, 2$ minutos a $95^{\circ} \mathrm{C}$ e ciclagem de 40 vezes de 10 segundos a $95^{\circ} \mathrm{C}, 30$ segundos a $60^{\circ} \mathrm{C}$, seguido pelo ciclo de dissociação para verificação de um produto através de análise pela curva melting. Os resultados foram analisados de acordo com o método do $\Delta \Delta \mathrm{Ct}$. $\mathrm{A}$ quantificação relativa dos níveis de RNAm foi expressa relativamente ao controle. A média dos valores de $\mathrm{C}_{t}$ de cada duplicata foi usada para o cálculo do $\Delta \mathrm{C}_{t}\left(\mathrm{C}_{t}\right.$ do gene interesse $-\mathrm{C}_{\mathrm{t}}$ do gene constitutivo). Os valores de $\Delta \Delta \mathrm{C}_{\mathrm{t}}\left(\Delta \mathrm{C}_{\mathrm{t}}\right.$ do grupo teste $-\Delta \mathrm{C}_{\mathrm{t}}$ do grupo controle $)$ foram calculados e a amplificação de RNAm foi determinada pela fórmula $2^{-\Delta \Delta C t}$ (Livak and Schmittgen 2001). 
A partir dos valores obtidos era feita a busca por possíveis valores outlier na distribuição gaussiana dos dados através do teste de Grubb's (disponível em http://www.graphpad.com/quickcalcs/).

Para as análises estatísticas tivemos a colaboração da Profa. Dra. Flávia Alessandra Guarnier (Universidade Estadual de Londrina, UEL). Todas as estatísticas foram realizadas com análise de variância simples One-way ANOVA não pareado e pósteste de Tukey, com valor de $p \leq 0,05$, no programa GraphPad Prism 5.0.

\begin{tabular}{|c|c|c|}
\hline GENE & HumanCyc & Primers Forward e Reverse \\
\hline AMD1 & $\begin{array}{c}\text { Adenosilmetionina } \\
\text { descarboxilase. Enzima } \\
\text { essencial para a } \\
\text { biossíntese de poliaminas. }\end{array}$ & $\begin{array}{l}\text { Forward: 5' CCATCCCAAGATCCGAGTGG 3' } \\
\text { Reverse: 5' GTGTGGGTACCCTTGGTGAG 3' }\end{array}$ \\
\hline APLN & Apelina ou ligante de APJ. & $\begin{array}{l}\text { Forward: 5' TGCCACGGACCGAGTTGCAG 3' } \\
\text { Reverse: 5' GGCAGCATCAGTGGCACTCCA 3' } \\
\text { Mouse/Forward: 5' ACCGTGCCTTCTAATGTCTTC 3' } \\
\text { Mouse/Reverse: 5' TTGGGCTCTGACTTTCTGTG 3' }\end{array}$ \\
\hline Atrogin-1 & $\begin{array}{l}\text { Controle positivo. } \\
\text { Atrogene. }\end{array}$ & $\begin{array}{l}\text { Rat/Forward: 5' CTTGGATGAGAAAAGCGGCACCTT 3' } \\
\text { Rat/Reverse: 5' GTTGCCCACCAGCACGGACTTG 3' } \\
\text { Mouse/ Forward: 5' CAGGTCGGTGATCGTGAG 3' } \\
\text { Mouse/ Reverse: 5' GCAGAGAGTCGGCAAGTC 3' }\end{array}$ \\
\hline CCK & $\begin{array}{l}\text { Colecistoquinina. Peptídeo } \\
\text { que induz liberação de } \\
\text { enzimas pancreáticas. } \\
\text { Ação na proliferação } \\
\text { celular e apoptose. }\end{array}$ & $\begin{array}{l}\text { Rat/ Forward: 5' GGTCCGCAAAGCTCCCTCTGG 3' } \\
\text { Rat/ Reverse: 5' GGCCGAAATCCATCCAGCCCAT 3' } \\
\text { Mouse/ Forward: 5' GGACCCCAGCCATAGAATAAG 3' } \\
\text { Mouse/ Reverse: 5' CAACATTAGGTCTGGGAGTCAC 3' }\end{array}$ \\
\hline CTGF & $\begin{array}{l}\text { Fator de crescimento do } \\
\text { tecido conjuntivo. }\end{array}$ & $\begin{array}{l}\text { Forward: 5' CAAGATTGGCGTGTGCCACTG 3' } \\
\text { Reverse: 5' CAGTCGGTAGGCAGCTAGGG 3' }\end{array}$ \\
\hline CXCL14 & $\begin{array}{c}\text { Proteína pertencente à } \\
\text { família de quimiocinas. } \\
\text { Expressa em músculo } \\
\text { esquelético. }\end{array}$ & $\begin{array}{l}\text { Forward: 5' GAGAAACGCAGGGTCTACGA 3' } \\
\text { Reverse: 5' TGAAGTCTGGTACGCAGGAG 3' }\end{array}$ \\
\hline DUSP5 & $\begin{array}{l}\text { Proteína fosfatase } 5 \text { de } \\
\text { dupla especificidade. } \\
\text { Apresenta atividade de } \\
\text { fosfatase para vários } \\
\text { substratos, como forte } \\
\text { interação com ERK1. } \\
\end{array}$ & $\begin{array}{l}\text { Forward: 5' TGACCAGGGTGGCCCAGTTGAA 3' } \\
\text { Reverse: 5' GGTTGGCGAGGAACTCGCACT 3' }\end{array}$ \\
\hline FOXO3 & $\begin{array}{l}\text { Fator de transcrição que } \\
\text { regula o sistema ubiquitina } \\
\text { proteassoma e a via de } \\
\text { autofagia durante a atrofia. }\end{array}$ & $\begin{array}{l}\text { Forward: 5' CGTGCCTTGTCAAATTCTGTC 3' } \\
\text { Reverse: 5' CCATTTCCCCTTTCCTCAGTG 3' }\end{array}$ \\
\hline
\end{tabular}




\begin{tabular}{|c|c|c|}
\hline HOPX & $\begin{array}{l}\text { Fator de transcrição. } \\
\text { Necessário para modular o } \\
\text { crescimento e } \\
\text { desenvolvimento cardíaco. } \\
\text { Recruta proteínas HDAC. }\end{array}$ & $\begin{array}{l}\text { Rat/Forward: 5' TCACGGAGGAGCAGACGCAGAAAT 3' } \\
\text { Rat/Reverse: 5' GCTCAAGGGCCTGGCTCCCTA 3' } \\
\text { Mouse/ Forward: 5' TCCTCTCCATCCTTAGTCAGAC 3' } \\
\text { Mouse/ Reverse: 5' GAAACATCAAAACAGCCTGGG 3' }\end{array}$ \\
\hline IGF-1 & $\begin{array}{l}\text { Fator de crescimento } \\
\text { semelhante à insulina tipo } \\
\text { 1. Atividade promotora de } \\
\text { crescimento. }\end{array}$ & $\begin{array}{l}\text { Forward: 5' CCTTTGCGGGGCTGAGCTGG 3' } \\
\text { Reverse: 5' CCATAGCCTGTGGGCTTGTTGAAGT3' } \\
\text { Mouse/Forward: 5' TCAACAGCAATCTACCCACG 3' } \\
\text { Mouse/Reverse: 5' GAAAACGAAGCTGCAAAGGAG 3' }\end{array}$ \\
\hline IGFBP3 & $\begin{array}{l}\text { Proteína } 3 \text { de ligação ao } \\
\text { fator de crescimento } \\
\text { semelhante à insulina. } \\
\text { Inibe ou estimula os efeitos } \\
\text { de promoção do } \\
\text { crescimento dos IGFs. }\end{array}$ & $\begin{array}{l}\text { Rat/Forward: 5' AGCCGTCTCCTGGAAACACCACT 3' } \\
\text { Rat/Reverse: 5' TCAGTCACGCGGTGTGTGCT 3' } \\
\text { Mouse/Forward: 5' AAATCCTCTTTCCATCCCCTG 3' } \\
\text { Mouse/Reverse: 5' CAACACATATCCTCTCCCACAG 3' }\end{array}$ \\
\hline KLF15 & $\begin{array}{l}\text { Fator } 15 \text { semelhante à } \\
\text { Kruppel. Regulador } \\
\text { transcricional envolvido no } \\
\text { controle da hipertrofia } \\
\text { cardíaca. }\end{array}$ & $\begin{array}{l}\text { Forward: 5' CTGCAGACAAGTCACCACAGGCT 3' } \\
\text { Reverse: 5' CCACTGGGCATTTCGGTGACGA 3' }\end{array}$ \\
\hline KLHL38 & $\begin{array}{l}\text { Proteína do tipo Kelch } 38 . \\
\text { Organizadores de actina. }\end{array}$ & $\begin{array}{l}\text { Forward: 5' TGTGCGCCTTATCCAGGTTTA 3' } \\
\text { Reverse: 5' CATGGTGCATCCTTCGGTCT 3' }\end{array}$ \\
\hline METTL7A & $\begin{array}{c}\text { Metiltransferase tipo 7A. } \\
\text { Atividade de } \\
\text { metiltransferase. }\end{array}$ & $\begin{array}{l}\text { Forward: 5' GCTGTGCTCGGTGAAGAGCCA 3' } \\
\text { Reverse: 5' CGTTCATCCGCCACATGCTCCA 3' }\end{array}$ \\
\hline MKL1 & $\begin{array}{l}\text { Proteína serina/treonina } \\
\text { quinase. Envolvida em uma } \\
\text { via de sinalização de } \\
\text { cálcio. Atividade catalítica. }\end{array}$ & $\begin{array}{l}\text { Forward: 5' CTCССAAGCССTCGGGTGAGA 3' } \\
\text { Reverse: 5' GTTCTGACGGGCCAGCCCAC 3' }\end{array}$ \\
\hline ODC1 & $\begin{array}{c}\text { Proteína ornitina } \\
\text { descarboxilase. Atua na } \\
\text { biossíntese de poliamina. }\end{array}$ & $\begin{array}{l}\text { Forward: 5' CGCTTCCCTGTGCTGTGAGGAGA 3' } \\
\text { Reverse: 5' TGGTTGGTTCTCGATGTGCCTCTGA 3' }\end{array}$ \\
\hline PGF & $\begin{array}{l}\text { Fator de crescimento } \\
\text { placentário. Ativo na } \\
\text { angiogênese e no } \\
\text { crescimento de células } \\
\quad \text { endoteliais. }\end{array}$ & $\begin{array}{l}\text { Rat/Forward: 5' AGGATGTGCTCTGCGAATGCAGG 3' } \\
\text { Rat/Reverse: 5' GCATCACAGGTGGGGTTCCTCAG 3' } \\
\text { Mouse/Forward: 5' TTTCTCAGGATGTGCTCTGTG 3' } \\
\text { Mouse/Reverse: 5' CCTTCCATGCCCCTTATCTTG 3' }\end{array}$ \\
\hline PI15 & $\begin{array}{l}\text { Inibidor de peptidase } 15 . \\
\text { Inibidor de serino } \\
\text { proteases }\end{array}$ & $\begin{array}{l}\text { Forward: 5' CATGGGCAGCAACTTGCATT 3' } \\
\text { Reverse: 5' AGTGGCCCAAACCATCTGTG 3' } \\
\text { Mouse/Forward: 5' ATTATGCCTTTCCTTACCCTCAG 3' } \\
\text { Mouse/Reverse: 5' GTGCTTCTCCTATCCAGTTACC 3' }\end{array}$ \\
\hline PIK3IP1 & $\begin{array}{l}\text { Proteína } 1 \text { de interação da } \\
\text { Fosfatidilinositol } 3 \text { quinase. } \\
\text { Regulador negativo da } \\
\text { atividade de PI3K. }\end{array}$ & $\begin{array}{l}\text { Forward: 5' GCTACATCAGCAGCGAGACT 3' } \\
\text { Reverse: 5' ACACGTAGCCCAAAGTTCCC 3' }\end{array}$ \\
\hline RPS6ka5 & $\begin{array}{l}\text { Proteína serina/treonina } \\
\text { quinase. Em mioblastos } \\
\text { esqueléticos é necessário } \\
\text { para a fosforilação do fator } \\
\text { de transcrição RELA } \\
\text { durante o estresse } \\
\text { oxidativo. }\end{array}$ & $\begin{array}{l}\text { Forward: 5' TGGTGACGTTGCACTATGCT 3' } \\
\text { Reverse: 5' ACGCTCTTTCGGCTTCATCA 3' }\end{array}$ \\
\hline
\end{tabular}




\begin{tabular}{c|c|l}
\hline RPL39 & $\begin{array}{c}\text { Controle endógeno para } \\
\text { rato (housekeeping). }\end{array}$ & $\begin{array}{l}\text { Forward: 5' TCCTGGCAAAGAAACAAAAGC 3' } \\
\text { Reverse: 5' TAGACCCAGCTTCGTTCTCCT 3' }\end{array}$ \\
\hline RPL32 & $\begin{array}{c}\text { Controle endógeno para } \\
\text { camundongo. } \\
\text { (housekeeping). }\end{array}$ & $\begin{array}{l}\text { Forward: 5' TCTGGTGAAGCCCAAAGATCG 3' } \\
\text { Reverse: 5' CTCTGGGTTTCCGCCAGTT 3' }\end{array}$ \\
\hline
\end{tabular}

Tabela 2. Identificação de genes e sequência de primers Forward e Reverse usados para amplificação de cDNA em ensaio de RT-PCR. Os alvos foram escolhidos dentro dos resultados do ensaio de microarray, com base nos parâmetros descritos. Os genes em destaque representam as sequências de expressão constitutiva (RPL32 e RPL39), FOXO3 e o controle positivo (Atrogin-1). Atrogin-1 foi escolhida com base em sua resposta conhecida aos desafios atróficos, bem como FOXO3. As sequências são diferentes entre ratos e camundongos nos genes onde os alvos foram avaliados para ambos.

\subsection{SUnSET}

Recentemente, um método não radioativo para avaliar a síntese proteica em culturas de células, conhecido como SUnSET (Surface Sensing of Translation), foi desenvolvido e validado contra os métodos existentes (Schmidt, Clavarino et al. 2009). O método baseia-se no princípio de que a puromicina é incorporada em cadeias peptídicas em alongamento, em baixa concentração, devido à sua estrutura em analogia ao tirosil t-RNA (Nathans 1964). Em alta concentração, a puromicina efetivamente encerra a tradução. No entanto, em concentrações muito baixas e durante breves períodos de tempo, ela não interfere nas taxas gerais de tradução nem induz uma resposta ao estresse. Os peptídeos conjugados com puromicina podem então ser detectados por imunoblotting utilizando um anticorpo antipuromicina, que representa a taxa global de síntese proteica (Schmidt, Clavarino et al. 2009).

Para os experimentos, a linhagem celular foi cultivada em DMEM (meio de Eagle modificado por Dulbecco) suplementado com $10 \%$ de soro fetal bovino (FBS Invitrogen Life Technologies, CA), $10 \mu \mathrm{g}$ de estreptomicina, $10 \mathrm{U} / \mathrm{mL}$ de penicilina $\mathrm{G}$ sódica e 29,2 $\mu \mathrm{g} / \mathrm{mL}$ de glutamina (Invitrogen Life Technologies, CA) mantidas em estufa de atmosfera úmida a $37^{\circ} \mathrm{C}$ em atmosfera de $5 \%$ de $\mathrm{CO}_{2}$. 
Para a realização dos experimentos, células HEK293T (células renais embrionárias humanas) foram utilizadas e transfectadas com plasmídeos de expressão contendo os genes: APLN (gentilmente cedido pelo Dr. Bernard Masri, da Universidade de Tolouse III) ou MKL1 (gentilmente cedido pela Dra. Akiko Atabuchi, da Universidade de Toyama). Como controle utilizou-se o plasmídeo pcDNA3.

As células foram plaqueadas em confluência de $70 \%$ em 7 poços de placas de 6 poços no dia anterior a transfecção. No dia seguinte, as células foram transfectadas em quadruplicata para o plasmídeo alvo e controle em placa de 6 poços.

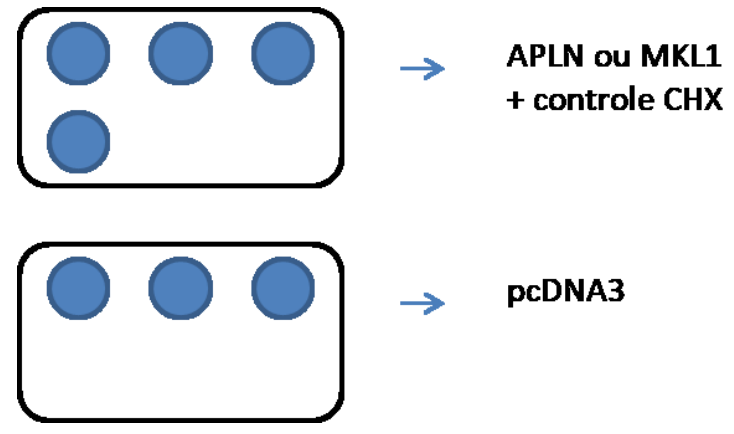

Figura 2. Esquema simplificado das montagens das placas para o experimento SUnSET.

Para a transfecção utilizou-se 2 ug de DNA para 6 uL de reagente de transfecção pEI (polietilenoimina) em 90 uL de Optimem, a solução foi incubada por 15 minutos em temperatura ambiente, gotejado-se o volume final por poço a ser transfectado. Após 36 horas de transfecção, as células foram incubadas por meia hora antes da lise com uma solução de Puromicina a 1 uM diluida em DMEM. Para os poços controles, utilizou-se além da Puromicina, a cicloheximida (um inibidor da síntese proteica) na concentração final de $10 \mathrm{mg} / \mathrm{mL}$ também por meia hora.

Após o período de tratamento das células, a lise foi feita em gelo, com o auxilio de rodinho, em 100 uL de solução de RIPA (Radioimmuno Precipitation Assay) 1x mais inibidores de fosfatase e proteases. Deixadas em homogenizador rotacional por 
meia hora a $4^{\circ} \mathrm{C}$. Em seguida, foram sonicadas com três pulsos de 10 segundos on/off com $20 \%$ de amplitude. Centrifugadas por $14.000 \mathrm{rpm}$ a $4^{\circ} \mathrm{C}$ por 20 minutos e o sobrenadante foi transferido para novos microtubos.

As amostras foram quantificadas pelo método de Bradford (Bradford 1976) (SigmaAldrich, EUA) e 60 ug de proteínas totais foram preparadas em tampão Laemmli (62,5 mM Tris- $\mathrm{HCl}, 5 \% \quad \beta$-mercaptoetanol, 10\% glicerol, 2\% SDS, 0,004\% azul bromofenol), fervidas a $100^{\circ} \mathrm{C}$ por cinco minutos para desnaturação das proteínas e corridas em gel de poliacrilamida $10 \%$ por duas horas a $100 \mathrm{~V}$ para separação. A transferência das proteínas foi feita para membrana de nitrocelulose utilizando tampão específico para o sistema semi-seco (tampão 48 mM Tris, 39 mM Glicina, 20\% metanol, 0,0375\% SDS) por 35 minutos no aparelho Trans-Blot (BioRad) em amperagem constante de 400 mA. Após o processo de transferência, a membrana foi corada com Ponceau (Ponceau S 50mg, Ácido Acético glacial 5\% e água Milli-Q q.s.p. $50 \mathrm{~mL}$ ) e a imagem da membrana corada foi utilizada para posterior análise da síntese proteica das amostras. A membrana foi bloqueada com uma solução de leite desnatado 5\% e incubada overnight com o anticorpo anti-Puromicina (1:25.000 MABE, clone 12D10, Sigma-Aldrich) e revelada pelo método de quimiluminescência. Para normalização utilizou-se o anticorpo anti-GAPDH (1:10.000 - G9295, SigmaAldrich). Também utilizamos o anticorpo anti-pS6 (1:500 - \#2215, Cell Signaling) para avaliar o possível aumento na via de síntese.

\subsection{Array de anticorpos anti-fosfoquinases}

Para a extração de proteínas totais, amostras de músculo EA armazenadas em freezer $-80^{\circ} \mathrm{C}$ foram mantidas em nitrogênio líquido e pulverizadas com o auxílio de cadinhos previamente esterilizados. Aproximadamente $15 \mathrm{mg}$ de músculo 
pulverizado foram transferidos para microtubos safer-lockers livres de RNAse, adicionado um volume de 300 uL de tampão de lise disponibilizado no kit acrescido de inibidor de fosfatases (Sigma-Aldrich, EUA). Todos os componentes foram mantidos em gelo durante todo o procedimento. Para a lise mecânica utilizou-se novamente a lise mecânica no equipamento TissueLyser II (Qiagen, Alemanha) com programação de 2 minutos a $30 \mathrm{~Hz}$.

Após o processo de ruptura mecânica, os tubos foram agitados em agitador rotacional por duas horas a $4^{\circ} \mathrm{C}$. Seguido de centrifugação por 20 minutos a $4^{\circ} \mathrm{C}$ a 14000 RPM. O sobrenadante foi colhido e armazenado em novos microtubos livres de RNAse. A quantificação de proteínas totais foi feita conforme já descrito.

Para a determinação dos níveis relativos de fosforilação de proteínas utilizou-se o kit Proteoma Profile Human Phospho-kinase array (R\&D Systems, EUA) seguindo as instruções do fabricante. Nele, as 43 fosfoquinases e os controles encontravam-se divididas em partes A e B. A parte 'A' contendo 29 anticorpos impressos em duplicata e a parte 'B' contendo 16 anticorpos impressos em duplicata. As respectivas coordenadas dos controles e das fosfoquinases nas membranas e seus sítios de fosforilação estão disponíveis no Anexo 2.

Dois jogos A-B foram utilizados para dois animais castrados 3 dias e outros dois $A-B$ foram utilizados para dois animais castrados 3 dias e tratados com PT por 8 horas. Para cada jogo de membranas A-B foram utilizadas 600 ug de proteínas totais para a incubação overninght. A marcação dos anticorpos foi feita com Streptavidina-HRP e reveladas com reagentes disponibilizados pelo fabricante.

As imagens, capturadas ImageQuant (GE Healthcare, EUA), foram analisadas com o módulo de extensão Microarray do software Image J (versão 1.47, National Institute of Health, EUA) medindo-se a densidade de pixel de cada poço, os valores 
exportados para uma planilha Microsoft Excel, a média do sinal da duplicata de cada fosfoquinase calculada e então foi extraído o valor de background (dos poços de PBS das membranas $A$ e $B$ ). O resultado foi obtido comparando-se os sinais correspondentes nos diferentes grupos para determinar a mudança do perfil de fosforilação de proteínas quinases dos animais castrados por 3 dias e tratados 8 horas com PT em relação ao grupo castrado 3 dias.

\subsection{Imunoblotting}

Todas as tentativas de validação das proteínas de maneira quantitativa, tanto do ensaio de RT-PCR quanto do array de anticorpos anti-fosfoquinases, foram feitas por Western blotting. Amostras contendo 60-100 ug de proteínas totais extraídas, já descritas anteriormente, foram preparadas em tampão Laemmli, fervidas por cinco minutos a $100^{\circ} \mathrm{C}$ para desnaturação das proteínas. Após fervuras, as amostras foram corridas em gel de poliacrilamida $10 \%, 100 \mathrm{~V}$ por duas horas ou mais dependendo do tamanho da proteína-alvo. A transferência das proteínas do gel para membrana de nitrocelulose foi feita no aparelho Trans-Blot (Bio-Rad, EUA) com tampão específico para o sistema semi-seco.

Seguido por bloqueio da membrana por uma hora em solução de leite 5\% em TTBS (tampão Tris- $\mathrm{HCl} 50$ mM, NaCl 0,1 M, Tween 20 0,05\%). Após as lavagens, as incubações com os anticorpos primários foram feitas overnight. A revelação foi feita por quimiluminescência utilizado o reagente Amersham ECL (GE Healthcare, EUA) e as imagens capturadas pelo aparelho ImageQuant (GE Healthcare, EUA).

As membranas de nitrocelulose coradas com Ponceau após a transferência das proteínas estão disponíveis no Apêndice C. 


\subsubsection{Anticorpos}

Anticorpos testados para validação dos resultados obtidos por RT-PCR:

AKT - Cell signaling, número de catálogo: \#4691

CCK - Proteintech, número de catálogo: 13074-2-AP

FOXO3a - Sigma-Aldrich, número de catálogo: F2178

Phospho-FOXO3a - Cell Signalling, número de catálogo: 07-695

HDAC4 (4A3)- Cell signaling, número de catálogo: \#5392

Phospho-HDAC4 (Ser246)/HDAC5 (Ser259)/ HDAC7 (Ser155) - Cell Signaling, número de catálogo: \#3443

Phospho-HDAC4 (Ser632)/HDAC5 (Ser498)/ HDAC7 (Ser486) - Cell Signaling, número de catálogo: \#3424

HOPX - Sigma-Aldrich, número de catálogo: HPA030180

IGFBP3 - OriGene, número de catálogo: TA303275

METTL7A - OriGene, número de catálogo: TA306679

MKL1 - Sigma-Aldrich, número de catálogo: HPA030782

PGF - Proteintech, número de catálogo: 10642-1AP

PIK3IP1 - Proteintech, número de catálogo: 16826-1-AP

Anticorpos testados para validação dos resultados obtidos pelo array de anticorpos anti-fosfoquinases:

Phospho-AKT (Ser473) (D9E) Cell signaling, número de catálogo: \#4060

Phospho-CREB (Ser133) (87G3) Cell signaling, número de catálogo: \#9198

Phospho-eNOS (Ser1177) Cell Signaling, número de catálogo: \#9571

Phospho-p70S6k (Thr389) Santa Cruz Biotechnology, número de catálogo: sc-11759

Phospho-STAT3 (Y705) R\&D Systems, número de catálogo: MAB4607 
RESULTADOS 


\section{Resultados}

\subsection{Modelo de privação de andrógeno}

Como esperado, no modelo utilizado de privação de andrógeno, nem a castração por 3 dias ou o tratamento androgênico por 8 horas ou 24 horas alteraram significativamente o peso corporal dos ratos analisados quando comparados ao grupo Sham.

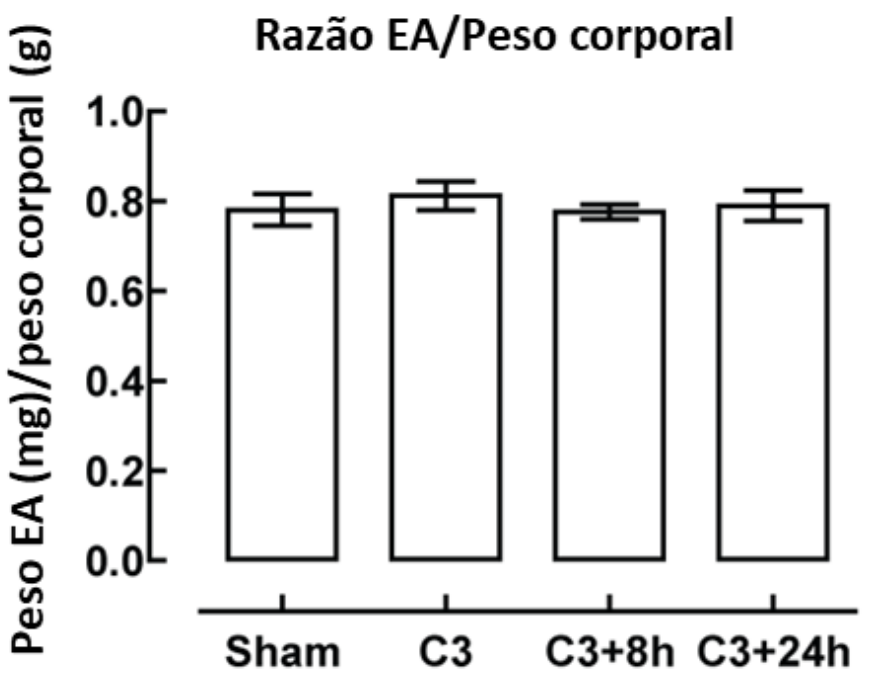

Figura 3. Peso do EA corrigido pela relação massa corporal em animais Sham, Castrados e Castrados e tratados $8 \mathrm{~h}$ e $24 \mathrm{~h}$ com propionato de testosterona. Sham - submetido somente ao procedimento cirúrgico, sem retirada do testículo, seguido por 3 dias e sacrificado; C3 - submetido à castração cirúrgica, seguido de 3 dias e sacrificado; C3pt8 - castrado, seguido de 3 dias, tratado com PT (dose única, $4 \mathrm{mg} / \mathrm{kg}$, em $1 \mathrm{~mL} / \mathrm{kg}$ de óleo de milho) e sacrificado após $8 \mathrm{~h}$; e C3tp24 - castrado, seguido de 3 dias, tratado com PT (dose única, $4 \mathrm{mg} / \mathrm{kg}$, em $1 \mathrm{~mL} / \mathrm{kg}$ de óleo de milho) e sacrificado após $24 \mathrm{~h}$. Nenhuma diferença foi detectada por One-way ANOVA seguido do pós-teste de Tukey.

A análise de microarray foi realizada após 8 h e 24 h de tratamento para identificar genes responsivos ao PT em um modelo de reversão de atrofia bem estabelecido. Modelos lineares foram aplicados a 26.276 genes únicos para estimar os efeitos do tratamento e sua significância associada usando o pacote Limma em R/Biocondutor (Ritchie, Phipson et al. 2015). Após 24 h de tratamento com PT, 241 genes foram regulados diferencialmente seguindo o critério: fold-change $\geq 1,5$ de expressão induzida ou reprimida e com um valor de FDR $<0,05$ (a tabela com todos os genes 
estão disponíveis no Apêndice A). A análise de enriquecimento de ontologia gênica foi realizada usando a ferramenta disponível na internet DAVID (Huang da, Sherman et al. 2009) e então foi possível observar que as 24 horas de tratamento com PT influenciaram significativamente os componentes extracelulares, a regulação positiva da proliferação de células musculares e a resposta ao estímulo mecânico (dados disponíveis no Apêndice B). Uma pesquisa adicional aos bancos de dados HumanCyc (disponível em http://humancyc.org) ou Uniprot (http://www.uniprot.org) foi aplicada para avaliar a relevância da via metabólica e da função e então a decisão sobre quais alvos seriam utilizados para a validação foram finalizados.

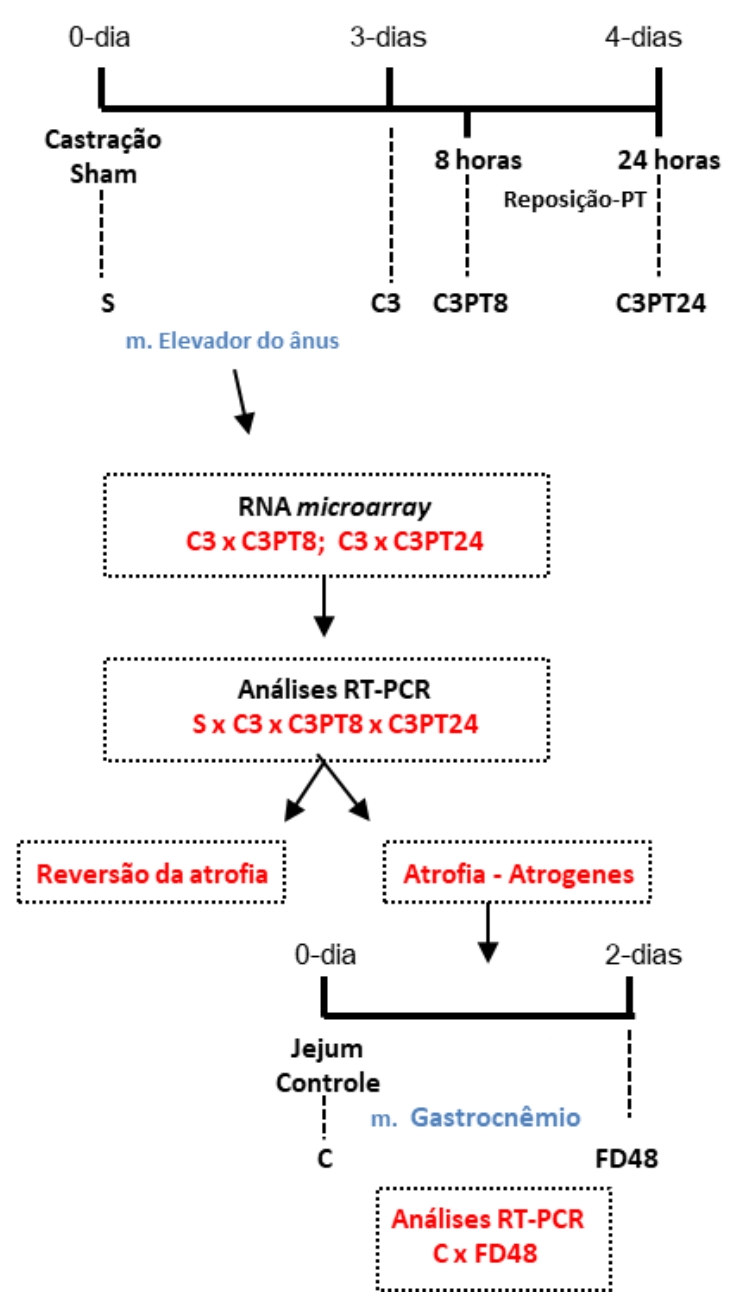

Figura 4. Representação algorítmica das condições experimentais. 


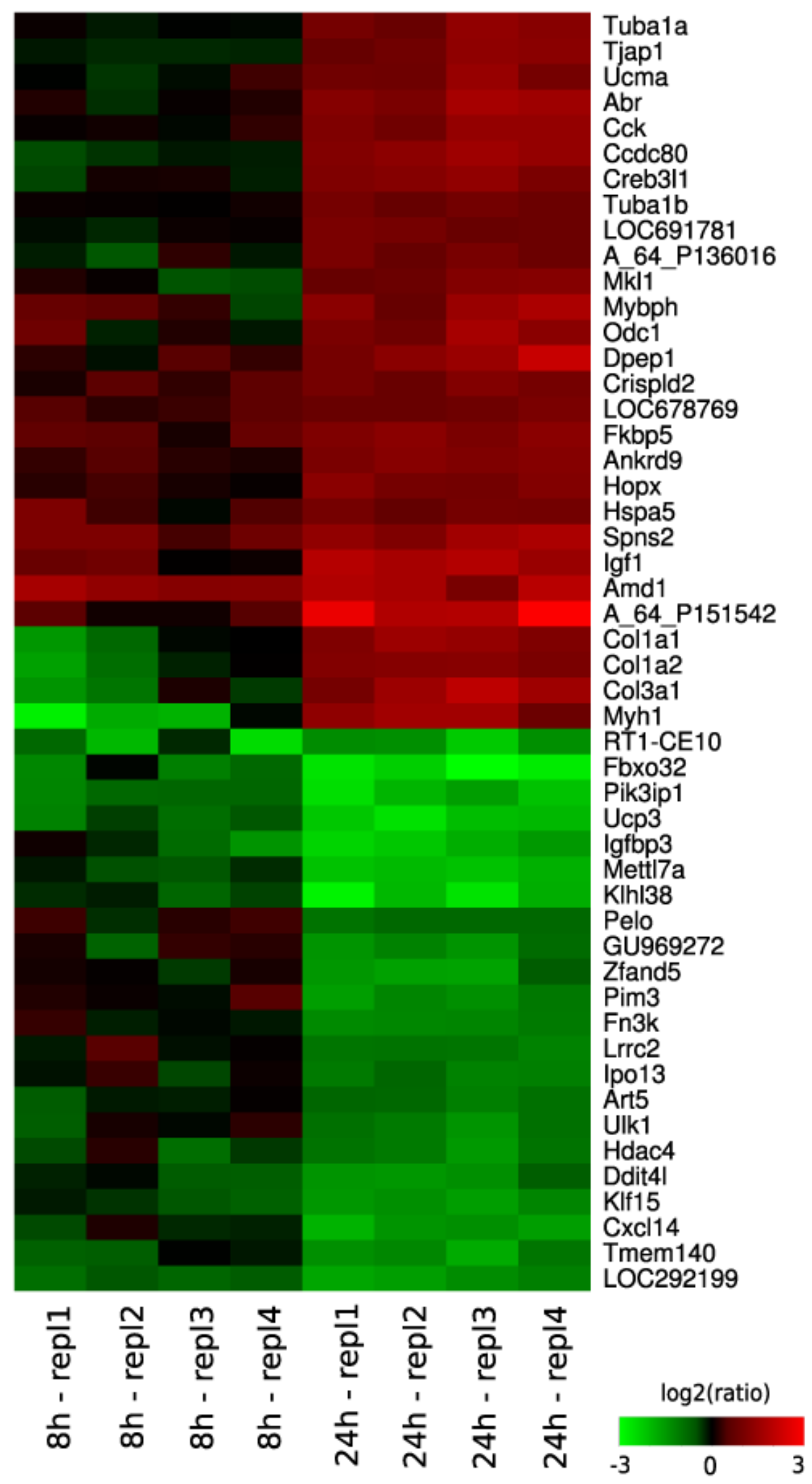

Figura 5. Heatmap dos 50 genes diferencialmente expressos entre castrados e castrados e tratados por $8 \mathrm{~h}$ ou $24 \mathrm{~h}$ após uma única dose de propionato de testosterona $(4 \mathrm{mg} / \mathrm{kg}$, em $1 \mathrm{~mL} / \mathrm{kg}$ de óleo de milho). O ensaio de microarray foi realizado utilizando quatro replicatas biológicas. A expressão 
diferencial dos genes foi avaliada com o pacote Limma em R/Bioconductor. Os genes foram considerados diferencialmente expressos se seus valores de $p$, ajustados para o teste de hipóteses múltiplas, fossem $<0,05$ e fold-change $\geq 1,5$. Expressões gênicas induzidas são indicadas em vermelho. Expressões gênicas reprimidas são indicadas em verde.

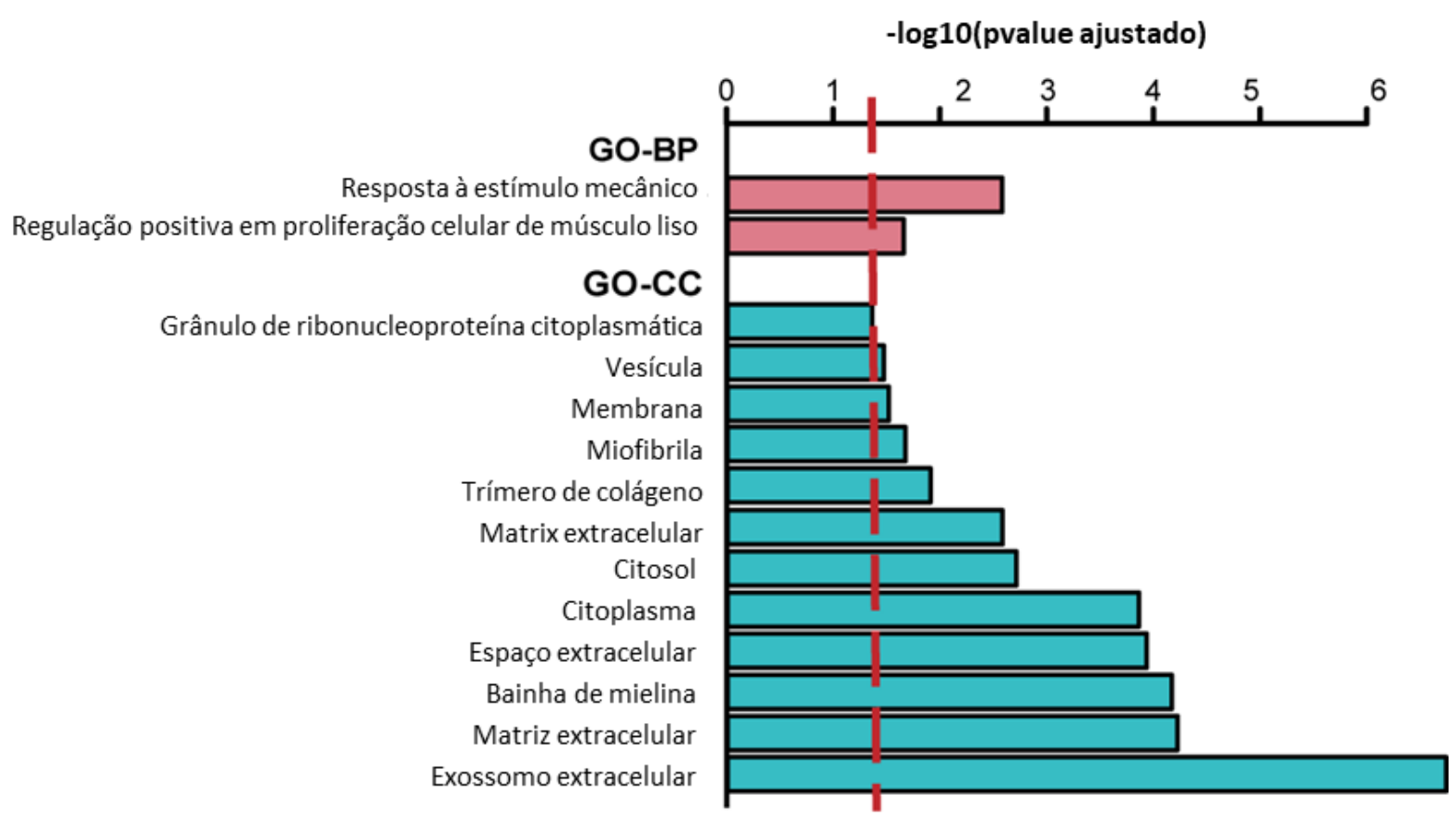

Figura 6. Ontologia de genes usando os 241 genes diferencialmente expressos após 24 horas de tratamento com PT. Somente termos significativamente enriquecidos (FDR $<0,05$, linha vermelha tracejada) são apresentados como -log10 (FDR). BP, processo biológico; CC, componente celular; $\mathrm{GO}$, ontologia genética. A análise de enriquecimento foi realizada usando o teste exato de Fisher, os valores de $\mathrm{p}$ foram ajustados para o FDR usando o método de Benjamini \& Hochberg.

\subsection{Controle da atrofia}

Como atrogene clássico, FBXO32 foi utilizado como gene de controle positivo, estando regulado negativamente após $24 \mathrm{~h}$ de tratamento com PT, quando $\mathrm{C} 3$ foi a referência. Pode-se observar a expressão característica de FBXO32 drasticamente aumentada durante o processo de atrofia no grupo de animais castrado por 3 dias $(8,2 \pm 6,3$ vezes). Depois do tratamento com PT, a expressão decaiu expressivamente em $8 \mathrm{~h}$ e $24 \mathrm{~h}$. 


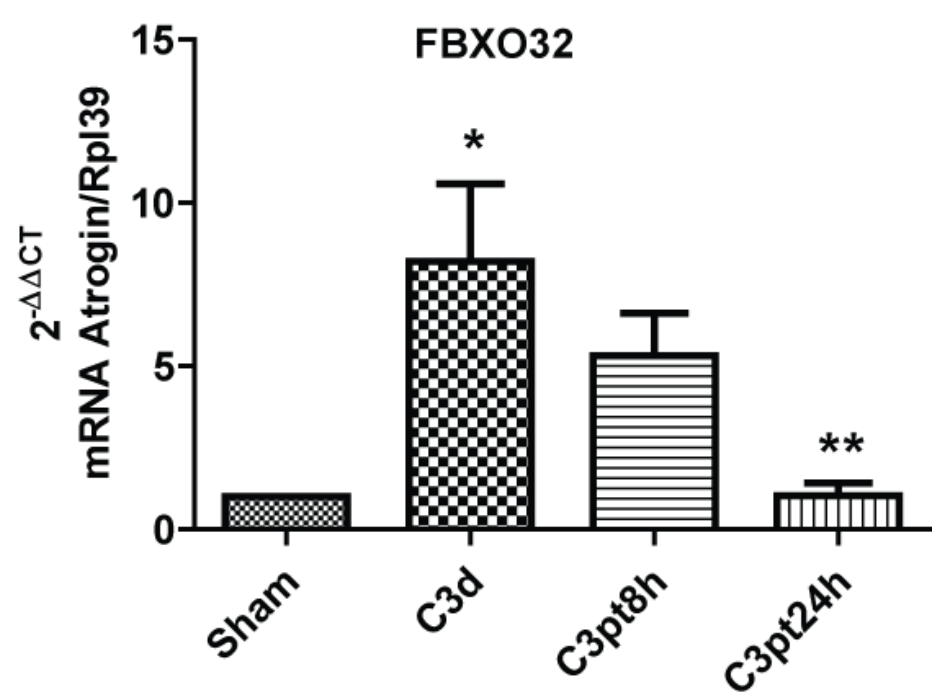

Figura 7. Regulação diferencial do FBXO32 no músculo Elevador do ânus, durante castração ou castração mais tratamento com propionato de testosterona. Os valores representam média \pm DP de 2 $\triangle \triangle \mathrm{Ct}$ mRNA FBXO32/RPL39 no músculo EA de ratos submetidos à castração por 3 dias $(C 3, n=8)$, sendo tratados para reversão da atrofia com propionato de testosterona (PT - dose única, $4 \mathrm{mg} / \mathrm{kg}$, em $1 \mathrm{~mL} / \mathrm{kg}$ de óleo de milho) após $8 \mathrm{~h}(\mathrm{C} 3 \mathrm{pt} 8 ; \mathrm{n}=8)$ ou após $24 \mathrm{~h}(\mathrm{C} 3 \mathrm{pt} 24 ; \mathrm{n}=8)$. Os valores foram normalizados pela expressão de RPL39 (housekeeping), e a razão de expressão estabelecida versus o grupo controle (Sham), que tem valor de expressão considerado $1 .{ }^{*} p<0,05$ comparado com Sham; ${ }^{* *} p<0,05$ quando comparado com C3, por One-way ANOVA seguido de pós-teste de Tukey.

\subsection{Grupo dos novos atrogenes}

Com a análise do microarray, foi observado que o número de genes diferencialmente expressos após $8 \mathrm{~h}$ foi muito menor do que após $24 \mathrm{~h}$ de tratamento com PT, inferindo que apenas $8 \mathrm{~h}$ de tratamento podem ser insuficientes para induzir resposta em todos os genes. Dessa maneira, decidiu-se por direcionar a análise das expressões e validar por RT-PCR o grupo dos animais castrados 3 dias e tratados com PT por 24 horas.

A partir dessa escolha refinada, foi feita a validação desses alvos por RT-PCR utilizando RPL39 como gene de expressão constitutiva. Os valores de Ct foram calculados em média (triplicatas, 8 animais por grupo) e os valores de $\Delta \mathrm{Ct}$ e $\Delta \Delta \mathrm{Ct}$ foram calculados e a amplificação do RNAm foi determinada como $2^{-\Delta \Delta C t}$. Com os valores obtidos, foi realizado o teste de Grubbs para deteç̧ão de outliers, já descrito, dentro do grupo de 8 animais, dados testados para distribuição gaussiana. 
As análises estatísticas foram realizadas com análise de variância simples One-way ANOVA não pareado e pós-teste de Tukey, com valor de $p<0,05$, plotados no programa GraphPad Prism 6.0.

Os genes validados foram agrupados em duas categorias distintas. Na primeira, foram separados genes de expressão similar aos Atrogenes. Foram considerados aqueles que apresentaram regulação significativa $(p<0,05)$ induzidos ou reprimidos após a castração (grupo C3 versus x Sham) e significativa $(p<0,05)$ induzidos ou reprimidos após reposição de testosterona (C3tp24 versus grupo C3). Dez genes participaram dessas condições: CCK, HOPX, METTL7A, IGFBP3, PGF, AMD1, CTGF, CXCL14, RPS6Ka5 e ODC1. O gene FOXO3 também foi avaliado como marcador de atrofia nos animais devido ao seu importante papel transcricional dos atrogenes MuRF-1 e FBXO32 quando em condição de atrofia muscular esquelética. 

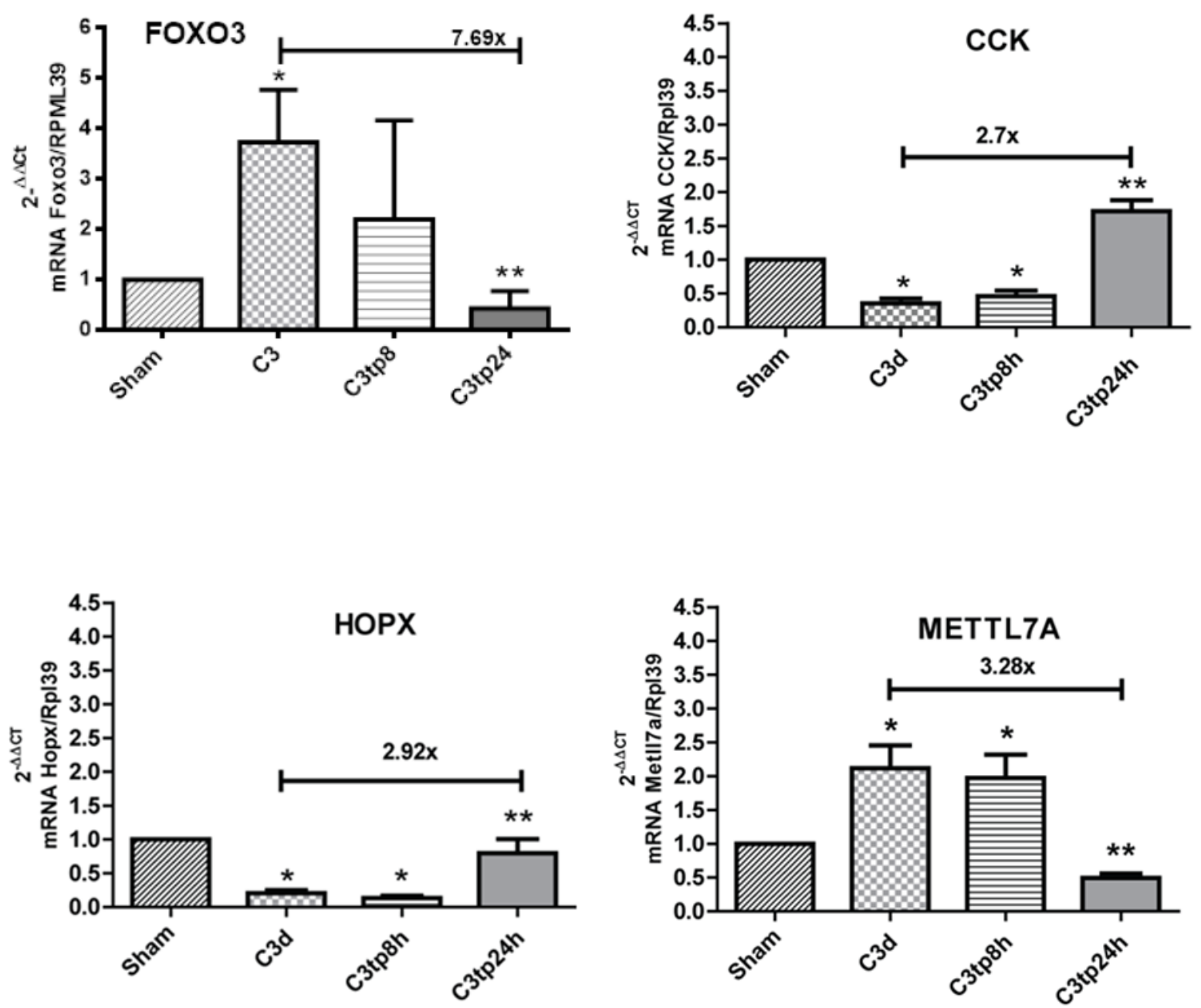

Figura 8. Genes FOXO3, CCK, HOPX e METTL7A identificados como novos atrogenes no músculo Elevador do ânus e validados por RT-PCR. Os genes considerados como atrogenes foram aqueles induzidos ou reprimidos de maneira significativa $(p<0,05$, por One-way ANOVA seguido pelo pósteste de Tukey) em amostras C3, e também de maneira significativa ( $p<0,05$, por One-way ANOVA seguido pós-teste de Tukey) induzidos ou reprimidos em C3pt24 quando comparado com C3. Sham submetido apenas ao procedimento cirúrgico, sem retirada do testículo, seguido de 3 dias e sacrificado; C3 - castrado, seguido de 3 dias e sacrificado; C3pt8 - castrado, seguido de 3 dias, tratado com propionato de testosterona (PT - dose única, $4 \mathrm{mg} / \mathrm{kg}$, em $1 \mathrm{~mL} / \mathrm{kg}$ de óleo de milho) e sacrificado após 8 h; e C3pt24 - castrado, seguido de 3 dias, tratado com propionato de testosterona (PT - dose única, $4 \mathrm{mg} / \mathrm{kg}$, em $1 \mathrm{~mL} / \mathrm{kg}$ de óleo de milho) e sacrificados após $24 \mathrm{~h}$. Cada barra representa média \pm DP dos genes validados $(n=8)$, normalizados pela expressão de cada gene em ratos Sham (considerados 1 ). Todos os valores foram calculados como $2^{-\Delta \Delta C t}$. 

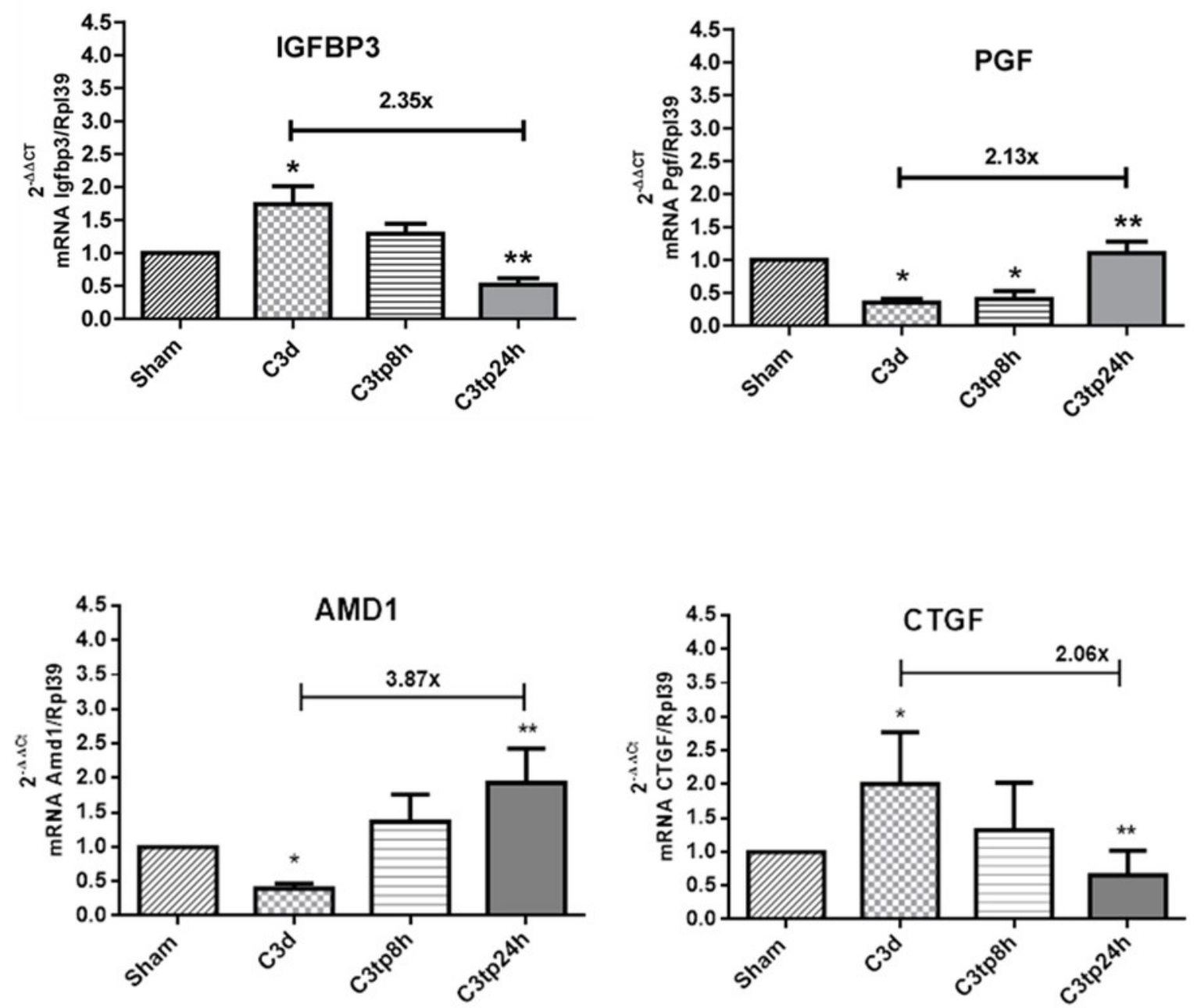

Figura 9. Genes IGFBP3, PGF, AMD1, CTGF identificados como novos atrogenes no músculo elevador do ânus e validados por RT-PCR. Os genes considerados como atrogenes foram aqueles induzidos ou reprimidos de maneira significativa ( $p<0,05$, por One-way ANOVA seguido pelo pósteste de Tukey) em amostras $C 3$, e também de maneira significativa ( $p<0,05$, por One-way ANOVA seguido pós-teste de Tukey) induzidos ou reprimidos em C3pt24 quando comparado com C3. Sham submetido apenas ao procedimento cirúrgico, sem retirada do testículo, seguido de 3 dias e sacrificado; C3 - castrado, seguido de 3 dias e sacrificado; C3pt8 - castrado, seguido de 3 dias, tratado com propionato de testosterona (PT - dose única, $4 \mathrm{mg} / \mathrm{kg}$, em $1 \mathrm{~mL} / \mathrm{kg}$ de óleo de milho) e sacrificado após $8 \mathrm{~h}$; e C3pt24 - castrado, seguido de 3 dias, tratado com propionato de testosterona (PT - dose única, $4 \mathrm{mg} / \mathrm{kg}$, em $1 \mathrm{~mL} / \mathrm{kg}$ de óleo de milho) e sacrificados após $24 \mathrm{~h}$. Cada barra representa média \pm DP dos genes validados $(n=8)$, normalizados pela expressão de cada gene em ratos Sham (considerados 1 ). Todos os valores foram calculados como $2^{-\Delta \Delta \mathrm{Ct}}$. 

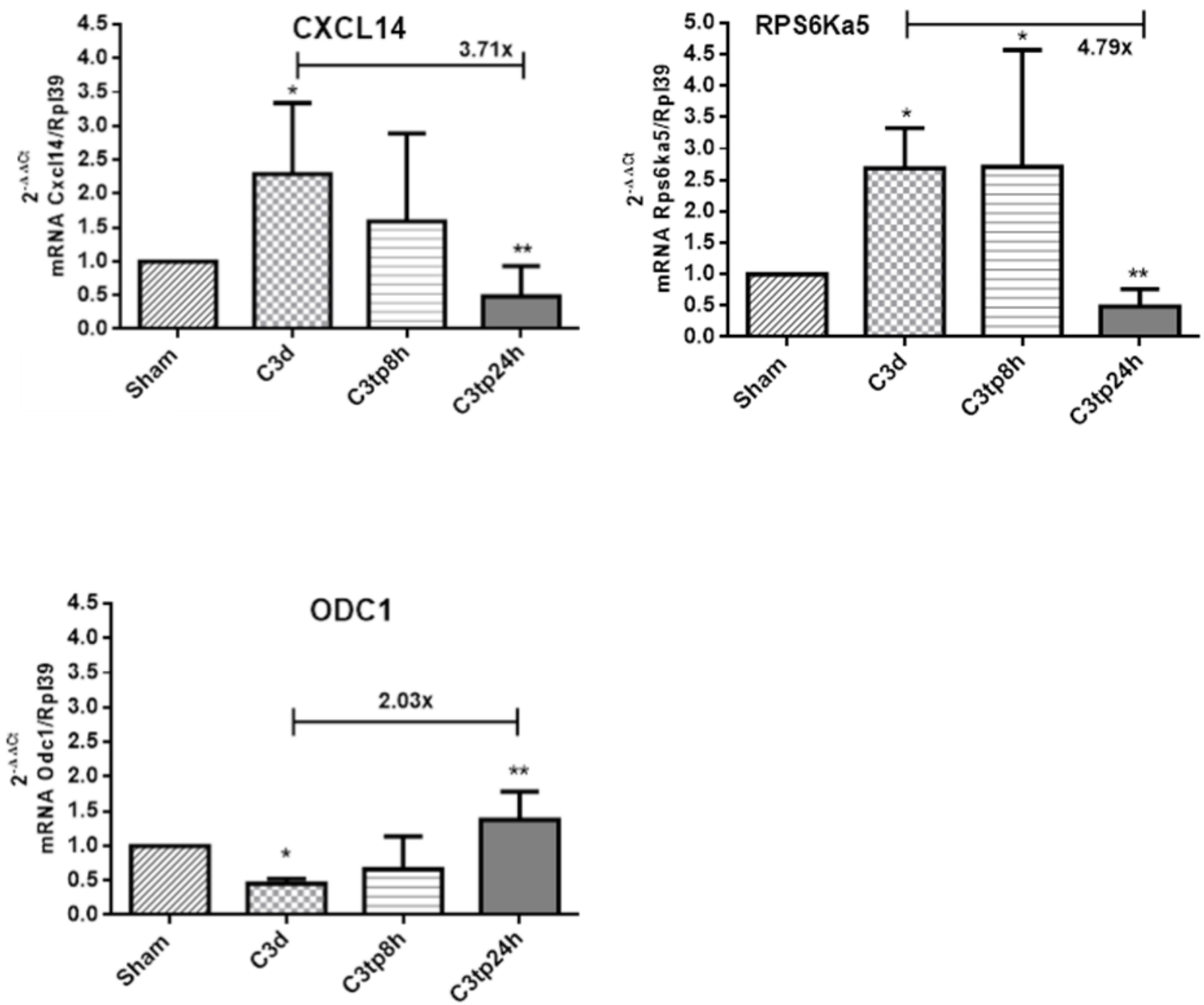

Figura 10. Genes CXCL14, RPS6Ka5 e ODC1 identificados como novos atrogenes no músculo elevador do ânus e validados por RT-PCR. Os genes considerados como atrogenes foram aqueles induzidos ou reprimidos de maneira significativa $(p<0,05$, por One-way ANOVA seguido pelo pósteste de Tukey) em amostras C3, e também de maneira significativa ( $p<0,05$, por One-way ANOVA seguido pós-teste de Tukey) induzidos ou reprimidos em C3pt24 quando comparado com C3. Sham submetido apenas ao procedimento cirúrgico, sem retirada do testículo, seguido de 3 dias e sacrificado; C3 - castrado, seguido de 3 dias e sacrificado; C3pt8 - castrado, seguido de 3 dias, tratado com propionato de testosterona (PT - dose única, $4 \mathrm{mg} / \mathrm{kg}$, em $1 \mathrm{~mL} / \mathrm{kg}$ de óleo de milho) e sacrificado após $8 \mathrm{~h}$; e C3pt24 - castrado, seguido de 3 dias, tratado com propionato de testosterona (PT - dose única, $4 \mathrm{mg} / \mathrm{kg}$, em $1 \mathrm{~mL} / \mathrm{kg}$ de óleo de milho) e sacrificados após $24 \mathrm{~h}$. Cada barra representa média \pm DP dos genes validados $(n=8)$, normalizados pela expressão de cada gene em ratos Sham (considerados 1 ). Todos os valores foram calculados como $2^{-\Delta \Delta C t}$. 


\subsection{Grupo dos genes associados à reversão da atrofia}

Em um segundo grupo estão os genes associados à reversão da atrofia. A condição para ser incluído neste grupo foi que sua regulação deveria ser exclusiva pela reposição hormonal. Sem diferença significativa comparando-se os grupos C3 x Sham, e ter diferença significativa, valor de $p<0,05$, com expressão induzida ou reprimida entre os grupos C3 x C3pt24. Participam deste grupo: APLN, DUSP5, IGF1, PIK3IP1, KLHL38, PI15 e MKL1.
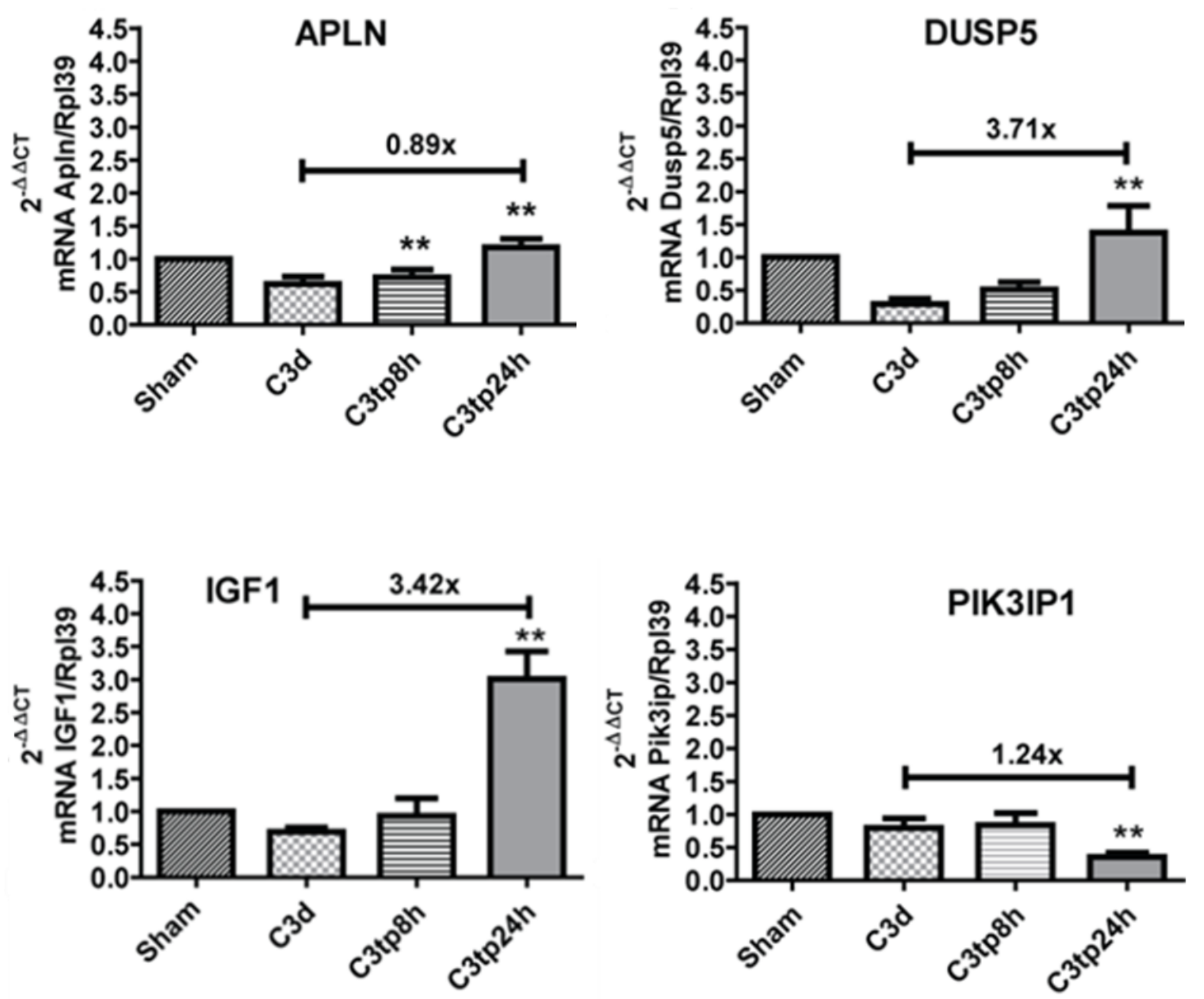

Figura 11. Genes APLN, DUSP5, IGF1 e PIK3IP1 associados à reversão da atrofia no músculo elevador do ânus e validados por RT-PCR. Os genes associados à reversão atrófica foram aqueles que não demonstraram expressão significativa $(p>0,05$, por One-way ANOVA seguido pelo pós-teste de Tukey) induzida ou reprimida nas amostras C3, mas demonstraram expressão significativa ( $p<$ 
0,05, por One-way ANOVA seguido pelo pós-teste de Tukey) induzida ou reprimida em C3pt24 quando comparado a C3. Cada barra representa média \pm DP dos genes validados $(n=8)$, normalizados pela expressão de cada gene em ratos Sham (considerados 1). Todos os valores foram calculados como $2^{-\Delta \Delta \mathrm{Ct}}$.
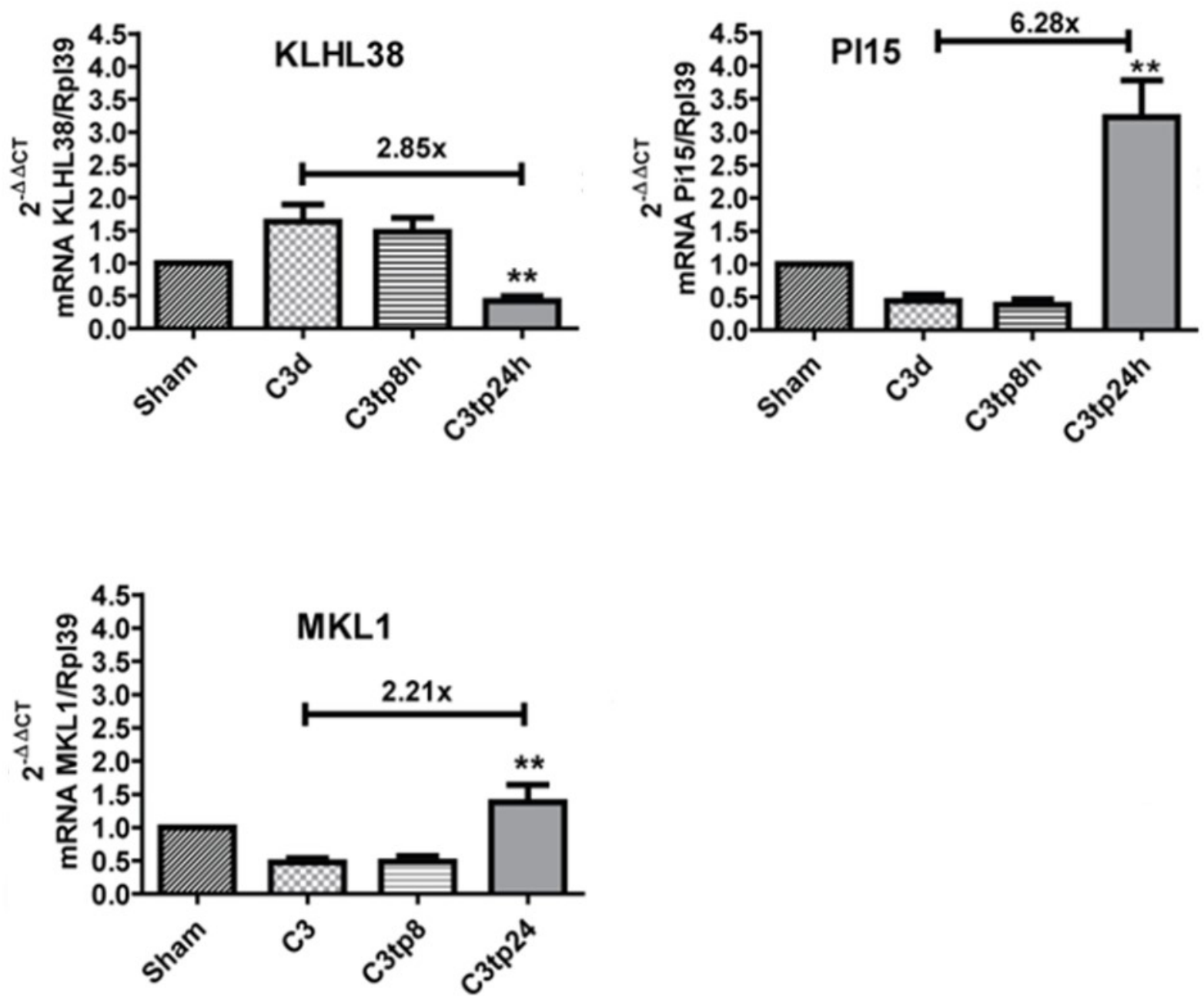

Figura 12. Genes KLHL38, PI15 e MKL1 associados à reversão da atrofia no músculo elevador do ânus e validados por RT-PCR. Os genes associados à reversão atrófica foram aqueles que não demonstraram expressão significativa ( $p>0,05$, por One-way ANOVA seguido pelo pós-teste de Tukey) induzida ou reprimida nas amostras $C 3$, mas demonstraram expressão significativa $(p<0,05$, por One-way ANOVA seguido pelo pós-teste de Tukey) induzida ou reprimida em C3pt24 quando comparado a C3. Cada barra representa média \pm DP dos genes validados $(n=8)$, normalizados pela expressão de cada gene em ratos Sham (considerados 1 ). Todos os valores foram calculados como $2^{-\Delta \Delta C t}$. 


\subsection{Comportamentos dos genes-alvo}

Resumidamente, é possível organizar o perfil de expressão dos genes-alvo no músculo EA através da classificação como atrogenes e genes associados à reversão da atrofia, ou anti-atrogenes.

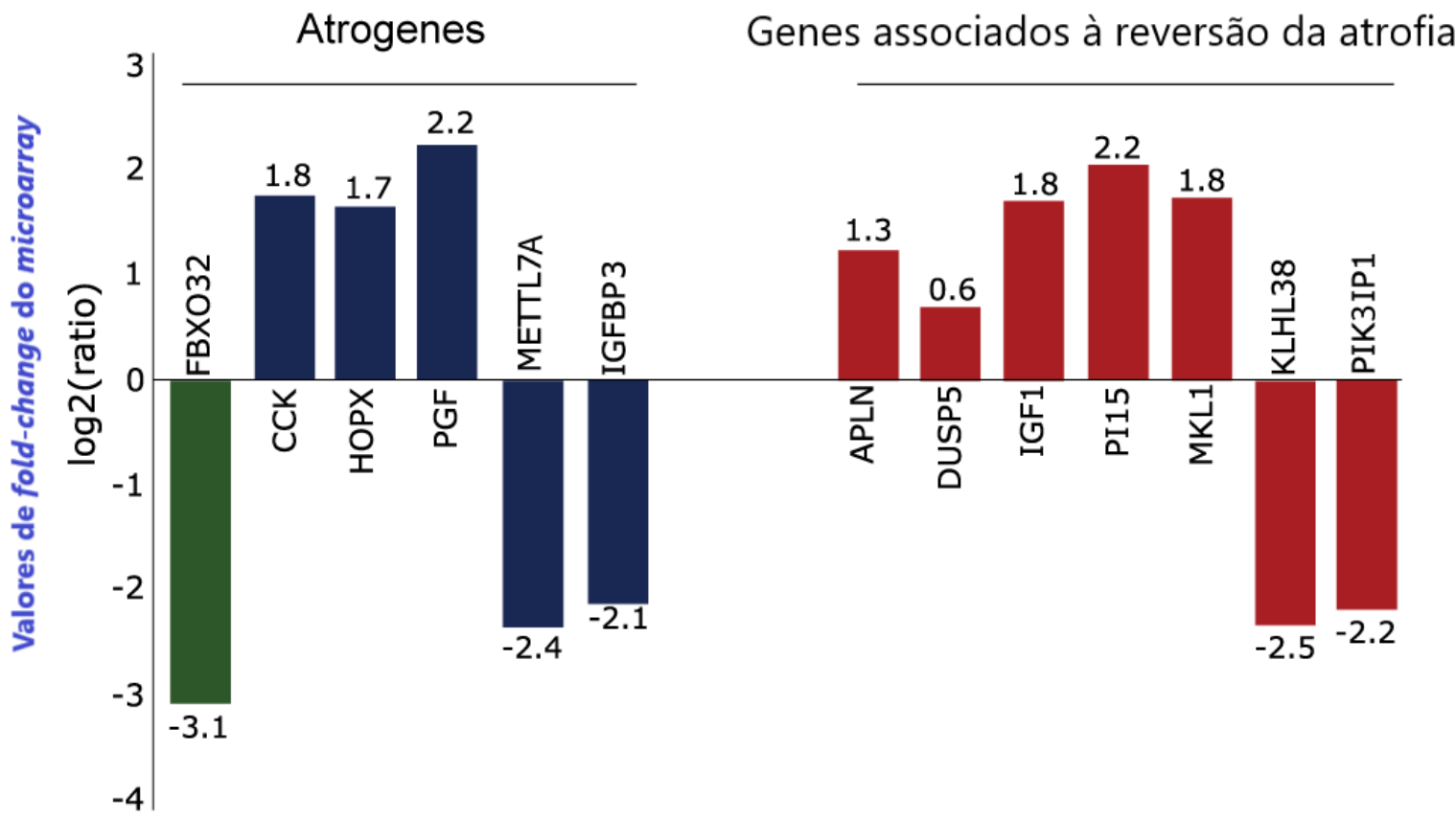

Figura 13. Gráficos de barras representando os valores de expressão de fold-change após $24 \mathrm{~h}$ de tratamento com PT. Os valores foram obtidos a partir do ensaio de microarray e a expressão gênica diferencial foi avaliada com o pacote Limma em R/Bioconductor. O log2 negativo (razão) indica genes reprimidos após 24 horas de tratamento com PT. O log2 positivo (razão) indica genes induzidos após 24 horas de tratamento com PT. Gráficos de barras em azul e verde indicam genes classificados como atrogenes. Gráficos de barras em vermelho indicam genes classificados como associados à reversão da atrofia. 


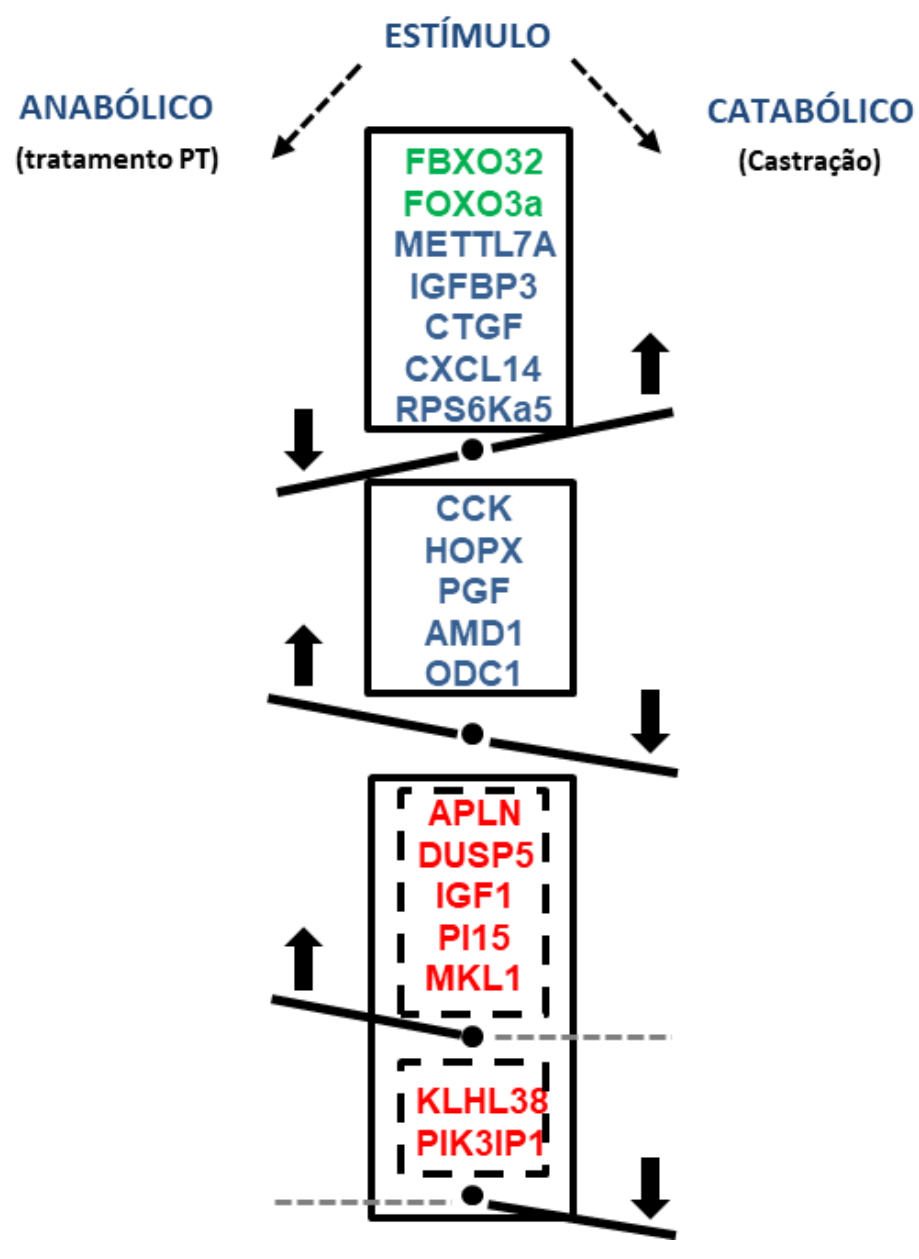

Figura 14. Modelo esquemático de crosstalk entre processos catabólicos e anabólicos no músculo esquelético. As cores das fontes indicam a classificação dos genes da seguinte forma: azul e verde indicam genes classificados como atrogenes e vermelho indicam genes classificados como associados à reversão da atrofia.

\subsection{Modelo de privação alimentar}

A atrofia muscular envolve um programa comum de adaptações transcricionais na expressão gênica (Lecker, Jagoe et al. 2004, Sacheck, Hyatt et al. 2007). Com a finalidade de validar se os novos atrogenes descritos no músculo EA são parte do mesmo programa adaptativo, utilizamos outro músculo esquelético, o Gastrocnêmio. Para a atrofia, foi escolhido o modelo de privação alimentar (jejum de 48 horas) em camundongos. Para tal, foram utilizados dois grupos com oito camundongos machos cada. 
Após dois dias sem alimentação, os camundongos foram sacrificados. Animais e músculo Gastrocnêmio foram pesados e observou-se que não houve alteração significativa do peso corporal dos camundongos quando comparado ao grupo Controle.

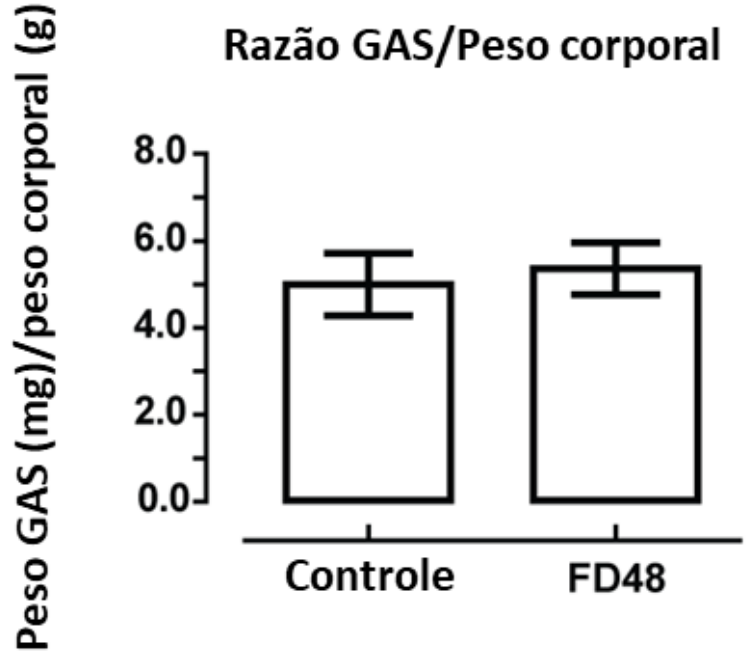

Figura 15. Peso do Gastrocnêmio (GAS) corrigido pela razão de massa corporal em animais do grupo controle e do grupo privados de alimentos após 48 horas (FD48). Cada barra indica M \pm DP de cada grupo. Nenhuma diferença foi detectada por teste $t$ de Student.

Oito atrogenes (FBXO32, FOXO3, CCK, PGF, HOPX, AMD1, ODC1 e IGFBP3) e cinco genes associados à reversão da atrofia (APLN, IGF-1, PI15, DUSP5 e KLHL38,) foram selecionados para validação por RT-PCR no músculo Gastrocnêmio. Como esperado, todos os atrogenes responderam à atrofia por privação alimentar de forma semelhante aos animais submetidos à castração. DUSP5 e KLHL38 reproduziram a resposta do modelo de castração, ou seja, não foi observado alteração nos seus níveis de RNAm pelo estímulo atrófico. Já PI15 teve uma pequena redução. Entretanto, os outros dois alvos (IGF-1 e APLN) foram fortemente reprimidos no jejum. 
Nesse estudo, os genes FBXO32 e FOXO3 foram utilizados como controle positivo para a sinalização de resposta atrófica. CCK, PGF, HOPX, AMD1, ODC1, APLN, IGF-1 e PI15 foram significativamente reprimidos durante a privação alimentar, enquanto o IGFBP3 teve sua expressão induzida durante o período de jejum.
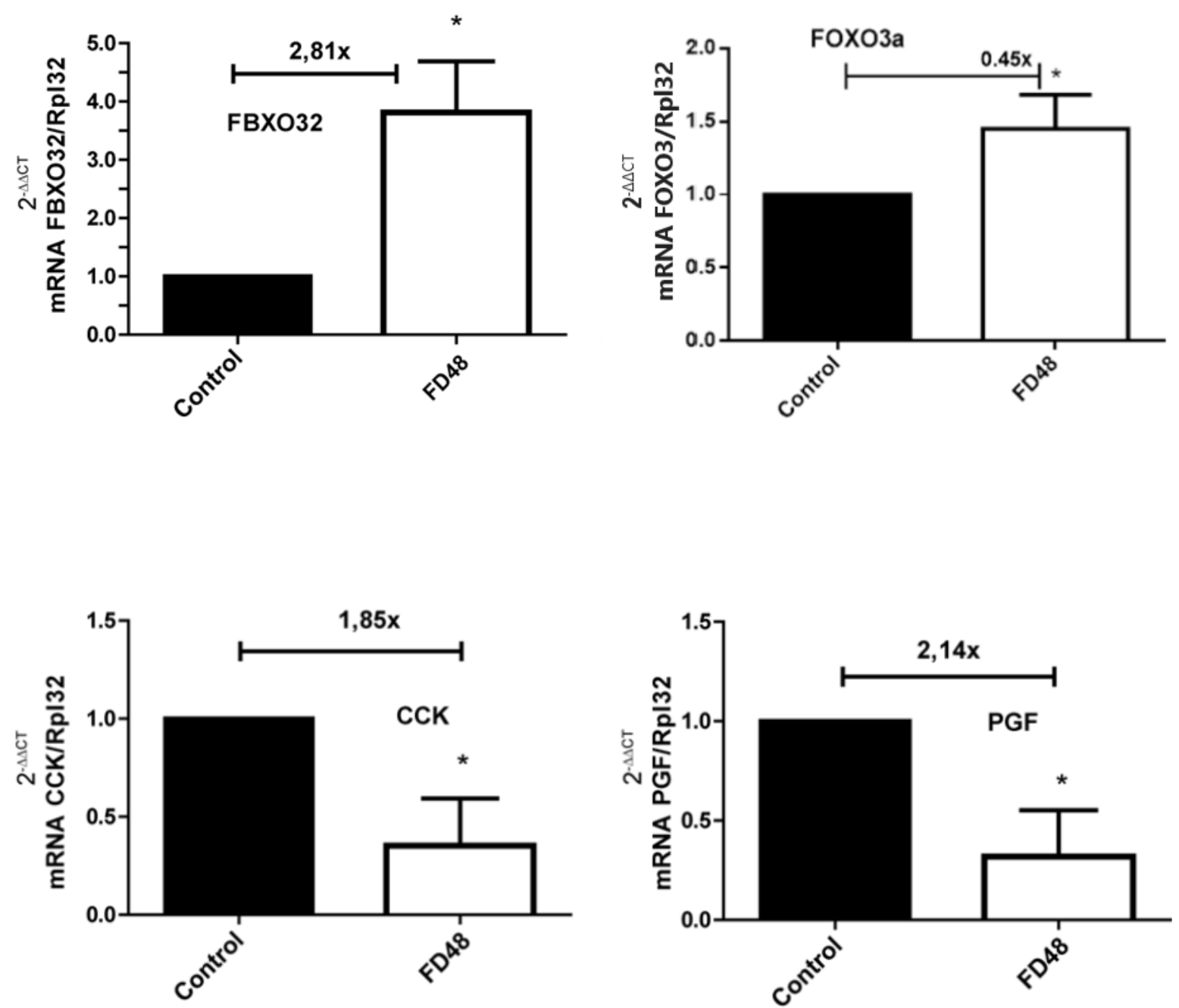

Figura 16. Expressão dos genes FBXO32 e FOXO3, atrogenes conhecidos e dos novos identificados CCK e PGF, em modelo murino de atrofia muscular por privação alimentar. Os valores representam

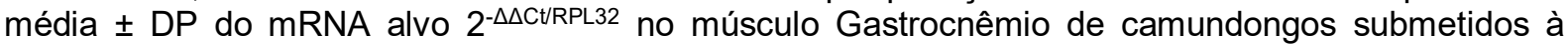
privação alimentar por $48 \mathrm{~h}$ (grupo FD48, $\mathrm{n}=8$ ), e camundongos controle (grupo Controle, $\mathrm{n}=8$ ). Os valores foram normalizados pela expressão RPL32 (housekeeping), e a razão de expressão estabelecida versus o grupo Controle, que tem seu valor de expressão considerado $1 .{ }^{*} p<0,05$ comparado ao Controle, pelo teste $t$ de Student. 

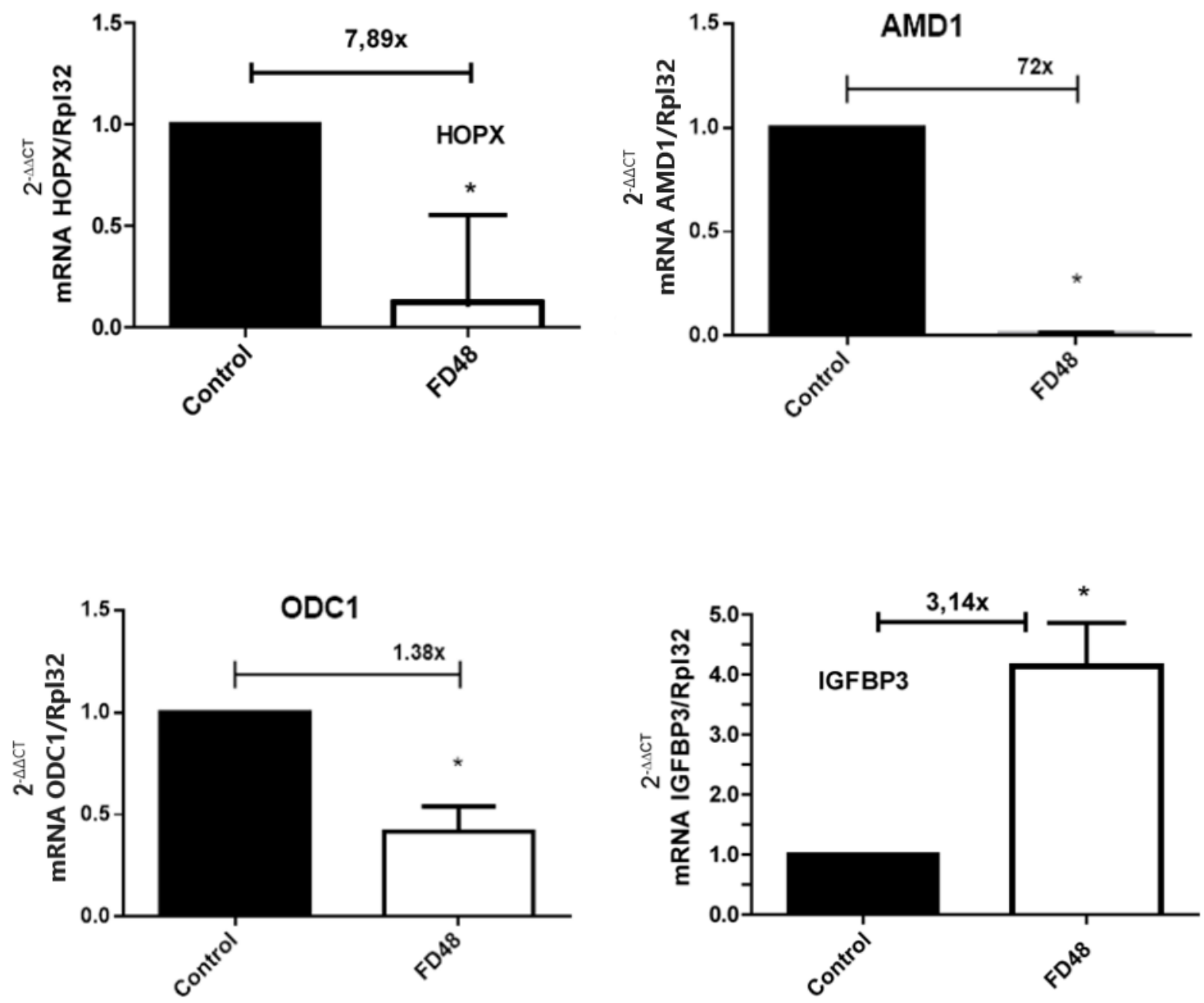

Figura 17. Expressão dos novos atrogenes identificados HOPX, AMD1, ODC1 e IGFBP3 em modelo murino de atrofia muscular por privação alimentar. Os valores representam média \pm DP do mRNA alvo $2^{-\Delta \Delta C t / R P L 32}$ no músculo Gastrocnêmio de camundongos submetidos à privação alimentar por $48 \mathrm{~h}$ (grupo FD48, $n=8$ ), e camundongos controle (grupo Controle, $n=8$ ). Os valores foram normalizados pela expressão RPL32 (housekeeping), e a razão de expressão estabelecida versus o grupo Controle, que tem seu valor de expressão considerado 1. * $p<0,05$ comparado ao Controle, pelo teste $t$ de Student. 

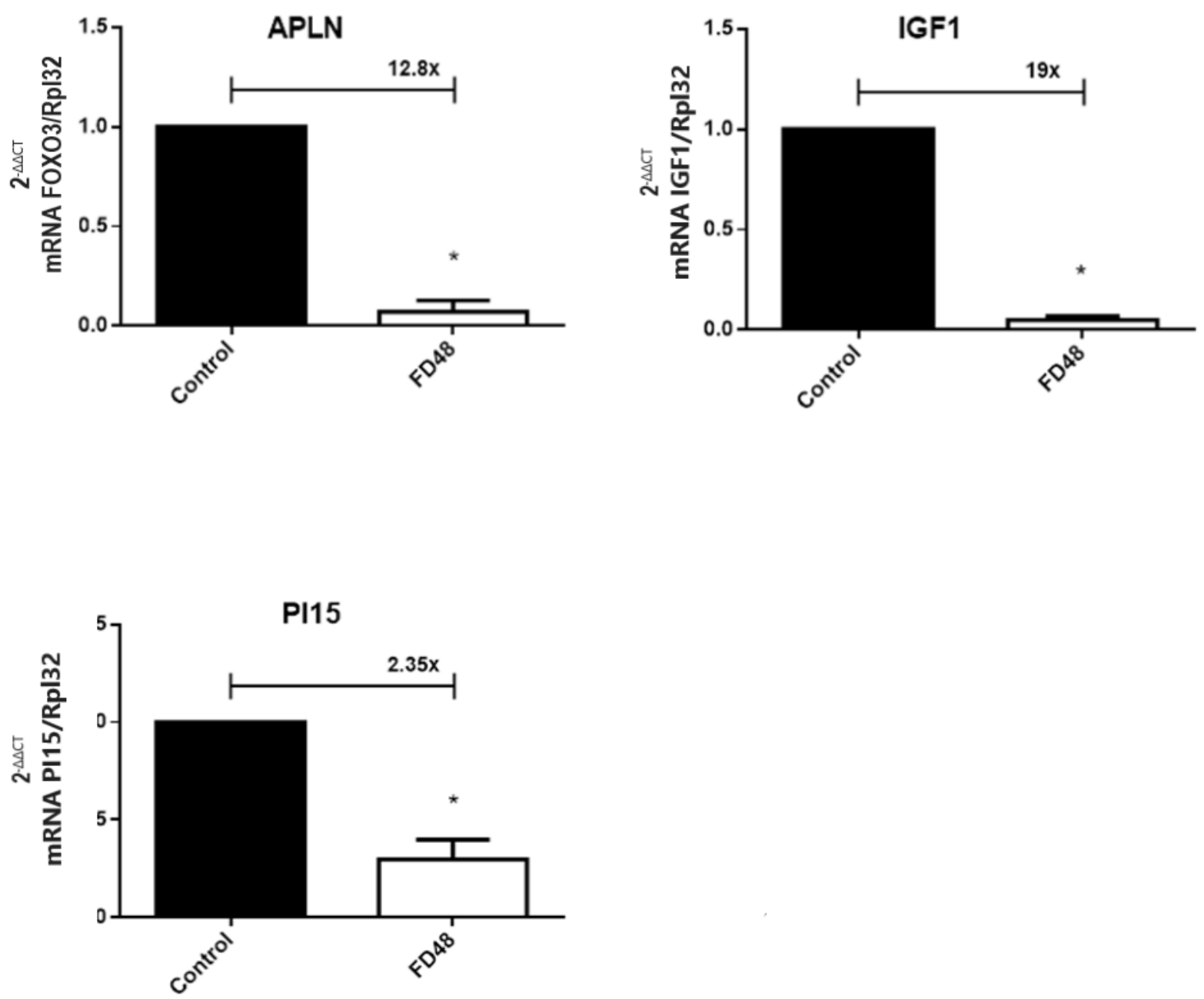

Figura 18. Expressão dos genes APLN, IGF-1 e PI15 classificados como anti-atrogenes em modelo de privação/reposição de andrógeno. Os valores representam média \pm DP do mRNA alvo $2^{-\triangle \triangle C t / R P L 32}$ no músculo Gastrocnêmio de camundongos submetidos à privação alimentar por 48 h (grupo FD48, $n$ $=8$ ), e camundongos controle (grupo Controle, $n=8$ ). Os valores foram normalizados pela expressão RPL32 (housekeeping), e a razão de expressão estabelecida versus o grupo Controle, que tem seu valor de expressão considerado $1 .{ }^{*} \mathrm{p}<0,05$ comparado ao Controle, pelo teste $t$ de Student. 

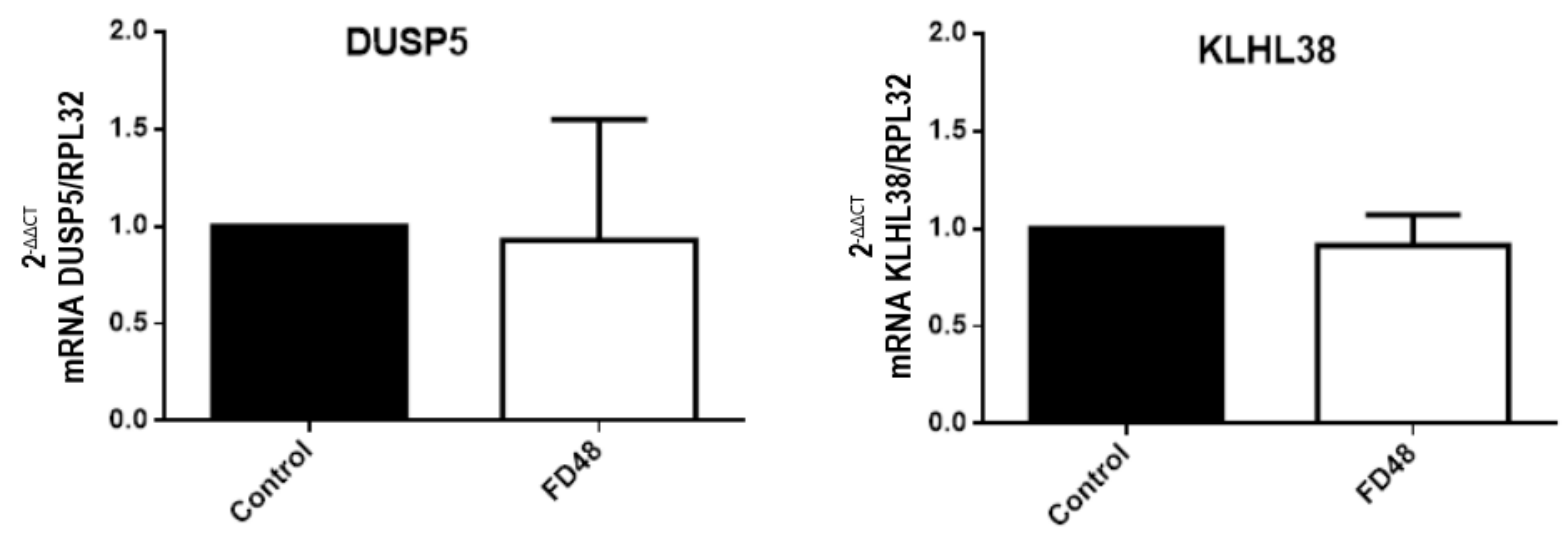

Figura 19. Expressão dos genes DUSP5 e KLHL38. Ambos reproduziram a resposta do modelo de castração, ou seja, não possuem resposta com alteração significativa de sua expressão $(p<0,05)$ no grupo jejum (grupo FD48, $n=8$ ) em relação ao grupo Controle (grupo Controle, $n=8$ ) no músculo Gastrocnêmio durante o período de atrofia.

\subsection{Ensaios SUnSET}

As taxas de síntese de proteínas são geralmente medidas usando marcadores isotópicos para quantificar a incorporação de um aminoácido marcado em proteínas musculares. Recentemente, no entanto, uma técnica não isotópica conhecida como SUnSET (SUrface SEnsing of Translation), que envolve o uso do antibiótico Puromicina, foi desenvolvida para medir a síntese de proteínas em células cultivadas. Dessa maneira, decidiu-se investigar se dois plasmídeos contendo genes associados à reversão da atrofia, APLN e MKL1 (APLN, gentilmente cedido pelo Dr. Bernard Masri, da Universidade de Tolouse III e MKL1, gentilmente cedido pela Dra. Akiko Atabuchi, da Universidade de Toyama) teriam influência na via de síntese de proteínas. Foi utilizada a técnica de SUnSET em células HEK293T (células renais embrionárias humanas) a fim de tentar detectar um aumento na síntese de proteínas nas células transfectadas com esses genes-alvos. 
Após a incubação com anticorpo anti-Puromicina, as amostras foram normalizadas da seguinte maneira: o arraste de proteínas marcadas com o anticorpo antiPuromicina de uma amostra normalizada pelo mesmo arraste da amostra de proteínas presentes no Ponceau, obtidas da mesma membrana transferida. Infortunadamente, não foi identificado, com valor de p significativo, mudanças na síntese proteica das células transfectadas com os plasmídeos MKL1 e APLN, apenas uma tendência ao aumento na síntese, mas sem significância estatística. Uma das possibilidades da não detecção desse aumento por Western blotting pode ser devido ao modelo celular (HEK293T) empregado.

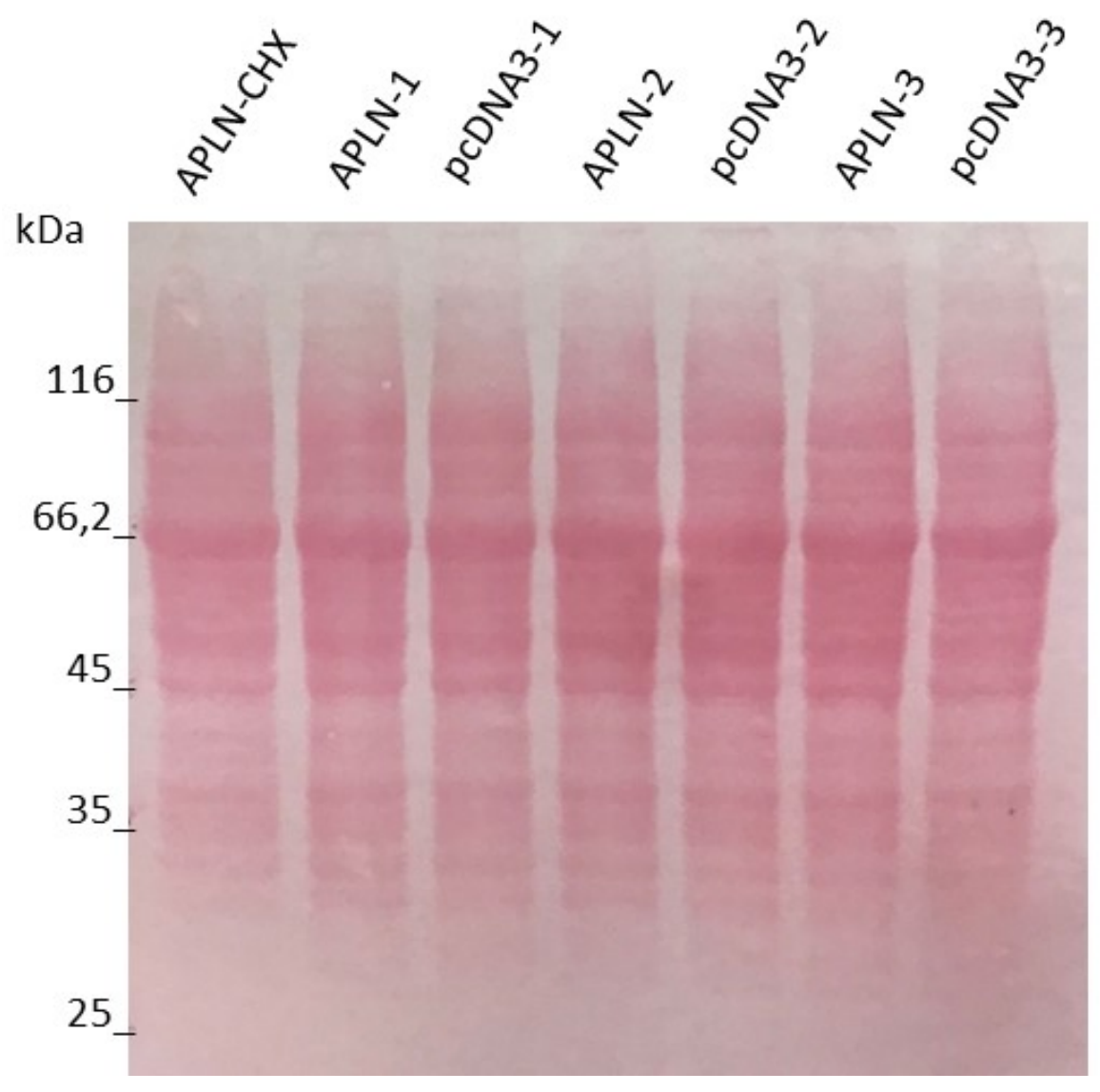

Figura 20. Plasmídeo APLN em HEK293T. Imagem do Ponceau da membrana de nitrocelulose corada contendo 60 ug de proteínas totais. O plasmídeo pcDNA3 foi utilizado como controle. $\mathrm{CHX}$ : cicloheximida, utilizada para inibição da síntese proteica. 


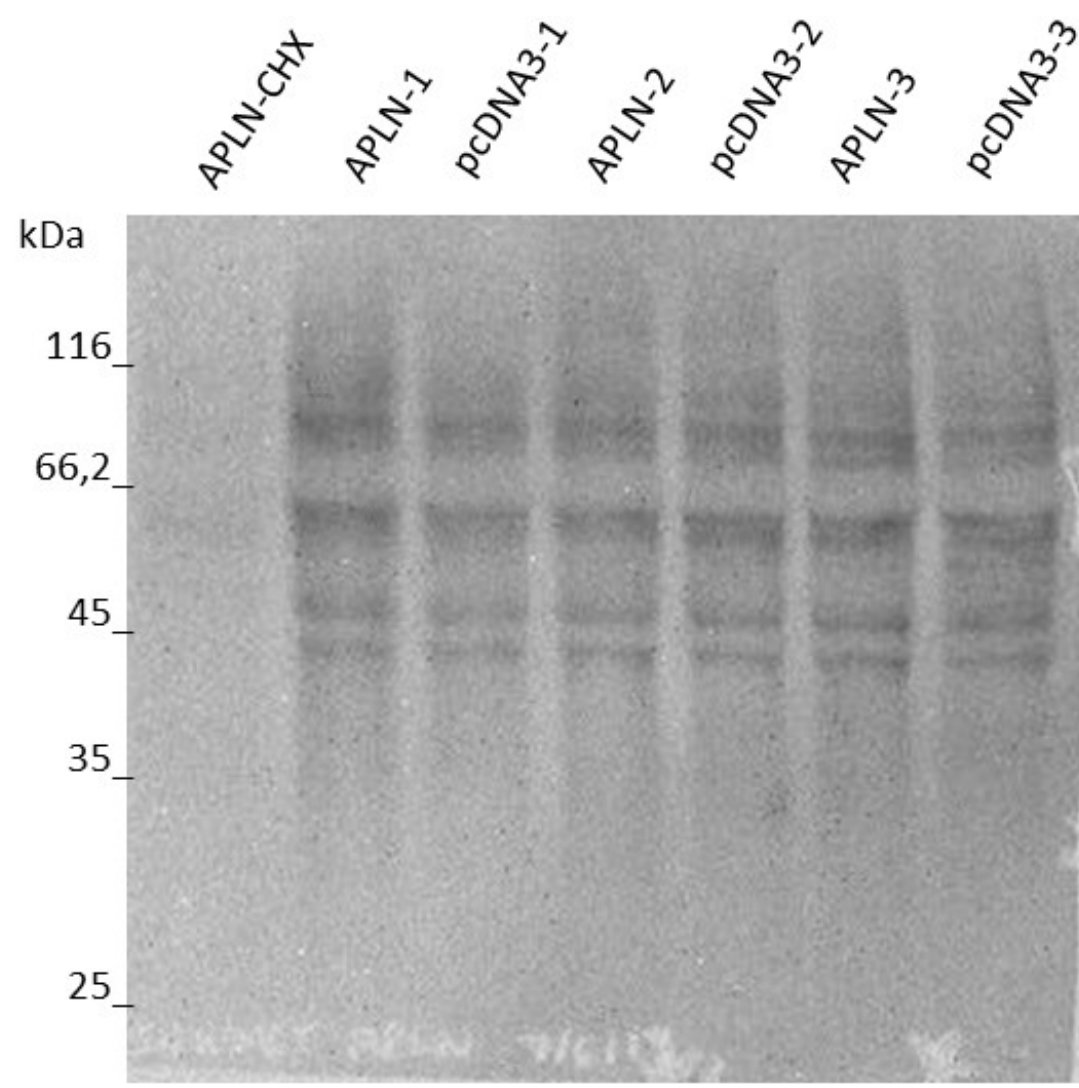

35

Figura 21. Plasmídeo APLN em HEK293T. Imagem da membrana revelada com anti-Puromicina e com anti-pS6. O plasmídeo pcDNA3 foi utilizado como controle. CHX: cicloheximida, utilizada para inibição da síntese proteica. 


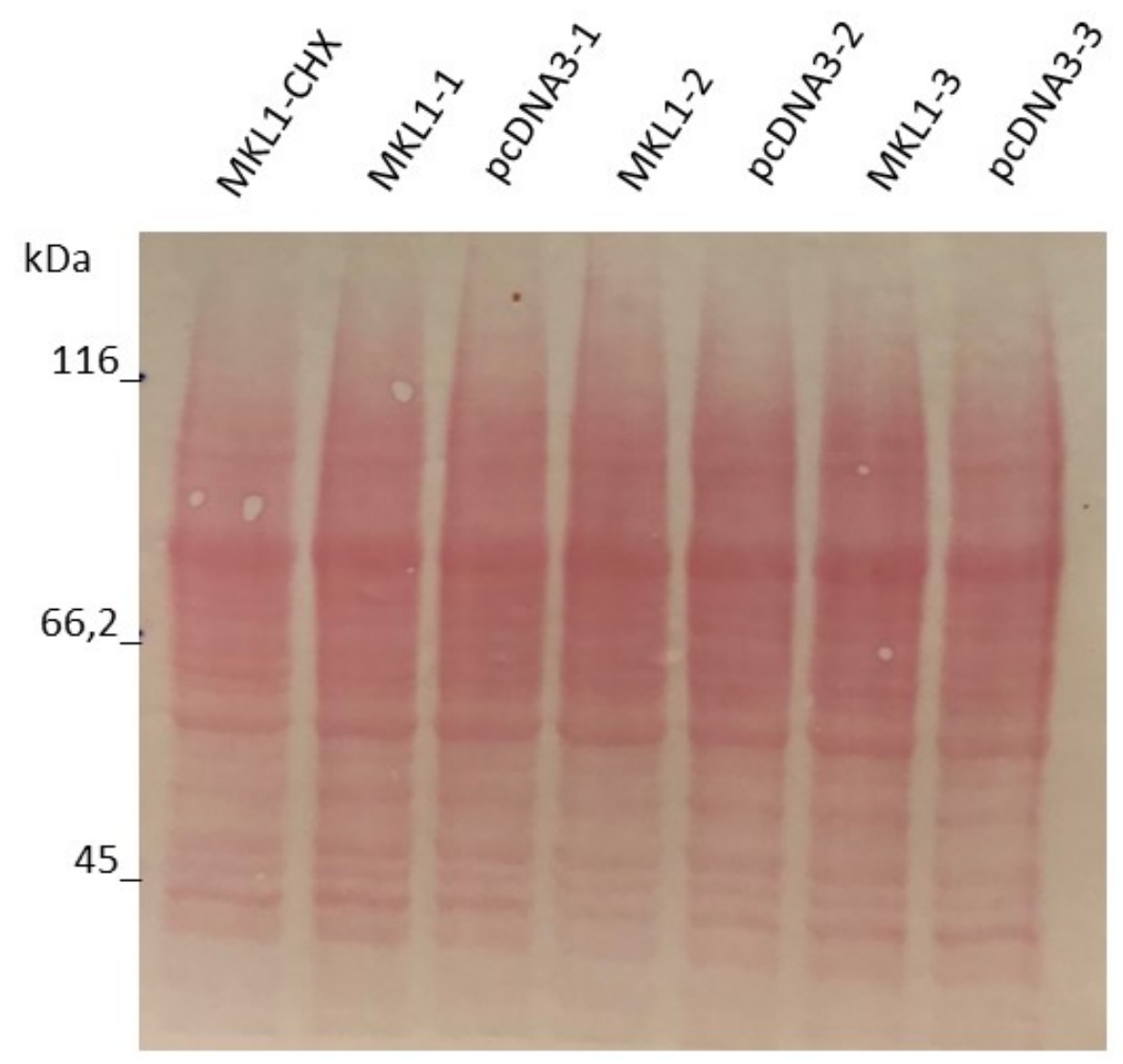

Figura 22. Plasmídeo MKL1 em HEK293T. Imagem do Ponceau da membrana de nitrocelulose corada contendo 60 ug de proteínas totais. O plasmídeo pcDNA3 foi utilizado como controle. $\mathrm{CHX}$ : cicloheximida, utilizada para inibição da síntese proteica. 

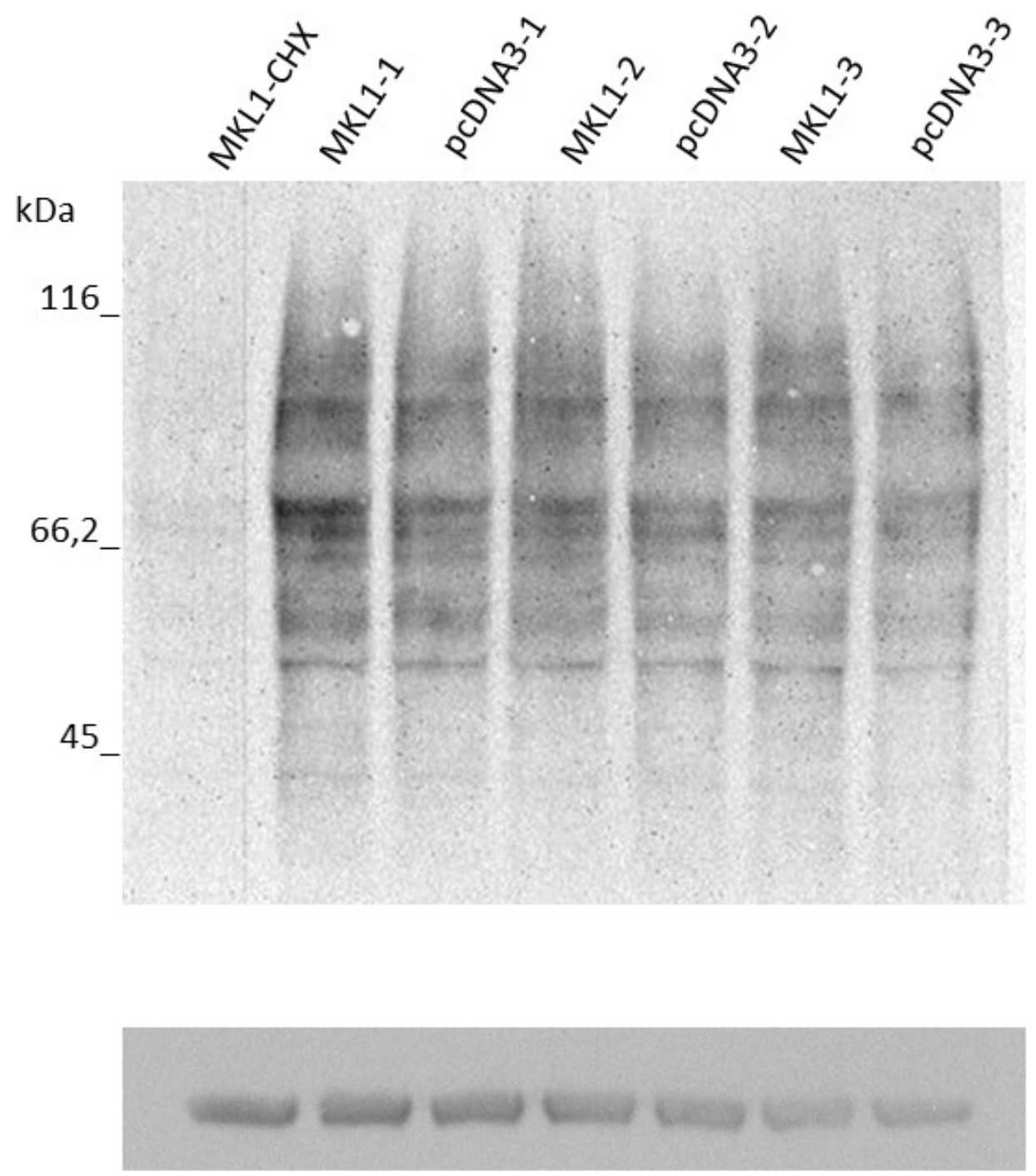

Figura 23. Plasmídeo MKL1 em HEK293T. Imagem da membrana revelada com anti-Puromicina e com anti-pS6. O plasmídeo pcDNA3 foi utilizado como controle. CHX: cicloheximida, utilizada para inibição da síntese proteica.

\subsection{Array de anticorpos anti-fosfoquinases}

As proteínas quinases são a maior classe de enzimas no genoma humano. Elas regulam quase todos os processos celulares adicionando grupos fosfato às proteínas, modificando assim a atividade, a localização e a função geral de seus alvos. Consequentemente, a atividade anormal de quinases está envolvida em muitas doenças, incluindo a atrofia muscular esquelética (Glass 2010). 
Como as quinases respondem rapidamente a estímulos, foi escolhido o menor tempo de tratamento com PT (8 horas) para a análise do perfil de fosforilação das fosfoquinases musculares. Selecionamos duas amostras de animais castrados por três dias e duas amostras de animais castrados e tratados 8 horas com PT para a realização do array. Comparamos o perfil de fosforilação das 43 quinases-alvo respeitando a mesma estratégia do microarray: C3pt8 x C3.

\section{Animais C3}
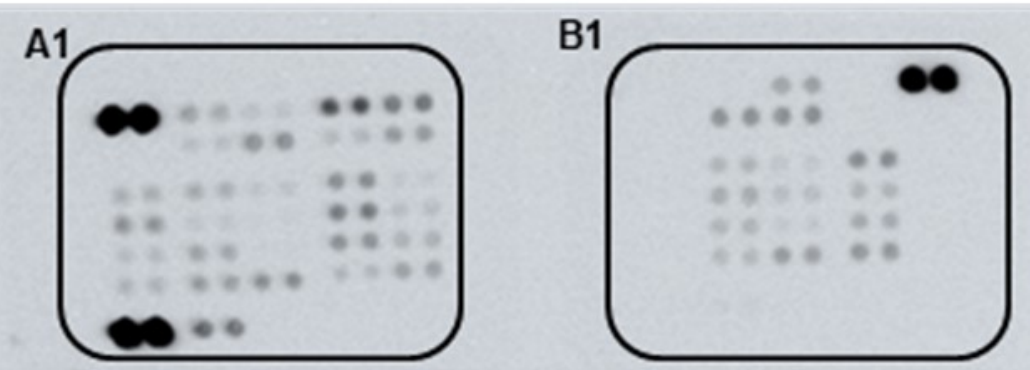

A2

B2
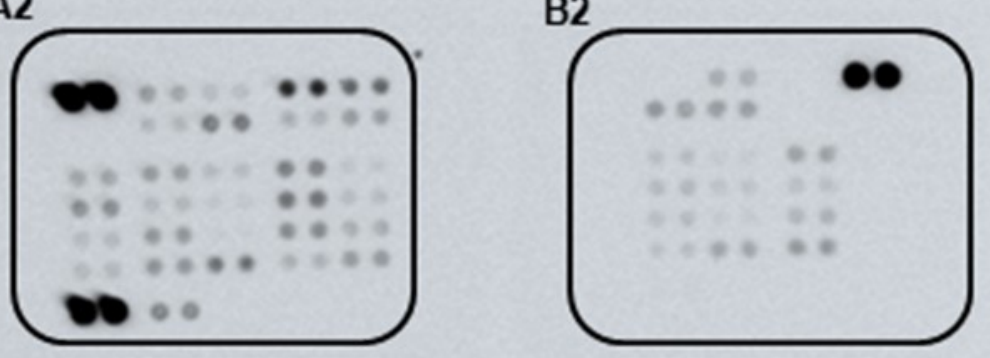

Figura 24. Membranas A-B de cada animal castrado por 3 dias contendo as duplicatas de poços de cada uma das 43 fosfoquinases e os controles da reação. Os experimentos foram realizados em duplicada. A avaliação do aumento ou diminuição dos níveis de fosforilação foi feita comparando-se amostras dos animais castrados 3 dias e tratados com PT por 8 horas com as amostras dos animais castrados por 3 dias. As coordenadas e os sítios de fosforilação se encontram disponíveis no Anexo 2. 


\section{Animais C3PT8}

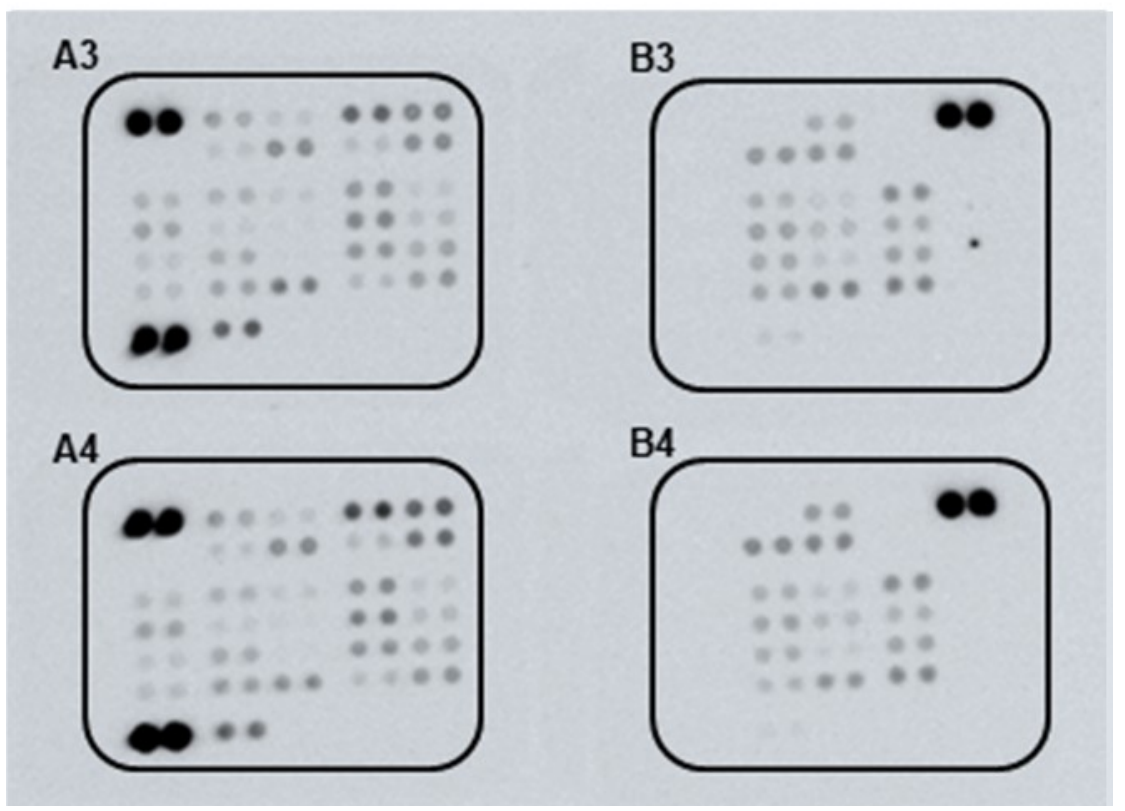

Figura 25. Membranas A-B de cada animal castrado por 3 dias e tratado com PT por 8 horas contendo as duplicatas de poços de cada uma das 43 fosfoquinases e os controles da reação. Os experimentos foram realizados em duplicata. A avaliação do aumento ou diminuição dos níveis de fosforilação foi feita comparando-se amostras dos animais castrados 3 dias e tratados com PT por 8 horas com amostras dos animais castrados por 3 dias. As coordenadas e os sítios de fosforilação se encontram disponíveis no Anexo 2.

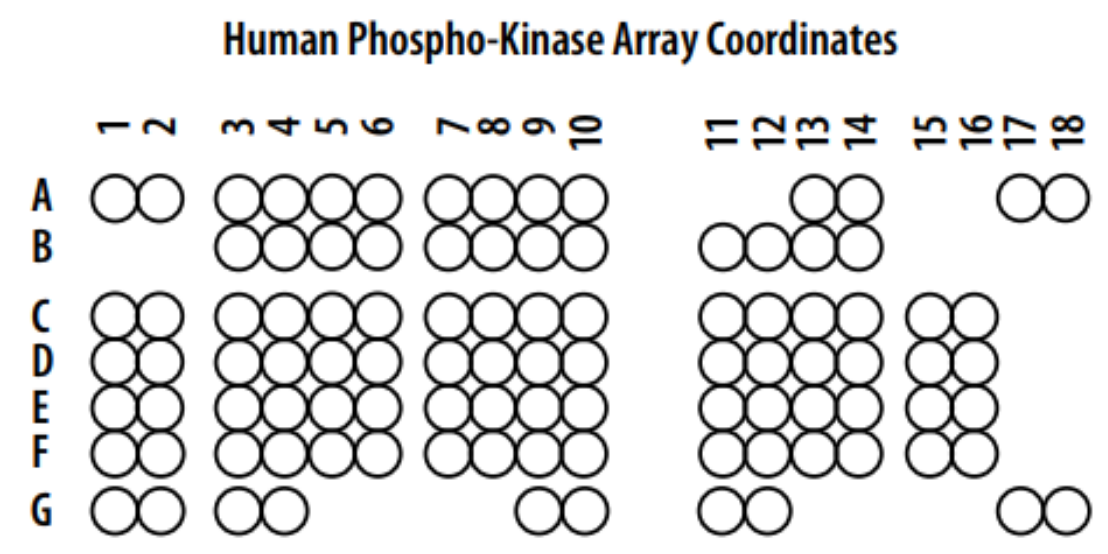

Figura 26. Representação esquemática da posição dos poços presentes nas membranas $A$ e $B$ do kit Proteoma Profile Human Phospho-kinase array (R\&D Systems, EUA). As coordenadas de cada duplicata de fosfoquinases, seus sítios de fosforilação e os poços controles do experimento estão disponíveis no Anexo 2. 


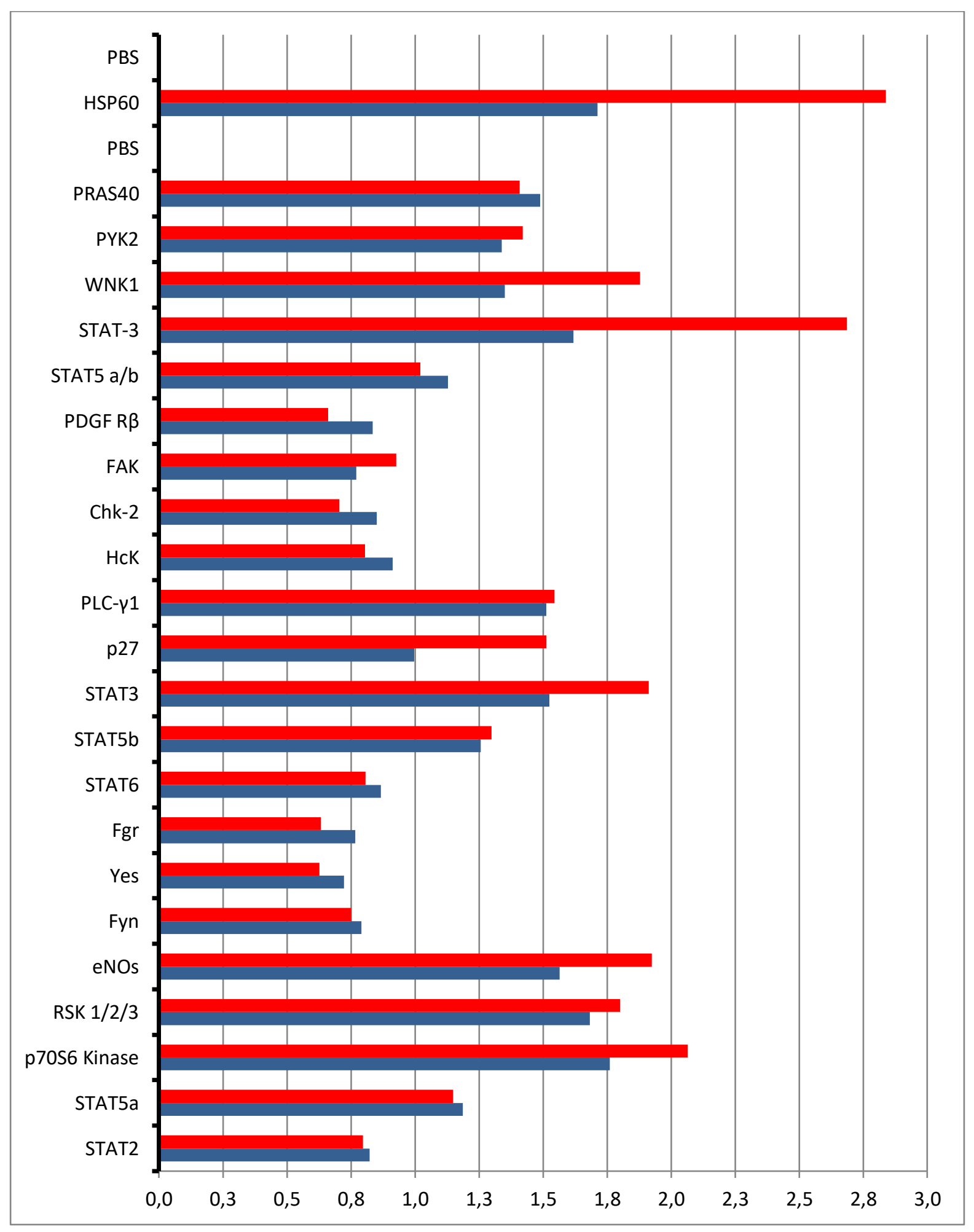




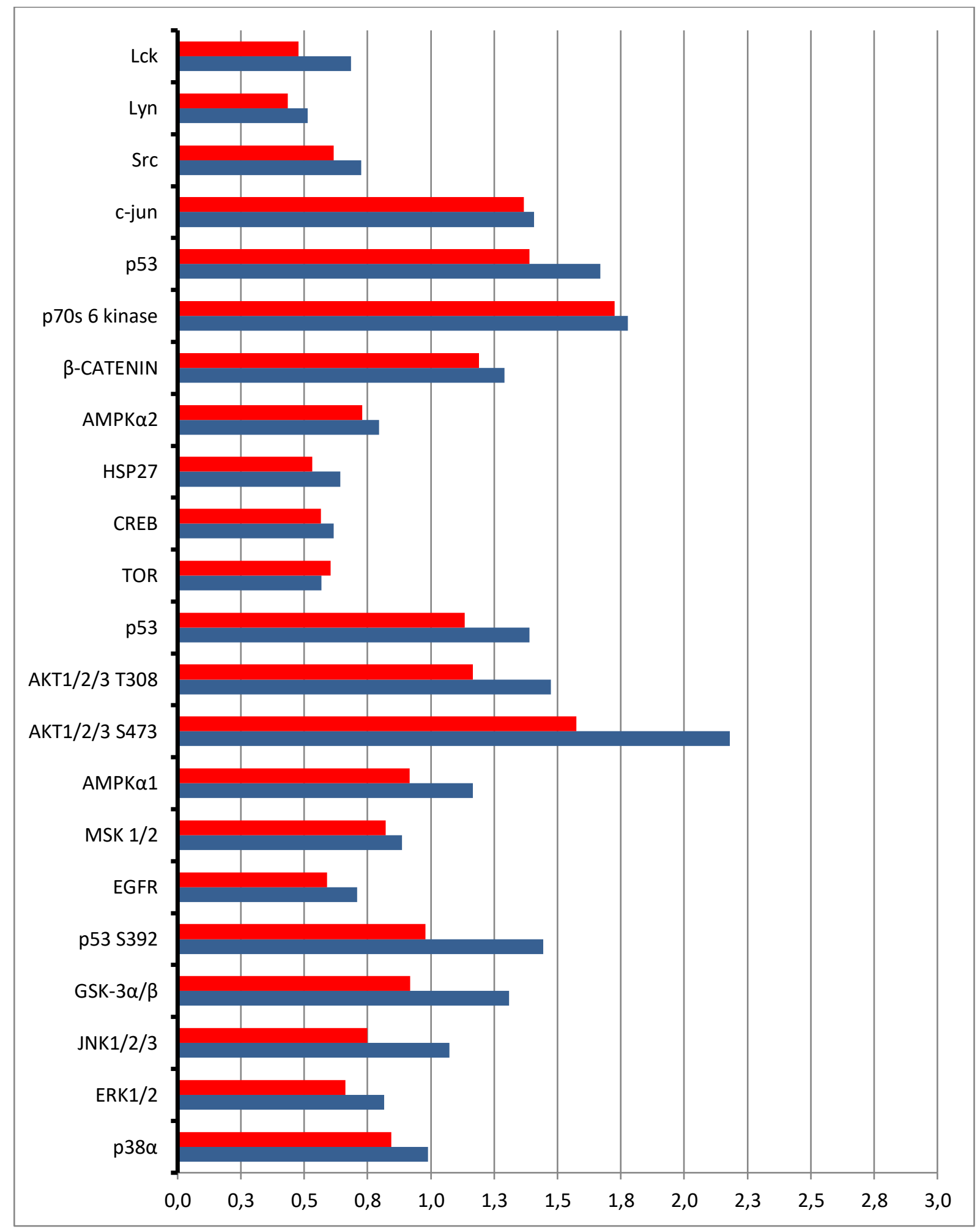

Figura 27. Gráficos do fold-change das quinases, valores de cada animal tratado por 8 horas com Propionato de Testosterona em relação a expressão média dos animais castrados por 3 dias, todos corrigido com o valor do background dos poços controle de PBS. Foram utilizadas 600 ug de proteínas totais por array A e B. Em vermelho e em azul, valores de expressão distintas de cada animal castrado e tratado com PT por 8 horas corrigidos pelo valor da média de background dos animais castrados 3 dias. 
Para validar os resultados obtidos com o array de fosfoquinases por Imunoblotting, foram selecionadas aquelas com regulação maior ou menor que $30 \%$ no tratamento de 8 horas com PT (valores menores que 0,7 ou maiores que 1,3 nos gráficos dispostos acima). As proteínas selecionadas foram escolhidas de acordo com a acessibilidade aos anticorpos.

Fosfoquinases testadas: Fosfo-AKT (Ser473), Fosfo-CREB (Ser133), Fosfo-eNOS (Ser1177), Fosfo-p70S6k (Thr389), Fosfo-STAT3.

Lamentavelmente, apesar de várias tentativas, não foi possível a validação desses dados pela técnica por Western blotting. 
DISCUSSÃO 


\section{DISCUSSÃO}

Os primeiros estudos de perfil de transcrição gênica (gene expression profiling) durante a atrofia muscular foram realizados pelos grupos do Dr. Alfred L. Goldberg, Harvard University, EUA e Dr. David J. Glass, Regeneron Pharmaceuticals, EUA (Bodine, Latres et al. 2001, Gomes, Lecker et al. 2001).

As comparações entre análises do perfil de transcrição em diferentes modelos de atrofia muscular possibilitaram a identificação de um conjunto de genes que são comumente expressos, induzidos ou reprimidos, revelando que a atrofia muscular é um processo ativo e controlado por vias de sinalização e programas transcricionais (Bonaldo and Sandri 2013). Acredita-se que essa resposta transcricional que ocorre durante a atrofia seja de alguma forma responsável pela perda de componentes musculares (Sacheck, Hyatt et al. 2007).

Nos últimos anos, vários grupos de pesquisa utilizaram várias técnicas de medidas de atividade de transcrição gênica para auxiliar na identificação de novos genes críticos de atrofia muscular, incluindo análise serial de expressão gênica, Gene-Tag differential display approach (Bodine, Latres et al. 2001), análise de microarray (Lecker, Jagoe et al. 2004, Sacheck, Hyatt et al. 2007) e técnica de hibridização subtrativa. Esses estudos quase sempre foram realizados em músculos atróficos e nenhum deles focou nos genes que se encontram diferencialmente expressos durante a reversão ou prevenção do processo de atrofia. Pode-se atribuir isto aos desafios de se intervir e obter sucesso na reversão dos processos de atrofia do músculo esquelético em modelos animais distintos, tais como diabetes, câncer, suspensão de membros posteriores, imobilização, distrofias miotônicas tipos 1 e 2 e desnervação. Para superar este problema e assim aumentar a possibilidade de 
identificar novos genes associados à atrofia, utilizamos um modelo bem estabelecido de castração e reposição androgênica, pouco explorado nos estudos de atrofia muscular.

A indução da atrofia muscular neste modelo, bem como o início das alterações de sinalização molecular, foi feita através da privação androgênica em ratos machos, sem lesão neuromuscular invasiva, como ocorre na desnervação, ou por distúrbio metabólico sistêmico como causado em modelos de caquexia ou jejum. O músculo Elevador do ânus de ratos machos adultos é particularmente sensível às variações androgênicas e atrofia significativamente em poucos dias após a privação de testosterona (obtida por castração) (Buresova, Gutmann et al. 1972). Pires-Oliveira (Pires-Oliveira, Maragno et al. 2010) demonstrou que a castração dos animais foi obtida de maneira eficiente após as análises dos pesos da glândula seminal e do músculo EA, que diminuem exponencialmente ao longo do tempo até 60 dias após o dia da castração.

A castração nos animais reduz a testosterona plasmática em $82 \%$ após um dia e continua a decair em níveis constantes até serem não detectáveis $(0,04 \mathrm{ng} / \mathrm{mL})$ após cinco dias (Mendes et al. 2004). A administração do propionato de testosterona foi modificada por Maróstica e colaboradores (Maróstica et al. 2005) para serem atingidas as concentrações plasmáticas de testosterona semelhantes ou ligeiramente superiores às dos animais do grupo controle. $\mathrm{O}$ éster PT é mais lipofílico, sendo absorvido lentamente após a dose única, feita em veículos a óleo, nos animais. A concentração plasmática máxima da testosterona ocorre após 24 horas e sua meia vida também é de 24 horas.

No modelo de atrofia de privação androgênica, Pires-Oliveira (Pires-Oliveira, Maragno et al. 2010) demonstrou que os níveis de RNAm de Atrogin-1 encontrava- 
se aumentada logo após 2 dias de castração. Essa característica também foi confirmada no nosso trabalho, após 3 dias de castração, no perfil de expressão de Atrogin-1 no grupo C3 na validação do microarray por RT-PCR. A indução expressiva de Atrogin-1 em um estágio inicial de perda muscular, antes mesmo da perda de peso muscular ser detectável, sugere fortemente seu importante papel no início da proteólise. Recentemente, Dalbo e colaboradores (Dalbo, Roberts et al. 2017) demostraram que a reposição crônica de testosterona ativa a via da miostatina, levando a um aumento da massa muscular em ratos idosos castrados.

Em consonância com os dados da literatura, alguns estudos já sugeriram que o processo de atrofia inicia-se principalmente a partir da ativação de um programa bioquímico comum que estimula a proteólise muscular (Mitch and Goldberg 1996, Hasselgren 1999, Lecker, Solomon et al. 1999, Gomes, Lecker et al. 2001) e a degradação de proteínas pelo proteassoma (Rusconi, Mancinelli et al. 2010, Timchenko 2013). Esses fatos juntos levam a conclusão, reforçada na última década, sobre a existência de um grupo de genes relacionados à atrofia, denominados atrogenes. Atualmente, a inibição dos atrogenes é considerada o único efeito terapêutico positivo de alguns tratamentos quando se considera a reversão da atrofia.

No presente trabalho, entre os genes identificados como possíveis novos atrogenes foram encontrados: CCK, HOPX, PGF, AMD1, ODC1, METTL7A, IGFBP3, CTGF, CXCL14 e RPS6Ka5. Nenhum dado na literatura, até o momento, demonstrou estes genes como pertencentes ao grupo dos atrogenes.

O comportamento destes genes foi similar ao controle positivo FBXO32, tanto no ensaio de microarray quanto na RT-PCR, ou seja, responderam (de maneira induzida ou reprimida) ao estímulo de castração, e também tiveram seus níveis de 
expressão revertidos pela administração do propionato de testosterona. A expressão do atrogene MuRF-1 não foi avaliada como marcador positivo de atrofia pois esta E3-ligase possui expressão tardia, tendo seu pico máximo de expressão em 7 dias de castração (Pires-Oliveira, Maragno et al. 2010) e também tardia também em outros modelos de atrofia (Bodine, Latres et al. 2001, Sacheck, Hyatt et al. 2007).

Sabe-se que os fatores de transcrição FOXO controlam a expressão das E3 ligases Atrogin-1 e MuRF-1 e a ativação do SUP, uma das principais vias envolvidas na degradação da proteína muscular e na atrofia muscular (Stitt, Drujan et al. 2004). Sandri e colaboradores em 2004 (Sandri, Sandri et al. 2004) demonstraram que em condições normais de crescimento de miotúbulos e fibras musculares adultas, a via IGF-1/PI3K/Akt suprime a expressão de Atrogin-1 por inativação dos fatores FOXO; a ativação de FOXO pode por si só causar atrofia dramática de miotúbulos e fibras musculares maduras e que inibir a função de FOXO reduz a indução de Atrogin-1 por glicocorticoides in vitro e por jejum in vivo. Assim, a ativação de FOXO3 é necessária e suficiente para a rápida atrofia. Dessa maneira, também optamos por validar o gene FOXO3 devido sua importância. Em um estudo publicado em 2007, Mammucari (Mammucari, Milan et al. 2007) e colaboradores, baseados principalmente em análises in vivo no músculo esquelético, identificaram uma via FOXO3-Bnip3 como um dos principais responsáveis na regulação transcricional de genes relacionados com autofagia. Dentre os 241 genes diferencialmente expressos com o tratamento de 24 h com PT (Lista completa disponível no Anexo 1), não foi encontrado genes como LC3 e Bnip. O que pode indicar que no curto tempo de privação de andrógeno bem como da reposição hormonal, a via de autofagia pode não estar significativamente ativa. 
Os genes que foram regulados negativamente quando comparados ao controle, e então positivamente regulados com o tratamento com PT, foram CCK, HOPX, PGF, AMD1 e ODC1.

A colecistocinina (CCK) é um hormônio envolvido no metabolismo de gorduras e proteínas, além da regulação da saciedade (Little, Horowitz et al. 2005). Foi recentemente demonstrado que esta proteína também está indiretamente envolvida na ativação do complexo de rapamicina em mamíferos (mTOR) e no processo de autofagia em alguns tecidos (Little, Horowitz et al. 2005). Além disso, a proteína CCK8, no músculo esquelético, pode ser hidrolisada por proteases ativadas por cálcio.

A proteína de único homeodomínio (HOPX) é codificada pelo gene HOPX. No músculo esquelético, ela foi demonstrada induzir indiretamente a diferenciação do músculo esquelético, através da interação com Enhancer of Polycomb 1 (Epc1), uma proteína de cromatina que pode modular a diferenciação do músculo esquelético (Kim, Kee et al. 2009). A diferenciação do músculo esquelético é prejudicada em mioblastos de camundongos nocautes para HOPX (Kee, Kim et al. 2007). Já o fator de crescimento placentário (PGF) é uma proteína codificada pelo gene da PGF e tem seu papel bem conhecido por regular a diferenciação e o desenvolvimento vascular (Maglione, Guerriero et al. 1991, Achen, Gad et al. 1997). PGF também foi demonstrado interagir com as vias de hipertrofia (Park, Chen et al. 1994).

Poliaminas têm sido mostradas envolvidas em numerosos processos celulares incluindo transcrição, proliferação celular e apoptose (Childs, Mehta et al. 2003). A putrescina, a espermidina e a espermina são consideradas fatores de crescimento essenciais em praticamente todas as células eucarióticas (Marton and Pegg 1995). Dentro da via se síntese das poliaminas, AMD1 e ODC1 possuem papel 
fundamental. A produção de putrescina a partir da ornitina é catalisada pela ornitina descarboxilase (ODC1), e a produção de S-adenosilmetionina descarboxilada, catalisada pela S-adenosilmetionina descarboxilase (AMD1). Reduções nos níveis dessas enzimas envolvidas na via das poliaminas estão intimamente associadas à indução de perda de massa muscular (Lee and MacLean 2011, Bongers, Fox et al. 2015). A associação entre o aumento das poliaminas e regeneração muscular foi demonstrada em outros envolvendo modelos experimentais como seccionamento de tendão e desnervação (Kaminska, Stern et al. 1982).

De modo contrário, os genes METTL7A, IGFBP3, CTGF, CXCL14 e RPS6Ka5 mostraram regulação induzida sob estímulo de castração e foram reprimidos com a reposição de PT, assim como o gene FBXO32 que codifica Atrogin-1.

O gene METTL7A codifica uma proteína do tipo metiltransferase (7A). Essa superfamília de proteínas transfere um grupo metil a resíduos de arginina e lisina, sendo muito comum em histonas na regulação da transcrição. Recentemente, a metilação da lisina também foi encontrada em algumas proteínas não histonas, sugerindo que a metilação reversível regula não apenas a transcrição, mas também uma ampla gama de processos celulares (Del Rizzo and Trievel 2011, Hamamoto, Saloura et al. 2015), incluindo o crescimento celular, embora o gene METTL21C tenha demonstrado ser um gene pleiotrópico, modulando a via de sinalização catabólica do NF-kB (Huang, Hsu et al. 2014). O gene METTL7A não demonstrou estar envolvido diretamente na regulação da massa muscular até o momento.

No entanto, a proteína 3 de ligação ao fator de crescimento semelhante a insulina codificada pelo gene IGFBP3 é uma das proteínas de ligação ao fator de crescimento de insulina (IGF) que transportam o IGF em circulação. Dentro dos tecidos, IGFBP3 pode se ligar ao IGF-1 e ao IGF-2 liberados por muitos tipos de 
células, dessa forma bloqueando seu acesso ao receptor do IGF (IGFR). IGFBP3 também interage com proteínas da superfície celular, afetando a sinalização celular de fora da célula (Stewart and Rotwein 1996). Assim, a diminuição da expressão de IGFBP3 significa diminuição do bloqueio do IGF-IGFR, o que resulta em hipertrofia (Musaro, McCullagh et al. 2001). Por outro lado, o aumento da expressão de IGFBP3 significa aumento do bloqueio do IGF-IGFR, resultando em hipoplasia/atrofia.

O gene CTGF é um fator de crescimento do tecido conjuntivo, uma proteína da matriz celular que pertence à família de proteínas $\mathrm{CCN}$. Ela atua regulando vários processos celulares, como proliferação, migração, adesão e diferenciação atingindo esses efeitos modulando a atividade de vários fatores de crescimento tais como o fator de crescimento transformador beta (TGF- $\beta$ ), proteínas morfogenéticas ósseas (BMPs) e fator de crescimento endotelial vascular (VEGF), entre muitos outros (Leask, Parapuram et al. 2009, Kubota and Takigawa 2015). A primeira evidência sobre o envolvimento de CTGF na biologia do músculo esquelético veio de estudos de microarray que identificaram a expressão do gene CTGF em células de rabdomiossarcoma (Astolfi, De Giovanni et al. 2001). Um estudo de 2005 mostrou que a desnervação do membro posterior e do músculo diafragma induz um aumento da expressão de CTGF e CCN1 no músculo esquelético (Magnusson, Svensson et al. 2005). A expressão desses dois genes também parece ser induzida no músculo esquelético humano após o exercício com alta carga mecânica (Kivela, Kyrolainen et al. 2007). No presente trabalho, o nível de expressão de CTGF se eleva durante o período de castração e diminui cerca de 2,06 vezes após o tratamento de 24 horas com PT corroborando com os dados apresentados na literatura. 
O gene CXCL14 codifica uma proteína com função de citocina quimiotática (motivo C-X-C) ligante 14 e faz parte de uma pequena família de citocinas derivadas de músculo. Em um estudo recente, CXCL14 foi demonstrada atuar como um inibidor endógeno da diferenciação de mioblastos e regeneração do músculo esquelético. A redução da sua expressão no tecido muscular após a lesão acelera o processo de regeneração em camundongos adultos jovens e resgata totalmente a capacidade de regeneração em camundongos em envelhecimento com resposta regenerativa prejudicada (Waldemer-Streyer, Reyes-Ordonez et al. 2017). No presente estudo, o gene CXCL14 mostrou aumento de seus níveis no grupo castrado e posterior diminuição de 3,71 vezes quando da reversão da atrofia com o tratamento, condizente com seu papel em músculo esquelético. O mecanismo de ação de CXCL14 na regeneração muscular parece único e ainda não foi encontrado em nenhum outro tecido.

O gene RPS6Ka5 codifica a proteína quinase S6 ribossomal alfa 5, uma serinatreonina quinase pertencente a família de quinases RSK. Também é conhecida como quinase 1 ativada por mitógeno e estresse (MSK1). Um trabalho publicado em 2006 (Kefaloyianni, Gaitanaki et al. 2006) mostrou que essa quinase é fortemente fosforilada pelo tratamento com $\mathrm{H}_{2} \mathrm{O}_{2}$ em mioblastos de $\mathrm{C} 2 \mathrm{C} 12$ e que esta fosforilação é mediada por ambas vias de ERK e p38-MAPK, e que estão implicadas na transativação de NF-kB por estímulo oxidativo, e que essa ação é provavelmente mediada por MSK1. Sua fosforilação por estresse oxidativo também foi relatada em outros tipos de células (Deak, Clifton et al. 1998, Aggeli, Gaitanaki et al. 2006), embora nesses casos a ativação de MSK1 tenha sido mediada apenas por p38MAPK e não por ERK. A ativação da quinase nos estudos acima foi correlacionada 
com a ativação subsequente dos fatores de transcrição (CREB e AP1, respectivamente).

RPS6ka5 também foi demonstrada estar regulada positivamente em tecidos de mioma e miométrio em mulheres portadoras de leiomioma (neoplasia benigna de músculo liso) (Lemeer, Gholami et al. 2015). Neste trabalho, foi observado o aumento dos níveis de RPS6Ka5 no grupo de animais castrados e quando tratados, sua expressão diminui-se em 4,79 vezes. Os dados apresentados condizem com os estudos publicados, já que níveis elevados dos fatores de transcrição NF-kB é frequentemente associada ao aumento da expressão de MuRF-1 e FBXO32 (Cai, Frantz et al. 2004, Wu, Kandarian et al. 2011).

No presente estudo, considerando as funções de síntese proteica e manutenção das vias de massa muscular, parece razoável e coerente supor que o grupo de genes mencionados até o momento possa ser validado dentro do grupo de atrogenes.

Destaca-se que a análise geral dos resultados apresentados neste estudo revelou uma possível nova realidade, considerando não só a resposta de um grupo de genes que respondeu ao estímulo atrófico e também à reversão/atenuação, mas também de um grupo que respondeu positivamente apenas quando o tratamento foi aplicado. Com estas características, os genes APLN, DUSP5, IGF-1, PI15, MKL1, KLHL38 e PIK3IP1 foram considerados parte deste grupo, sendo os dois últimos reprimidos, enquanto todos os outros apresentaram indução de expressão com o tratamento.

A proteína apelina, codificada pelo gene APLN, é um ligante endógeno para a proteína G, que é expressa na superfície de várias células (Huang da, Sherman et al. 2009). Esta proteína parece ter uma espécie de múltiplas funções fisiológicas, 
incluindo regulação da homeostase de fluidos corporais, ingestão de alimentos, proliferação celular, pressão sanguínea e angiogênese (O'Carroll, Lolait et al. 2013). Além disso, DUSP5, um gene que codifica a fosfatase 5 de dupla especificidade, interage com via da superfamília das proteínas quinases ativadas por mitógeno (MAPK), regulando a hipertrofia dos cardiomiócitos (Ferguson, Harrison et al. 2013). Embora a sua importância na hipertrofia do músculo cardíaco tenha sido sugerida (Ferguson, Harrison et al. 2013), seu papel no trofismo do músculo esquelético ainda não está bem definido. No presente estudo, o gene DUSP5 mostrou um aumento de 3,4 vezes nos níveis de expressão de C3pt24 em relação ao C3, indicando que sua interação específica com a via MAPK sob administração do PT seria benéfica na reversão de perda de massa muscular esquelética com a depleção androgênica.

Como mencionado, o IGF-1 é um fator de crescimento de insulina que pode ser bloqueado pelo IGFBP3 em vários tecidos. Como observado, os níveis de IGFBP3 é completamente reprimido no grupo C3pt24, então é razoável dizer que IGF-1 teve sua expressão induzida no grupo C3pt24 uma vez que ela é liberada de sua ligação com o receptor. Mais uma vez, os resultados se mostram conectados e demonstram a viabilidade do modelo.

Já o gene PI15, que codifica o inibidor de peptidase 15 foi a proteína que demonstrou os níveis mais altos de regulação positiva entre os genes identificados como genes associados à reversão da atrofia $(6,28 \mathrm{x})$. PI15 é o gene que codifica um inibidor de tripsina que foi previamente purificado do meio de cultura de células de glioblastoma humano (Yamakawa, Miyata et al. 1998) e não tem função específica identificada no músculo esquelético, até o momento. Por fim, a leucemia megacarioblástica 1 (MKL1) é um fator de transcrição com papéis importantes no sistema cardiovascular (Olson and Nordheim 2010). O aumento da importação 
nuclear dessa proteína, simultaneamente com a diminuição da sua exportação, causa o acúmulo de MKL1 no núcleo, onde ele ativa o fator de resposta sérica (SRF) para ativar os genes que regulam a mobilidade celular e a contratilidade, interagindo com o rearranjo de actina (Ho, Jaalouk et al. 2013). O aumento de 2,2 vezes na expressão do gene MKL1 apenas no grupo C3pt24 reforça a ideia de que os genes associados à reversão da atrofia seriam expressos sob o comando de reorganização da expressão dos atrogenes.

Não houve diferença na expressão do gene PIK3IP1 e KLHL38 entre os grupos C3 e Sham. No entanto, quando os ratos castrados foram submetidos ao tratamento com PT, estes genes foram significativamente reprimidos. He e colaboradores em 2008 (He, Zhu et al. 2008) identificaram a Proteína 1 de interação da Fosfatidilinositol 3 quinase (PIK3IP1) suprimindo a atividade da fosfatidilinositol 3 quinase (PI3K), enquanto que a atividade de PI3K aumenta quando os níveis de PIK3IP1 são reduzidos experimentalmente. De fato, a PI3K regula importantes processos celulares, como proliferação, crescimento, sobrevivência, motilidade e metabolismo. Ela se liga a Akt, (proteína quinase B) e outras moléculas de transdução de sinal para a membrana, uma associação que desencadeia respostas celulares típicas dependentes de PI3K, como a hipertrofia (Engelman, Luo et al. 2006). No entanto, as consequências do PIK3IP1 na sinalização PI3K in vivo permanecem desconhecidas (Zhu, He et al. 2007), o que o torna um possível alvo de futuras investigações sobre o campo muscular esquelético. O gene KLHL38 codifica a $38^{a}$ proteína identificada membro da família Kelch. No músculo esquelético, esse grupo de proteínas possui poucas funções identificadas até agora. Elas parecem ter algum tipo de interação com E3 ligases in vitro, porém mais investigações são necessárias. 
Em conjunto, os resultados apresentados abrem caminhos para a possibilidade da existência de um grupo de genes que são capazes de responder positivamente apenas sob estímulo relacionado ao tratamento de recuperação da atrofia, possibilitando uma nova via terapêutica no campo das síndromes relacionadas à atrofia. Além disso, também traz à luz um caminho em potencial no tratamento da atrofia ocasionada por doenças relacionadas com disfunção do proteassoma, como a distrofia miotônica do tipo 2 (Timchenko 2013).

Entre os genes com um papel em potencial para investigações na reversão da atrofia, APLN, o DUSP5, o IGF-1, o MKL1 e PI15 merecem uma investigação mais aprofundada. Em longo prazo, esses resultados podem ter relevância clínica em reverter ou atenuar a atrofia causada pela privação androgênica, um processo muito comum associado à castração farmacológica no tratamento do câncer de próstata. De fato, a castração remove andrógenos e muitas outras substâncias, como as produzidas pelas células de Sertoli, que incluem transferrina, fatores de crescimento transformadores $\alpha$ e $\beta$ (TGF $\alpha$, TGF $\beta$ ), fator de crescimento semelhante à insulina (IGF-1) e os hormônios inibina B e hormônio anti-Mülleriano (AMH) (lliadou, Tsametis et al. 2015). No entanto, a reposição de propionato de testosterona por 15 dias é capaz de reverter completamente a atrofia do músculo EA induzida pela castração (Godinho, Lima-Landman et al. 1987), indicando que a privação de testosterona é a principal causa de atrofia induzida por gonadectomia.

Os genes alvos também foram avaliados por RT-PCR com amostras do músculo gastrocnêmio no modelo murino de jejum. No total, 13 alvos foram testados, entre eles os atrogenes FBXO32, FOXO3, AMD1, CCK, HOPX, IGFBP3, ODC1 e PGF. E os genes associados à reversão APLN, DUSP5, IGF1, KLHL38 e PI15. 
Como esperado, o atrogene clássico FBXO32 teve seu aumento característico de expressão do RNAm no grupo jejum, bem como o fator de transcrição FOXO3, mostrando a eficiência da imposição do estímulo atrófico nos animais. Todos os genes pertencentes ao grupo dos atrogenes foram validados, reforçando a hipótese inicial de que esses resultados poderiam ser generalizados para outros músculos esqueléticos. IGFBP3 manteve sua indução de expressão no grupo jejum em relação ao controle, enquanto os demais tiveram sua expressão reprimida no grupo jejum. METTL7a, CTGF, RPS6Ka5 e CXCL14 ainda não foram testados nesse modelo pois os seus primers são específicos para ratos e suas sequências de bases não amplificavam em amostras de camundongos. Também foram testados cinco genes do grupo dos associados à reversão da atrofia: IGF-1, APLN, PI15, DUSP5 e KLHL38.

Observou-se que no modelo murino de atrofia os níveis de IGF-1 decaem no grupo jejum, de maneira contrária ao observado no grupo C3 do modelo de privação. Como IGF-1 e a insulina atuam através da via PI3K/Akt/mTOR, isso explica seus baixos níveis no grupo jejum, pois condições de mal nutrição estão associados com baixos níveis de RNAm de IGF-1 em músculos (Clemmons 2009) já que ele é responsável por controlar o crescimento e metabolismo. Este resultado também corrobora com o aumento observado de 3,14 vezes na expressão de IGFBP3 no grupo jejum. Como descrito previamente, IGFBP3 pode bloquear IGF-1 em vários tecidos. No entanto, outros diversos modelos de atrofia não demonstraram alterar os níveis de IGF-1, como descrito por Lecker (Lecker, Jagoe et al. 2004). Por isso, ainda nos leva a acreditar que IGF-1 possa compor o grupo dos genes associados à reversão da atrofia. 
O gene PI15 teve sua expressão reprimida em 2,35 vezes durante estímulo atrófico no grupo jejum. Na literatura, poucos estudos mostram suas funções, principalmente em músculo esquelético. Como o segundo modelo de atrofia escolhido foi o de privação alimentar, no qual os animais ficaram 48 horas em completa ausência de alimento, podemos atribuir essa diminuição como consequência do período prolongado de jejum. Para a digestão dos alimentos, o pâncreas produz a tripsina, uma serino-protease responsável por hidrolisar proteínas encontradas no sistema digestivo de muito vertebrados (Rawlings and Barrett 1994). Porém, também é necessária a liberação de inibidores de tripsina para prevenir a ação da enzima no próprio pâncreas. Entende-se que essa discreta diminuição da expressão de PI15 possa ser devido às características do modelo utilizado. Portanto, a investigação deste gene em modelos diferentes se faz necessário.

Assim como PI15, o gene APLN também respondeu à atrofia reprimindo sua expressão em 12,8 vezes no grupo jejum. Este hormônio peptídeo foi recentemente demonstrado evidências de estar associada à resistência à insulina. A apelina tem sua expressão induzida pela insulina (Boucher, Masri et al. 2005, Glassford, Yue et al. 2007) e inibe a secreção pancreática de insulina (Sorhede Winzell, Magnusson et al. 2005). Em estudos clínicos, os níveis de apelina estão aumentados em casos de obesidade (Boucher, Masri et al. 2005, Heinonen, Purhonen et al. 2005) e de resistência à insulina (Li, Yang et al. 2006); além disso, a redução do peso corporal resulta em um declínio simultâneo na expressão de apelina (Castan-Laurell, Vitkova et al. 2008). Diante das evidências, acredita-se que esse declínio na expressão de APLN no grupo jejum seja devido à característica do modelo utilizado e, assim como PI15, se faz necessário sua investigação em outros modelos distintos de atrofia. 
Entretanto, os genes DUSP5 e KLHL38 tiveram seus níveis de expressão durante a atrofia no grupo jejum de maneira semelhante ao modelo de privação androgênica, mantendo seus níveis iguais aos animais do grupo Controle/Sham.

Para a validação dos resultados obtidos por RT-PCR e pelo array de fosfoquinases com a técnica de Western blotting foram enfrentados vários percalços. O primeiro e principal problema que tomou grande parte do tempo foi a qualidade de extração das amostras de proteínas totais dos músculos EA dos animais de todos os grupos. Durante muito tempo foram feitas alterações nos passos de extração, nos tampões utilizados, nos parâmetros de corrida dos géis, até que recentemente chegou-se ao protocolo ideal de extração de proteínas musculares.

Logo após, com as membranas ideais, passou-se a ter problemas de detecção das proteínas alvos com os anticorpos incubados. Seja por falta de quantidade da proteína alvo contida na amostra do extrato total de proteínas ou pelo baixo poder de detecção/qualidade do anticorpo disponível. As membranas de amostras musculares coradas com Ponceau estão disponíveis no Apêndice C.

Para a realização do ensaio do array de quinases foi escolhido o grupo de 8 horas com PT. Isto se deve ao fato de que o número de genes diferencialmente expressos nesse período foi muito menor que no período de tratamento com $24 \mathrm{~h}$, no qual 241 genes responderam ao tratamento contra somente um único gene (Amd1) no tratamento de 8 horas. Dado que o processo de fosforilação de proteínas por quinases ocorre de maneira mais rápida do que a expressão gênica, optou-se por avaliar a resposta das fosfoquinases no grupo de animais com menor tempo de tratamento com PT desse estudo.

As proteínas quinases são enzimas que catalisam a fosforilação de proteínas por meio da transferência de um grupo fosfato de ATP ou GTP (em raros casos), para 
resíduos de tirosina (Tyr), treonina (Thr) e serina (Ser) (GRIFFIN 1992). Elas compõem a maior família de proteínas nos seres eucariontes e são componentes fundamentais da cascata de "comunicação" que ocorre no controle intracelular, na regulação e transdução de sinais. O mecanismo regulador inclui vários fenômenos que vão desde alterações químicas e estruturais das proteínas até ao controle transcricional. Adicionar e remover grupos fosfato são mecanismos fisiológicos importantes na regulação de proteínas intracelulares, as quais podem ser enzimas, receptores ou segundos mensageiros. Uma série de respostas celulares mediadas por receptores e vias metabólicas podem ser ativadas e desativadas pelas quinases ou fosfatases (enzimas que removem grupos fosfato) intracelulares. As quinases e as fosfatases, por sua vez, são reguladas por sinais bioquímicos extrínsecos, tais como hormônios e fatores de crescimento. As quinases celulares são divididas entre as que fosforilam proteínas em resíduos Tyr (tirosina-quinases) e as que fosforilam proteínas em resíduos Ser e Thr (serina/treonina-quinases) (DEVLIN 1992, GRIFFIN 1992).

Dentre os resultados observados, o aumento do perfil de fosforilação de AKT 1/2/3 é esperado com a administração de PT para reversão/atenuação da atrofia, já que essa quinase está intrinsicamente envolvida nas vias de hipertrofia. Porém, mTOR aparentemente teve seu perfil de fosforilação diminuído, já a quinase PRAS40 teve sua fosforilação aumentada. PRAS40 faz a regulação inibitória de mTORC1, e inibindo a ligação de 4E-BP1 de se ligar a raptor inibindo sua atividade de quinase (Wang, Harris et al. 2007). Porém, Akt pode diretamente fosforilar e inativar PRAS40.

Como mTOR fosforila downstream alvos como 4E-BP1 e p70S6k, novamente isto explica os altos níveis de fosforilação encontrados de p70S6k. 
A quinase HSP60 também teve um grande aumento do seu perfil de fosforilação. Essa proteína de choque térmico 60 (HSP60), ativada sob condições de estresse, é uma das principais chaperonas nas mitocôndrias que auxiliam no dobramento de proteínas, transporte e degradação para manter a homeostase proteica mitocondrial (Bukau and Horwich 1998, Fersht and Daggett 2002, White, Gianni et al. 2005, Lianos, Alexiou et al. 2015). Estudos mostram a correlação entre HSP60 e adaptações do músculo esquelético, em modelos de exercício em roedores, indicando que o aumento na sua expressão em camundongos facilita a importação de proteínas e de seu dobramento, induzindo a biogênese mitocondrial (Hood, Takahashi et al. 2000).

STAT3 é um fator de transcrição que faz o intermédio da sinalização de várias citocinas, sendo especialmente relevante para a sinalização de IL-6 e outras citocinas da mesma família, incluindo IL-10, IL-11 ou fator inibidor de leucemia (FIL) (Yu, Lee et al. 2014, Nakamura, Sene et al. 2015). Entre as suas mudanças póstranscricionais podemos citar a fosforilação de STAT3 na serina de posição 727, que aumenta sua atividade transcricional, e mTOR e várias MAPKs podem fosforilar este sítio (Yu, Lee et al. 2014, You, Wang et al. 2015). Quando é fosforilada na tirosina de posição 705 , induz sua dimerização e translocação para o núcleo onde regula transcrição de genes (Yu, Lee et al. 2014, You, Wang et al. 2015).

Vários estudos demostraram que STAT3 é um regulador importante da massa e metabolismo do músculo esquelético. Porém, a ativação de STAT3 tem sido diretamente relacionada à perda de massa muscular em vários modelos murinos de perda de massa muscular, como diabetes, doença renal crônica (DRC) e caquexia por câncer (Zhang, Pan et al. 2013, Gilabert, Calvo et al. 2014, Pretto, Ghilardi et al. 2015, Silva, Dong et al. 2015). Isto pode explicar os resultados obtidos com o array, 
onde os níveis de fosforilação de STAT3 ainda estão aumentados em 8 horas, provavelmente pelo curto tempo de tratamento.

Estudos funcionais adicionais ainda são necessários para investigar se as proteínas codificadas pelos atrogenes são essenciais para a recuperação em massa do músculo esquelético. Observar o perfil de resposta desses genes no grupo Sham na sua posterior inclusão em novas lâminas de microarray, também auxiliará na melhor detecção dos atrogenes possibilitando detectar seus níveis basais antes das intervenções de castração e tratamento. Também, que a validação das técnicas de RT-PCR e array de quinases apresentadas no trabalho sejam feitas demonstrando as proteínas-alvo a níveis detectáveis por Western blotting.

A busca por genes relacionados à atrofia é um nicho promissor, que pode render bons resultados em longo prazo no campo clínico. 
CONCLUSÃO 


\section{CONCLUSÃO}

No desenvolvimento do trabalho apresentado, durante as validações dos alvos por RT-PCR, nos deparamos com um grupo de genes cujo perfil de expressão nos levou a caracterizar um novo grupo de genes, aqui chamados de anti-atrogenes, devido ao seu perfil de expressão. Essa descoberta de importante relevância nos permite especular sobre um grupo de genes que teriam função, com expressão diferencialmente regulada, somente na reversão do quadro de atrofia, não exatamente um estado de hipertrofia.

A observação de padrão de resposta semelhante em modelo diferente de atrofia, por privação alimentar, demonstram como nossos dados estão em consonância entre eles e a literatura.

Nossos dados nos levaram a hipótese da existência de um novo grupo de genes, com perfil de expressão associados à reversão da atrofia. Isto nos abriu novas possibilidades para investigar outros genes pertencentes a esse grupo. 
REFERENCIAS 


\section{REFERÊNCIAS}

Achen, M. G., J. M. Gad, S. A. Stacker and A. F. Wilks (1997). "Placenta growth factor and vascular endothelial growth factor are co-expressed during early embryonic development." Growth Factors 15(1): 69-80.

Adams, V., H. Jiang, J. Yu, S. Mobius-Winkler, E. Fiehn, A. Linke, C. Weigl, G. Schuler and R. Hambrecht (1999). "Apoptosis in skeletal myocytes of patients with chronic heart failure is associated with exercise intolerance." J Am Coll Cardiol 33(4): 959-965.

Aggeli, I. K., C. Gaitanaki and I. Beis (2006). "Involvement of JNKs and p38-MAPK/MSK1 pathways in H2O2-induced upregulation of heme oxygenase-1 mRNA in H9c2 cells." Cell Signal 18(10): 1801-1812.

Ahima, R. S., D. Prabakaran, C. Mantzoros, D. Qu, B. Lowell, E. Maratos-Flier and J. S. Flier (1996). "Role of leptin in the neuroendocrine response to fasting." Nature 382(6588): 250252.

Allbrook, D. (1981). Skeletal muscle regeneration, Muscle Nerve 4

Allen, D. L., A. S. Cleary, S. F. Lindsay, A. S. Loh and J. M. Reed (2010). "Myostatin expression is increased by food deprivation in a muscle-specific manner and contributes to muscle atrophy during prolonged food deprivation in mice." J Appl Physiol (1985) 109(3): 692-701.

Allen, D. L., J. K. Linderman, R. R. Roy, A. J. Bigbee, R. E. Grindeland, V. Mukku and V. R. Edgerton (1997). "Apoptosis: a mechanism contributing to remodeling of skeletal muscle in response to hindlimb unweighting." Am J Physiol 273(2 Pt 1): C579-587.

Astolfi, A., C. De Giovanni, L. Landuzzi, G. Nicoletti, C. Ricci, S. Croci, L. Scopece, P. Nanni and P. L. Lollini (2001). "Identification of new genes related to the myogenic differentiation arrest of human rhabdomyosarcoma cells." Gene 274(1-2): 139-149.

Aucello, M., G. Dobrowolny and A. Musaro (2009). "Localized accumulation of oxidative stress causes muscle atrophy through activation of an autophagic pathway." Autophagy 5(4): 527-529.

Bar-Shai, M., E. Carmeli, P. Ljubuncic and A. Z. Reznick (2008). "Exercise and immobilization in aging animals: the involvement of oxidative stress and NF-kappaB activation." Free Radic Biol Med 44(2): 202-214.

Bentzinger, C. F., Y. X. Wang, N. A. Dumont and M. A. Rudnicki (2013). "Cellular dynamics in the muscle satellite cell niche." EMBO Rep 14(12): 1062-1072.

Bhasin, S., T. W. Storer, N. Berman, C. Callegari, B. Clevenger, J. Phillips, T. J. Bunnell, R. Tricker, A. Shirazi and R. Casaburi (1996). "The effects of supraphysiologic doses of testosterone on muscle size and strength in normal men." N Engl J Med 335(1): 1-7.

Bodine, S. C., E. Latres, S. Baumhueter, V. K. Lai, L. Nunez, B. A. Clarke, W. T. Poueymirou, F. J. Panaro, E. Na, K. Dharmarajan, Z. Q. Pan, D. M. Valenzuela, T. M. DeChiara, T. N. Stitt, G. D. Yancopoulos and D. J. Glass (2001). "Identification of ubiquitin ligases required for skeletal muscle atrophy." Science 294(5547): 1704-1708.

Bodine, S. C., T. N. Stitt, M. Gonzalez, W. O. Kline, G. L. Stover, R. Bauerlein, E. Zlotchenko, A. Scrimgeour, J. C. Lawrence, D. J. Glass and G. D. Yancopoulos (2001). "Akt/mTOR pathway is a crucial regulator of skeletal muscle hypertrophy and can prevent muscle atrophy in vivo." Nat Cell Biol 3(11): 1014-1019.

Bonaldo, P. and M. Sandri (2013). "Cellular and molecular mechanisms of muscle atrophy." Dis Model Mech 6(1): 25-39.

Bongers, K. S., D. K. Fox, S. D. Kunkel, L. V. Stebounova, D. J. Murry, M. A. Pufall, S. M. Ebert, M. C. Dyle, S. A. Bullard, J. M. Dierdorff and C. M. Adams (2015). "Spermine oxidase maintains basal skeletal muscle gene expression and fiber size and is strongly repressed by conditions that cause skeletal muscle atrophy." Am J Physiol Endocrinol Metab 308(2): E144-158.

Borisov, A. B. and B. M. Carlson (2000). "Cell death in denervated skeletal muscle is distinct from classical apoptosis." Anat Rec 258(3): 305-318. 
Boucher, J., B. Masri, D. Daviaud, S. Gesta, C. Guigne, A. Mazzucotelli, I. Castan-Laurell, I. Tack, B. Knibiehler, C. Carpene, Y. Audigier, J. S. Saulnier-Blache and P. Valet (2005). "Apelin, a newly identified adipokine up-regulated by insulin and obesity." Endocrinology 146(4): 1764-1771.

Bradford, M. M. (1976). "A rapid and sensitive method for the quantitation of microgram quantities of protein utilizing the principle of protein-dye binding." Anal Biochem 72: 248-254.

Braga, M., S. Bhasin, R. Jasuja, S. Pervin and R. Singh (2012). "Testosterone inhibits transforming growth factor-beta signaling during myogenic differentiation and proliferation of mouse satellite cells: potential role of follistatin in mediating testosterone action." Mol Cell Endocrinol 350(1): 39-52.

Bukau, B. and A. L. Horwich (1998). "The Hsp70 and Hsp60 chaperone machines." Cell 92(3): 351-366.

Buresova, M., E. Gutmann and V. Hanzlikova (1972). "Differential effects of castration and denervation on protein synthesis in the levator ani muscle of the rat." J Endocrinol 54(1): 314.

Cai, D., J. D. Frantz, N. E. Tawa, Jr., P. A. Melendez, B. C. Oh, H. G. Lidov, P. O. Hasselgren, W. R. Frontera, J. Lee, D. J. Glass and S. E. Shoelson (2004). "IKKbeta/NFkappaB activation causes severe muscle wasting in mice." Cell 119(2): 285-298.

Castan-Laurell, I., M. Vitkova, D. Daviaud, C. Dray, M. Kovacikova, Z. Kovacova, J. Hejnova, V. Stich and P. Valet (2008). "Effect of hypocaloric diet-induced weight loss in obese women on plasma apelin and adipose tissue expression of apelin and APJ." Eur J Endocrinol 158(6): 905-910.

Champy, M. F., M. Selloum, L. Piard, V. Zeitler, C. Caradec, P. Chambon and J. Auwerx (2004). "Mouse functional genomics requires standardization of mouse handling and housing conditions." Mamm Genome 15(10): 768-783.

Cheek, D. B. (1985). "The control of cell mass and replication. The DNA unit--a personal 20year study." Early Hum Dev 12(3): 211-239.

Chen, C. D., D. S. Welsbie, C. Tran, S. H. Baek, R. Chen, R. Vessella, M. G. Rosenfeld and C. L. Sawyers (2004). "Molecular determinants of resistance to antiandrogen therapy." Nat Med 10(1): 33-39.

Childs, A. C., D. J. Mehta and E. W. Gerner (2003). "Polyamine-dependent gene expression." Cell Mol Life Sci 60(7): 1394-1406.

Clark, A. S. and L. P. Henderson (2003). "Behavioral and physiological responses to anabolic-androgenic steroids." Neurosci Biobehav Rev 27(5): 413-436.

Clemmons, D. R. (2009). "Role of IGF-I in skeletal muscle mass maintenance." Trends Endocrinol Metab 20(7): 349-356.

Cleveland, W. S. D., Susan J. (1988). "Locally-Weighted Regression: An Approach to Regression Analysis by Local Fitting." Journal of the American Statistical Association. 83 (403): 596-610.

Collins, C. A., P. S. Zammit, A. P. Ruiz, J. E. Morgan and T. A. Partridge (2007). "A population of myogenic stem cells that survives skeletal muscle aging." Stem Cells 25(4): 885-894.

Cruz-Jentoft, A. J., J. P. Baeyens, J. M. Bauer, Y. Boirie, T. Cederholm, F. Landi, F. C. Martin, J. P. Michel, Y. Rolland, S. M. Schneider, E. Topinkova, M. Vandewoude, M. Zamboni and P. European Working Group on Sarcopenia in Older (2010). "Sarcopenia: European consensus on definition and diagnosis: Report of the European Working Group on Sarcopenia in Older People." Age Ageing 39(4): 412-423.

Dalbo, V. J., M. D. Roberts, C. B. Mobley, C. Ballmann, W. C. Kephart, C. D. Fox, V. A. Santucci, C. F. Conover, L. A. Beggs, A. Balaez, F. J. Hoerr, J. F. Yarrow, S. E. Borst and D. T. Beck (2017). "Testosterone and trenbolone enanthate increase mature myostatin protein expression despite increasing skeletal muscle hypertrophy and satellite cell number in rodent muscle." Andrologia 49(3).

Daniel, P. M. (1977). "The metabolic homoeostatic role of muscle and its function as a store of protein." Lancet 2(8035): 446-448. 
Deak, M., A. D. Clifton, L. M. Lucocq and D. R. Alessi (1998). "Mitogen- and stress-activated protein kinase-1 (MSK1) is directly activated by MAPK and SAPK2/p38, and may mediate activation of CREB." EMBO J 17(15): 4426-4441.

Del Rizzo, P. A. and R. C. Trievel (2011). "Substrate and product specificities of SET domain methyltransferases." Epigenetics 6(9): 1059-1067.

Derynck, R., Y. Zhang and X. H. Feng (1998). "Smads: transcriptional activators of TGF-beta responses." Cell 95(6): 737-740.

DEVLIN, T. M. (1992). Textbook of biochemistry with clinical correlations, Wiley-Liss.

Dirks-Naylor, A. J. and S. Lennon-Edwards (2011). "Cellular and molecular mechanisms of apoptosis in age-related muscle atrophy." Curr Aging Sci 4(3): 269-278.

Dobrowolny, G., M. Aucello, E. Rizzuto, S. Beccafico, C. Mammucari, S. Boncompagni, S. Belia, F. Wannenes, C. Nicoletti, Z. Del Prete, N. Rosenthal, M. Molinaro, F. Protasi, G. Fano, M. Sandri and A. Musaro (2008). "Skeletal muscle is a primary target of SOD1G93Amediated toxicity." Cell Metab 8(5): 425-436.

Dupont-Versteegden, E. E., R. J. Murphy, J. D. Houle, C. M. Gurley and C. A. Peterson (1999). "Activated satellite cells fail to restore myonuclear number in spinal cord transected and exercised rats." Am J Physiol 277(3): C589-597.

Earnshaw, W. C., L. M. Martins and S. H. Kaufmann (1999). "Mammalian caspases: structure, activation, substrates, and functions during apoptosis." Annu Rev Biochem 68: 383-424.

Engelman, J. A., J. Luo and L. C. Cantley (2006). "The evolution of phosphatidylinositol 3kinases as regulators of growth and metabolism." Nat Rev Genet 7(8): 606-619.

Fanzani, A., V. M. Conraads, F. Penna and W. Martinet (2012). "Molecular and cellular mechanisms of skeletal muscle atrophy: an update." J Cachexia Sarcopenia Muscle 3(3): 163-179.

Ferguson, B. S., B. C. Harrison, M. Y. Jeong, B. G. Reid, M. F. Wempe, F. F. Wagner, E. B. Holson and T. A. McKinsey (2013). "Signal-dependent repression of DUSP5 by class I HDACs controls nuclear ERK activity and cardiomyocyte hypertrophy." Proc Natl Acad Sci U S A 110(24): 9806-9811.

Ferrando, A. A., M. Sheffield-Moore, C. W. Yeckel, C. Gilkison, J. Jiang, A. Achacosa, S. A. Lieberman, K. Tipton, R. R. Wolfe and R. J. Urban (2002). "Testosterone administration to older men improves muscle function: molecular and physiological mechanisms." Am J Physiol Endocrinol Metab 282(3): E601-607.

Fersht, A. R. and V. Daggett (2002). "Protein folding and unfolding at atomic resolution." Cell 108(4): 573-582.

Gavrilova, O., L. R. Leon, B. Marcus-Samuels, M. M. Mason, A. L. Castle, S. Refetoff, C. Vinson and M. L. Reitman (1999). "Torpor in mice is induced by both leptin-dependent and independent mechanisms." Proc Natl Acad Sci U S A 96(25): 14623-14628.

Giannoulis, M. G., N. Jackson, F. Shojaee-Moradie, K. S. Nair, P. H. Sonksen, F. C. Martin and A. M. Umpleby (2008). "The effects of growth hormone and/or testosterone on whole body protein kinetics and skeletal muscle gene expression in healthy elderly men: a randomized controlled trial." J Clin Endocrinol Metab 93(8): 3066-3074.

Gilabert, M., E. Calvo, A. Airoldi, T. Hamidi, V. Moutardier, O. Turrini and J. lovanna (2014). "Pancreatic cancer-induced cachexia is Jak2-dependent in mice." $\mathrm{J}$ Cell Physiol 229(10): 1437-1443.

Glass, D. J. (2005). "Skeletal muscle hypertrophy and atrophy signaling pathways." Int J Biochem Cell Biol 37(10): 1974-1984.

Glass, D. J. (2010). "PI3 kinase regulation of skeletal muscle hypertrophy and atrophy." Curr Top Microbiol Immunol 346: 267-278.

Glassford, A. J., P. Yue, A. Y. Sheikh, H. J. Chun, S. Zarafshar, D. A. Chan, G. M. Reaven, T. Quertermous and P. S. Tsao (2007). "HIF-1 regulates hypoxia- and insulin-induced expression of apelin in adipocytes." Am J Physiol Endocrinol Metab 293(6): E1590-1596.

Gobinet, J., N. Poujol and C. Sultan (2002). "Molecular action of androgens." Mol Cell Endocrinol 198(1-2): 15-24. 
Godinho, R. O., M. T. Lima-Landman, C. Souccar and A. J. Lapa (1987). "Trophic control of cholinesterase activity in a testosterone-dependent muscle of the rat. II. Effects of testosterone administration." Exp Neurol 98(1): 93-102.

Gomes, M. D., S. H. Lecker, R. T. Jagoe, A. Navon and A. L. Goldberg (2001). "Atrogin-1, a muscle-specific F-box protein highly expressed during muscle atrophy." Proc Natl Acad Sci U S A 98(25): 14440-14445.

GRIFFIN, J. E. O. S. R. (1992). Texbook of endocrine physiology. , Oxford University Press, New York.

Hallows, W. C., W. Yu, B. C. Smith, M. K. Devries, J. J. Ellinger, S. Someya, M. R. Shortreed, T. Prolla, J. L. Markley, L. M. Smith, S. Zhao, K. L. Guan and J. M. Denu (2011). "Sirt3 promotes the urea cycle and fatty acid oxidation during dietary restriction." Mol Cell 41(2): 139-149.

Hamamoto, R., V. Saloura and Y. Nakamura (2015). "Critical roles of non-histone protein lysine methylation in human tumorigenesis." Nat Rev Cancer 15(2): 110-124.

Hasselgren, P. O. (1999). "Glucocorticoids and muscle catabolism." Curr Opin Clin Nutr Metab Care 2(3): 201-205.

He, X., Z. Zhu, C. Johnson, J. Stoops, A. E. Eaker, W. Bowen and M. C. DeFrances (2008). "PIK3IP1, a negative regulator of PI3K, suppresses the development of hepatocellular carcinoma." Cancer Res 68(14): 5591-5598.

Heinonen, M. V., A. K. Purhonen, P. Miettinen, M. Paakkonen, E. Pirinen, E. Alhava, K. Akerman and K. H. Herzig (2005). "Apelin, orexin-A and leptin plasma levels in morbid obesity and effect of gastric banding." Regul Pept 130(1-2): 7-13.

Ho, C. Y., D. E. Jaalouk, M. K. Vartiainen and J. Lammerding (2013). "Lamin A/C and emerin regulate MKL1-SRF activity by modulating actin dynamics." Nature 497(7450): 507-511.

Hood, D. A., M. Takahashi, M. K. Connor and D. Freyssenet (2000). "Assembly of the cellular powerhouse: current issues in muscle mitochondrial biogenesis." Exerc Sport Sci Rev 28(2): 68-73.

Huang da, W., B. T. Sherman and R. A. Lempicki (2009). "Systematic and integrative analysis of large gene lists using DAVID bioinformatics resources." Nat Protoc 4(1): 44-57.

Huang, J., Y. H. Hsu, C. Mo, E. Abreu, D. P. Kiel, L. F. Bonewald, M. Brotto and D. Karasik (2014). "METTL21C is a potential pleiotropic gene for osteoporosis and sarcopenia acting through the modulation of the NF-kappaB signaling pathway." J Bone Miner Res 29(7): 15311540.

Hughes, I. A., H. N. Lim, H. Martin, N. P. Mongan, L. Dovey, S. F. Ahmed and J. R. Hawkins (2001). "Developmental aspects of androgen action." Mol Cell Endocrinol 185(1-2): 33-41.

Hunter, R. B., E. Stevenson, A. Koncarevic, H. Mitchell-Felton, D. A. Essig and S. C. Kandarian (2002). "Activation of an alternative NF-kappaB pathway in skeletal muscle during disuse atrophy." FASEB J 16(6): 529-538.

lliadou, P. K., C. Tsametis, A. Kaprara, I. Papadimas and D. G. Goulis (2015). "The Sertoli cell: Novel clinical potentiality." Hormones (Athens) 14(4): 504-514.

Izumiya, Y., T. Hopkins, C. Morris, K. Sato, L. Zeng, J. Viereck, J. A. Hamilton, N. Ouchi, N. K. LeBrasseur and K. Walsh (2008). "Fast/Glycolytic muscle fiber growth reduces fat mass and improves metabolic parameters in obese mice." Cell Metab 7(2): 159-172.

Jagoe, R. T., S. H. Lecker, M. Gomes and A. L. Goldberg (2002). "Patterns of gene expression in atrophying skeletal muscles: response to food deprivation." FASEB J 16(13): 1697-1712.

Judge, A. R., A. Koncarevic, R. B. Hunter, H. C. Liou, R. W. Jackman and S. C. Kandarian (2007). "Role for IkappaBalpha, but not c-Rel, in skeletal muscle atrophy." Am J Physiol Cell Physiol 292(1): C372-382.

Kaminska, A. M., L. Z. Stern and D. H. Russell (1982). "Polyamine metabolism in muscle: differential response to tenotomy and denervation in the soleus and gastrocnemius muscle of adult rats." Exp Neurol 78(2): 331-339. 
Kang, Z., O. A. Janne and J. J. Palvimo (2004). "Coregulator recruitment and histone modifications in transcriptional regulation by the androgen receptor." Mol Endocrinol 18(11): 2633-2648.

Kee, H. J., J. R. Kim, K. I. Nam, H. Y. Park, S. Shin, J. C. Kim, Y. Shimono, M. Takahashi, M. H. Jeong, N. Kim, K. K. Kim and H. Kook (2007). "Enhancer of polycomb1, a novel homeodomain only protein-binding partner, induces skeletal muscle differentiation." $\underline{\mathrm{J} \text { Biol }}$ Chem 282(10): 7700-7709.

Kefaloyianni, E., C. Gaitanaki and I. Beis (2006). "ERK1/2 and p38-MAPK signalling pathways, through MSK1, are involved in NF-kappaB transactivation during oxidative stress in skeletal myoblasts." Cell Signal 18(12): 2238-2251.

Kim, J. R., H. J. Kee, J. Y. Kim, H. Joung, K. I. Nam, G. H. Eom, N. Choe, H. S. Kim, J. C. Kim, H. Kook, S. B. Seo and H. Kook (2009). "Enhancer of polycomb1 acts on serum response factor to regulate skeletal muscle differentiation." J Biol Chem 284(24): 1630816316.

Kivela, R., H. Kyrolainen, H. Selanne, P. V. Komi, H. Kainulainen and V. Vihko (2007). "A single bout of exercise with high mechanical loading induces the expression of Cyr61/CCN1 and CTGF/CCN2 in human skeletal muscle." J Appl Physiol (1985) 103(4): 1395-1401.

Koryakina, Y., H. Q. Ta and D. Gioeli (2014). "Androgen receptor phosphorylation: biological context and functional consequences." Endocr Relat Cancer 21(4): T131-145.

Kubota, S. and M. Takigawa (2015). "Cellular and molecular actions of CCN2/CTGF and its role under physiological and pathological conditions." Clin Sci (Lond) 128(3): 181-196.

Lang, T., T. Streeper, P. Cawthon, K. Baldwin, D. R. Taaffe and T. B. Harris (2010). "Sarcopenia: etiology, clinical consequences, intervention, and assessment." Osteoporos Int 21(4): 543-559.

Leask, A., S. K. Parapuram, X. Shi-Wen and D. J. Abraham (2009). "Connective tissue growth factor (CTGF, CCN2) gene regulation: a potent clinical bio-marker of fibroproliferative disease?" J Cell Commun Signal 3(2): 89-94.

Lecker, S. H., A. L. Goldberg and W. E. Mitch (2006). "Protein degradation by the ubiquitinproteasome pathway in normal and disease states." J Am Soc Nephrol 17(7): 1807-1819.

Lecker, S. H., R. T. Jagoe, A. Gilbert, M. Gomes, V. Baracos, J. Bailey, S. R. Price, W. E. Mitch and A. L. Goldberg (2004). "Multiple types of skeletal muscle atrophy involve a common program of changes in gene expression." FASEB J 18(1): 39-51.

Lecker, S. H., V. Solomon, W. E. Mitch and A. L. Goldberg (1999). "Muscle protein breakdown and the critical role of the ubiquitin-proteasome pathway in normal and disease states." J Nutr 129(1S Suppl): 227S-237S.

Lee, D. and A. Goldberg (2011). "Atrogin1/MAFbx: what atrophy, hypertrophy, and cardiac failure have in common." Circ Res 109(2): 123-126.

Lee, N. K. and H. E. MacLean (2011). "Polyamines, androgens, and skeletal muscle hypertrophy." J Cell Physiol 226(6): 1453-1460.

Lee, R. C., Z. Wang, M. Heo, R. Ross, I. Janssen and S. B. Heymsfield (2000). "Total-body skeletal muscle mass: development and cross-validation of anthropometric prediction models." Am J Clin Nutr 72(3): 796-803.

Lee, S. J. and A. C. McPherron (2001). "Regulation of myostatin activity and muscle growth." Proc Natl Acad Sci U S A 98(16): 9306-9311.

Lemeer, S., A. M. Gholami, Z. Wu and B. Kuster (2015). "Quantitative proteome profiling of human myoma and myometrium tissue reveals kinase expression signatures with potential for therapeutic intervention." Proteomics 15(2-3): 356-364.

Li, L., G. Yang, Q. Li, Y. Tang, M. Yang, H. Yang and K. Li (2006). "Changes and relations of circulating visfatin, apelin, and resistin levels in normal, impaired glucose tolerance, and type 2 diabetic subjects." Exp Clin Endocrinol Diabetes 114(10): 544-548.

Lianos, G. D., G. A. Alexiou, A. Mangano, A. Mangano, S. Rausei, L. Boni, G. Dionigi and D. H. Roukos (2015). "The role of heat shock proteins in cancer." Cancer Lett 360(2): 114-118.

Little, T. J., M. Horowitz and C. Feinle-Bisset (2005). "Role of cholecystokinin in appetite control and body weight regulation." Obes Rev 6(4): 297-306. 
Livak, K. J. and T. D. Schmittgen (2001). "Analysis of relative gene expression data using real-time quantitative PCR and the 2(-Delta Delta C(T)) Method." Methods 25(4): 402-408.

Lu, N. Z., S. E. Wardell, K. L. Burnstein, D. Defranco, P. J. Fuller, V. Giguere, R. B. Hochberg, L. McKay, J. M. Renoir, N. L. Weigel, E. M. Wilson, D. P. McDonnell and J. A. Cidlowski (2006). "International Union of Pharmacology. LXV. The pharmacology and classification of the nuclear receptor superfamily: glucocorticoid, mineralocorticoid, progesterone, and androgen receptors." Pharmacol Rev 58(4): 782-797.

Maglione, D., V. Guerriero, G. Viglietto, P. Delli-Bovi and M. G. Persico (1991). "Isolation of a human placenta cDNA coding for a protein related to the vascular permeability factor." Proc Natl Acad Sci U S A 88(20): 9267-9271.

Magnusson, C., A. Svensson, U. Christerson and S. Tagerud (2005). "Denervation-induced alterations in gene expression in mouse skeletal muscle." Eur J Neurosci 21(2): 577-580.

Mammucari, C., G. Milan, V. Romanello, E. Masiero, R. Rudolf, P. Del Piccolo, S. J. Burden, R. Di Lisi, C. Sandri, J. Zhao, A. L. Goldberg, S. Schiaffino and M. Sandri (2007). "FoxO3 controls autophagy in skeletal muscle in vivo." Cell Metab 6(6): 458-471.

Martin-Magniette, M. L., J. Aubert, E. Cabannes and J. J. Daudin (2005). "Evaluation of the gene-specific dye bias in cDNA microarray experiments." Bioinformatics 21(9): 1995-2000.

Marton, L. J. and A. E. Pegg (1995). "Polyamines as targets for therapeutic intervention." Annu Rev Pharmacol Toxicol 35: 55-91.

Mayer, M. and F. Rosen (1977). "Interaction of glucocorticoids and androgens with skeletal muscle." Metabolism 26(8): 937-962.

McCroskery, S., M. Thomas, L. Maxwell, M. Sharma and R. Kambadur (2003). "Myostatin negatively regulates satellite cell activation and self-renewal." J Cell Biol 162(6): 1135-1147.

Mendler, L., Z. Baka, A. Kovacs-Simon and L. Dux (2007). "Androgens negatively regulate myostatin expression in an androgen-dependent skeletal muscle." Biochem Biophys Res Commun 361(1): 237-242.

Mitch, W. E. and A. L. Goldberg (1996). "Mechanisms of muscle wasting. The role of the ubiquitin-proteasome pathway." N Engl J Med 335(25): 1897-1905.

Mizushima, N., A. Yamamoto, M. Matsui, T. Yoshimori and Y. Ohsumi (2004). "In vivo analysis of autophagy in response to nutrient starvation using transgenic mice expressing a fluorescent autophagosome marker." Mol Biol Cell 15(3): 1101-1111.

Mlekusch, W., B. Paletta, W. Truppe, E. Paschke and R. Grimus (1981). "Plasma concentrations of glucose, corticosterone, glucagon and insulin and liver content of metabolic substrates and enzymes during starvation and additional hypoxia in the rat." Horm Metab Res 13(11): 612-614.

Mooradian, A. D., J. E. Morley and S. G. Korenman (1987). "Biological actions of androgens." Endocr Rev 8(1): 1-28.

Mourkioti, F., P. Kratsios, T. Luedde, Y. H. Song, P. Delafontaine, R. Adami, V. Parente, R. Bottinelli, M. Pasparakis and N. Rosenthal (2006). "Targeted ablation of IKK2 improves

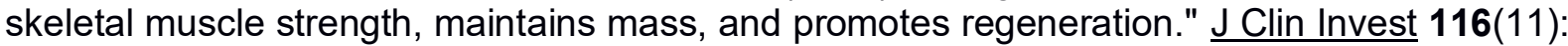
2945-2954.

Musaro, A., K. McCullagh, A. Paul, L. Houghton, G. Dobrowolny, M. Molinaro, E. R. Barton, H. L. Sweeney and N. Rosenthal (2001). "Localized Igf-1 transgene expression sustains hypertrophy and regeneration in senescent skeletal muscle." Nat Genet 27(2): 195-200.

Nakamura, R., A. Sene, A. Santeford, A. Gdoura, S. Kubota, N. Zapata and R. S. Apte (2015). "IL10-driven STAT3 signalling in senescent macrophages promotes pathological eye angiogenesis." Nat Commun 6: 7847.

Nathans, D. (1964). "Puromycin Inhibition of Protein Synthesis: Incorporation of Puromycin into Peptide Chains." Proc Natl Acad Sci U S A 51: 585-592.

O'Carroll, A. M., S. J. Lolait, L. E. Harris and G. R. Pope (2013). "The apelin receptor APJ: journey from an orphan to a multifaceted regulator of homeostasis." J Endocrinol 219(1): R13-35. 
Olguin, H. C., Z. Yang, S. J. Tapscott and B. B. Olwin (2007). "Reciprocal inhibition between Pax7 and muscle regulatory factors modulates myogenic cell fate determination." $\underline{\mathrm{J} \text { Cell Biol }}$ 177(5): 769-779.

Olson, E. N. and A. Nordheim (2010). "Linking actin dynamics and gene transcription to drive cellular motile functions." Nat Rev Mol Cell Biol 11(5): 353-365.

Orngreen, M. C., M. Zacho, A. Hebert, M. Laub and J. Vissing (2003). "Patients with severe muscle wasting are prone to develop hypoglycemia during fasting." Neurology 61(7): 9971000.

Pallafacchina, G., E. Calabria, A. L. Serrano, J. M. Kalhovde and S. Schiaffino (2002). "A protein kinase B-dependent and rapamycin-sensitive pathway controls skeletal muscle growth but not fiber type specification." Proc Natl Acad Sci U S A 99(14): 9213-9218.

Park, J. E., H. H. Chen, J. Winer, K. A. Houck and N. Ferrara (1994). "Placenta growth factor. Potentiation of vascular endothelial growth factor bioactivity, in vitro and in vivo, and high affinity binding to Flt-1 but not to Flk-1/KDR." J Biol Chem 269(41): 25646-25654.

Pires-Oliveira, M., A. L. Maragno, L. T. Parreiras-e-Silva, T. Chiavegatti, M. D. Gomes and R. O. Godinho (2010). "Testosterone represses ubiquitin ligases atrogin-1 and Murf-1 expression in an androgen-sensitive rat skeletal muscle in vivo." J Appl Physiol (1985) 108(2): 266-273.

Podhorska-Okolow, M., M. Sandri, S. Zampieri, B. Brun, K. Rossini and U. Carraro (1998). "Apoptosis of myofibres and satellite cells: exercise-induced damage in skeletal muscle of the mouse." Neuropathol Appl Neurobiol 24(6): 518-531.

Pretto, F., C. Ghilardi, M. Moschetta, A. Bassi, A. Rovida, V. Scarlato, L. Talamini, F. Fiordaliso, C. Bisighini, G. Damia, M. R. Bani, R. Piccirillo and R. Giavazzi (2015). "Sunitinib prevents cachexia and prolongs survival of mice bearing renal cancer by restraining STAT3 and MuRF-1 activation in muscle." Oncotarget 6(5): 3043-3054.

Rawlings, N. D. and A. J. Barrett (1994). "Families of serine peptidases." Methods Enzymol 244: $19-61$.

Rebbapragada, A., H. Benchabane, J. L. Wrana, A. J. Celeste and L. Attisano (2003). "Myostatin signals through a transforming growth factor beta-like signaling pathway to block adipogenesis." Mol Cell Biol 23(20): 7230-7242.

Remels, A. H., H. R. Gosker, P. Schrauwen, P. P. Hommelberg, P. Sliwinski, M. Polkey, J. Galdiz, E. F. Wouters, R. C. Langen and A. M. Schols (2010). "TNF-alpha impairs regulation of muscle oxidative phenotype: implications for cachexia?" FASEB J 24(12): 5052-5062.

Rhoads, M. G., S. C. Kandarian, F. Pacelli, G. B. Doglietto and M. Bossola (2010). "Expression of NF-kappaB and IkappaB proteins in skeletal muscle of gastric cancer patients." Eur J Cancer 46(1): 191-197.

Richard, L. (2002). Skeletal Muscle - Structure, Function and Plasticity. Baltimore: Lippincott Ritchie, M. E., B. Phipson, D. Wu, Y. Hu, C. W. Law, W. Shi and G. K. Smyth (2015). "limma powers differential expression analyses for RNA-sequencing and microarray studies." Nucleic Acids Res 43(7): e47.

Rommel, C., S. C. Bodine, B. A. Clarke, R. Rossman, L. Nunez, T. N. Stitt, G. D. Yancopoulos and D. J. Glass (2001). "Mediation of IGF-1-induced skeletal myotube hypertrophy by $\mathrm{PI}(3) \mathrm{K} / \mathrm{Akt} / \mathrm{mTOR}$ and $\mathrm{PI}(3) \mathrm{K} / \mathrm{Akt} / \mathrm{GSK} 3$ pathways." Nat Cell Biol 3(11): 10091013.

Rusconi, F., E. Mancinelli, G. Colombo, R. Cardani, L. Da Riva, I. Bongarzone, G. Meola and R. Zippel (2010). "Proteome profile in Myotonic Dystrophy type 2 myotubes reveals dysfunction in protein processing and mitochondrial pathways." Neurobiol Dis 38(2): 273280.

Sacheck, J. M., J. P. Hyatt, A. Raffaello, R. T. Jagoe, R. R. Roy, V. R. Edgerton, S. H. Lecker and A. L. Goldberg (2007). "Rapid disuse and denervation atrophy involve transcriptional changes similar to those of muscle wasting during systemic diseases." FASEB J 21(1): 140-155. 
Sambasivan, R., R. Yao, A. Kissenpfennig, L. Van Wittenberghe, A. Paldi, B. Gayraud-Morel, H. Guenou, B. Malissen, S. Tajbakhsh and A. Galy (2011). "Pax7-expressing satellite cells are indispensable for adult skeletal muscle regeneration." Development 138(17): 3647-3656.

Sandri, M. (2013). "Protein breakdown in muscle wasting: role of autophagy-lysosome and ubiquitin-proteasome." Int J Biochem Cell Biol 45(10): 2121-2129.

Sandri, M., C. Sandri, A. Gilbert, C. Skurk, E. Calabria, A. Picard, K. Walsh, S. Schiaffino, S. H. Lecker and A. L. Goldberg (2004). "Foxo transcription factors induce the atrophy-related ubiquitin ligase atrogin-1 and cause skeletal muscle atrophy." Cell 117(3): 399-412.

Sartori, R., G. Milan, M. Patron, C. Mammucari, B. Blaauw, R. Abraham and M. Sandri (2009). "Smad2 and 3 transcription factors control muscle mass in adulthood." Am J Physiol Cell Physiol 296(6): C1248-1257.

Schiaffino, S., K. A. Dyar, S. Ciciliot, B. Blaauw and M. Sandri (2013). "Mechanisms regulating skeletal muscle growth and atrophy." FEBS J 280(17): 4294-4314.

Schiaffino, S. and V. Hanzlikova (1972). "Studies on the effect of denervation in developing muscle. II. The lysosomal system." J Ultrastruct Res 39(1): 1-14.

Schmidt, E. K., G. Clavarino, M. Ceppi and P. Pierre (2009). "SUnSET, a nonradioactive method to monitor protein synthesis." Nat Methods 6(4): 275-277.

Shavlakadze, T. and M. Grounds (2006). "Of bears, frogs, meat, mice and men: complexity of factors affecting skeletal muscle mass and fat." Bioessays 28(10): 994-1009.

Shortreed K., J. A., Hawke T.J (2008). Satellite cells and muscle repair. In: Skeletal muscle damage and repair., Human Kinetics, Champaign IL:

Silva, K. A., J. Dong, Y. Dong, Y. Dong, N. Schor, D. J. Tweardy, L. Zhang and W. E. Mitch (2015). "Inhibition of Stat3 activation suppresses caspase-3 and the ubiquitin-proteasome system, leading to preservation of muscle mass in cancer cachexia." J Biol Chem 290(17): 11177-11187.

Singh, R., J. N. Artaza, W. E. Taylor, M. Braga, X. Yuan, N. F. Gonzalez-Cadavid and S. Bhasin (2006). "Testosterone inhibits adipogenic differentiation in 3T3-L1 cells: nuclear translocation of androgen receptor complex with beta-catenin and T-cell factor 4 may bypass canonical Wnt signaling to down-regulate adipogenic transcription factors." Endocrinology 147(1): 141-154.

Singh, R., S. Bhasin, M. Braga, J. N. Artaza, S. Pervin, W. E. Taylor, V. Krishnan, S. K. Sinha, T. B. Rajavashisth and R. Jasuja (2009). "Regulation of myogenic differentiation by androgens: cross talk between androgen receptor/ beta-catenin and follistatin/transforming growth factor-beta signaling pathways." Endocrinology 150(3): 1259-1268.

Skurk, C., Y. Izumiya, H. Maatz, P. Razeghi, I. Shiojima, M. Sandri, K. Sato, L. Zeng, S. Schiekofer, D. Pimentel, S. Lecker, H. Taegtmeyer, A. L. Goldberg and K. Walsh (2005). "The FOXO3a transcription factor regulates cardiac myocyte size downstream of AKT signaling." J Biol Chem 280(21): 20814-20823.

Sloper, J. C. and T. A. Partridge (1980). "Skeletal muscle: regeneration and transplantation studies." Br Med Bull 36(2): 153-158.

Smith, H. K., L. Maxwell, J. A. Martyn and J. J. Bass (2000). "Nuclear DNA fragmentation and morphological alterations in adult rabbit skeletal muscle after short-term immobilization." Cell Tissue Res 302(2): 235-241.

Smyth, G. K. (2005). Linear Models for Microarray Data. New York, Springer, New York.

Sorhede Winzell, M., C. Magnusson and B. Ahren (2005). "The apj receptor is expressed in pancreatic islets and its ligand, apelin, inhibits insulin secretion in mice." Regul Pept 131(13): $12-17$.

Stewart, C. E. and P. Rotwein (1996). "Growth, differentiation, and survival: multiple physiological functions for insulin-like growth factors." Physiol Rev 76(4): 1005-1026.

Stitt, T. N., D. Drujan, B. A. Clarke, F. Panaro, Y. Timofeyva, W. O. Kline, M. Gonzalez, G. D. Yancopoulos and D. J. Glass (2004). "The IGF-1/PI3K/Akt pathway prevents expression of muscle atrophy-induced ubiquitin ligases by inhibiting FOXO transcription factors." Mol Cell 14(3): 395-403. 
Tews, D. S., H. H. Goebel and H. M. Meinck (1997). "DNA-fragmentation and apoptosisrelated proteins of muscle cells in motor neuron disorders." Acta Neurol Scand 96(6): 380386.

Thomas, D. R. (2007). "Loss of skeletal muscle mass in aging: examining the relationship of starvation, sarcopenia and cachexia." Clin Nutr 26(4): 389-399.

Timchenko, L. (2013). "Molecular mechanisms of muscle atrophy in myotonic dystrophies." Int J Biochem Cell Biol 45(10): 2280-2287.

Tisdale, M. J. (2010). "Cancer cachexia." Curr Opin Gastroenterol 26(2): 146-151.

Trendelenburg, A. U., A. Meyer, D. Rohner, J. Boyle, S. Hatakeyama and D. J. Glass (2009). "Myostatin reduces Akt/TORC1/p70S6K signaling, inhibiting myoblast differentiation and myotube size." Am J Physiol Cell Physiol 296(6): C1258-1270.

van der Meer, S. F., R. T. Jaspers, D. A. Jones and H. Degens (2011). "Time-course of changes in the myonuclear domain during denervation in young-adult and old rat gastrocnemius muscle." Muscle Nerve 43(2): 212-222.

Van Gammeren, D., J. S. Damrauer, R. W. Jackman and S. C. Kandarian (2009). "The IkappaB kinases IKKalpha and IKKbeta are necessary and sufficient for skeletal muscle atrophy." FASEB J 23(2): 362-370.

Vivanco, I. and C. L. Sawyers (2002). "The phosphatidylinositol 3-Kinase AKT pathway in human cancer." Nat Rev Cancer 2(7): 489-501.

Waldemer-Streyer, R. J., A. Reyes-Ordonez, D. Kim, R. Zhang, N. Singh and J. Chen (2017). "Cxcl14 depletion accelerates skeletal myogenesis by promoting cell cycle withdrawal." NPJ Regen Med 2.

Wang, L., T. E. Harris, R. A. Roth and J. C. Lawrence, Jr. (2007). "PRAS40 regulates mTORC1 kinase activity by functioning as a direct inhibitor of substrate binding." J Biol Chem 282(27): 20036-20044.

White, G. W., S. Gianni, J. G. Grossmann, P. Jemth, A. R. Fersht and V. Daggett (2005). "Simulation and experiment conspire to reveal cryptic intermediates and a slide from the nucleation-condensation to framework mechanism of folding." J Mol Biol 350(4): 757-775.

Wu, C. L., S. C. Kandarian and R. W. Jackman (2011). "Identification of genes that elicit disuse muscle atrophy via the transcription factors p50 and Bcl-3." PLoS One 6(1): e16171.

Wysong, A., M. Couch, S. Shadfar, L. Li, J. E. Rodriguez, S. Asher, X. Yin, M. Gore, A. Baldwin, C. Patterson and M. S. Willis (2011). "NF-kappaB inhibition protects against tumorinduced cardiac atrophy in vivo." Am J Pathol 178(3): 1059-1068.

Yamakawa, T., S. Miyata, N. Ogawa, N. Koshikawa, H. Yasumitsu, T. Kanamori and K. Miyazaki (1998). "cDNA cloning of a novel trypsin inhibitor with similarity to pathogenesisrelated proteins, and its frequent expression in human brain cancer cells." Biochim Biophys Acta 1395(2): 202-208.

Yang, Z. and D. J. Klionsky (2010). "Mammalian autophagy: core molecular machinery and signaling regulation." Curr Opin Cell Biol 22(2): 124-131.

You, L., Z. Wang, H. Li, J. Shou, Z. Jing, J. Xie, X. Sui, H. Pan and W. Han (2015). "The role of STAT3 in autophagy." Autophagy 11(5): 729-739.

Yu, H., H. Lee, A. Herrmann, R. Buettner and R. Jove (2014). "Revisiting STAT3 signalling in cancer: new and unexpected biological functions." Nat Rev Cancer 14(11): 736-746.

Zhang, L., J. Pan, Y. Dong, D. J. Tweardy, Y. Dong, G. Garibotto and W. E. Mitch (2013). "Stat3 activation links a C/EBPdelta to myostatin pathway to stimulate loss of muscle mass." Cell Metab 18(3): 368-379.

Zhu, Z., X. He, C. Johnson, J. Stoops, A. E. Eaker, D. S. Stoffer, A. Bell, R. Zarnegar and M. C. DeFrances (2007). "PI3K is negatively regulated by PIK3IP1, a novel p110 interacting protein." Biochem Biophys Res Commun 358(1): 66-72. 
APÊNDICES 
APENDICE A. Genes diferencialmente expressos em 24 horas.

Tabela com os 241 genes responsivos ao tratamento com propionato de testosterona por 24 horas após o período de castração.

\begin{tabular}{|c|c|c|c|c|}
\hline Nome do Gene & Nome sistemático & $\log \mathrm{FC}$ & P.Value & adj.P.Val \\
\hline MettI7a & NM_001037355 & $-2,01972$ & 0,00000 & 0,00005 \\
\hline Ucp3 & NM_013167 & $-2,19137$ & 0,00000 & 0,00005 \\
\hline $\lg 11$ & NM 001082479 & 1,75830 & 0,00000 & 0,00013 \\
\hline Fbxo32 & NM_133521 & $-2,82584$ & 0,00000 & 0,00013 \\
\hline Pik3ip1 & NM_001017453 & $-2,02938$ & 0,00000 & 0,00019 \\
\hline KlhI38 & NM_001025008 & $-2,30089$ & 0,00000 & 0,00019 \\
\hline Igfbp3 & NM_012588 & $-1,97467$ & 0,00000 & 0,00021 \\
\hline Cxcl14 & NM_001013137 & $-1,57930$ & 0,00000 & 0,00023 \\
\hline A_64_P151542 & A_64_P151542 & 2,35920 & 0,00000 & 0,00023 \\
\hline Klf15 & NM_053536 & $-1,40288$ & 0,00000 & 0,00030 \\
\hline Ccdc80 & NM_022543 & 1,39079 & 0,00000 & 0,00033 \\
\hline Spns2 & NM_001144991 & 1,48704 & 0,00000 & 0,00040 \\
\hline LOC292199 & NM_001144859 & $-1,43942$ & 0,00000 & 0,00040 \\
\hline Fn3k & NM_001109051 & $-1,21431$ & 0,00000 & 0,00053 \\
\hline Col1a2 & NM_053356 & 1,18587 & 0,00000 & 0,00057 \\
\hline Col1a1 & $\mathrm{NM}^{-} 053304$ & 1,32139 & 0,00000 & 0,00058 \\
\hline Fkbp5 & NM_001012174 & 1,19394 & 0,00000 & 0,00058 \\
\hline Ankrd9 & NM_001012112 & 1,15767 & 0,00000 & 0,00061 \\
\hline Creb3l1 & NM_001005562 & 1,19873 & 0,00000 & 0,00064 \\
\hline Amd1 & NM_031011 & 1,62631 & 0,00000 & 0,00064 \\
\hline Abr & NM_001105814 & 1,38766 & 0,00000 & 0,00070 \\
\hline Pim3 & NM_022602 & $-1,29813$ & 0,00000 & 0,00070 \\
\hline RT1-CE10 & NM_001008833 & $-1,57351$ & 0,00000 & 0,00099 \\
\hline Cck & NM_012829 & 1,22835 & 0,00000 & 0,00109 \\
\hline Col3a1 & NM 032085 & 1,53833 & 0,00000 & 0,00111 \\
\hline Tmem140 & NM_001009709 & $-1,34613$ & 0,00000 & 0,00111 \\
\hline Hopx & NM_133621 & 1,09990 & 0,00000 & 0,00111 \\
\hline Myh1 & NM_001135158 & 1,37510 & 0,00000 & 0,00126 \\
\hline GU969272 & GŪ̄69272 & $-1,22943$ & 0,00000 & 0,00127 \\
\hline Lrrc2 & NM_001012001 & $-1,02104$ & 0,00000 & 0,00141 \\
\hline Ulk1 & NM_001108341 & $-1,09551$ & 0,00000 & 0,00220 \\
\hline Crispld2 & NM_138518 & 0,98864 & 0,00000 & 0,00220 \\
\hline Tuba1a & NM_022298 & 1,11302 & 0,00000 & 0,00220 \\
\hline Hdac4 & XM_001067733 & $-1,13281$ & 0,00000 & 0,00220 \\
\hline Ipo13 & NM_053778 & $-1,03596$ & 0,00000 & 0,00220 \\
\hline Odc1 & NM_012615 & 1,24151 & 0,00000 & 0,00254 \\
\hline Mybph & NM 031813 & 1,34157 & 0,00000 & 0,00255 \\
\hline Dpep1 & NM_053591 & 1,49742 & 0,00000 & 0,00267 \\
\hline LOC691781 & XR_086096 & 0,92942 & 0,00000 & 0,00303 \\
\hline Tjap1 & NM_001108203 & 1,09783 & 0,00000 & 0,00318 \\
\hline Ddit4I & NM_080399 & $-1,23425$ & 0,00001 & 0,00318 \\
\hline Ucma & NM_001106121 & 1,06624 & 0,00001 & 0,00318 \\
\hline A_64_P136016 & A $\overline{64}$ P136016 & 0,92715 & 0,00001 & 0,00318 \\
\hline Hspa 5 & NM_013083 & 0,91309 & 0,00001 & 0,00334 \\
\hline Mkl1 & $\mathrm{XM}^{-} 235497$ & 0,99130 & 0,00001 & 0,00344 \\
\hline
\end{tabular}




\begin{tabular}{|c|c|c|c|c|}
\hline Tuba1b & NM_001044270 & 0,88402 & 0,00001 & 0,00344 \\
\hline LOC678769 & NM 001126298 & 0.89275 & 0.00001 & 0.00344 \\
\hline Art5 & NM_001013039 & $-0,91438$ & 0,00001 & 0,00420 \\
\hline Zfand5 & NM_001106356 & $-1,34599$ & 0,00001 & 0,00420 \\
\hline Pelo & NM_001007634 & $-0,84566$ & 0,00001 & 0,00420 \\
\hline Manba & NM_001031655 & 0,99594 & 0,00001 & 0,00420 \\
\hline Rprml & NM_001109481 & 0,87400 & 0,00001 & 0,00429 \\
\hline A_64_P164335 & A_64_P164335 & $-0,91323$ & 0,00001 & 0,00474 \\
\hline Cygb & NM_130744 & $-0,93032$ & 0,00001 & 0,00485 \\
\hline Mapk14 & NM_031020 & 0,85146 & 0,00001 & 0,00498 \\
\hline Itgb6 & NM 001004263 & 0,90776 & 0,00001 & 0,00577 \\
\hline A 64_P006473 & A $\overline{64}$ P006473 & 1,05641 & 0,00001 & 0,00617 \\
\hline Kēnk̄ & NM $\overline{053806}$ & 0,83351 & 0,00001 & 0,00617 \\
\hline AW920845 & AW920845 & 0,80830 & 0,00001 & 0,00619 \\
\hline Maf & NM 019318 & 0,87502 & 0,00001 & 0,00624 \\
\hline Bag3 & NM 001011936 & 0,92624 & 0,00002 & 0,00662 \\
\hline Aqp4 & NM 001142366 & $-1,09144$ & 0,00002 & 0,00662 \\
\hline Ubc & NM 017314 & $-1,65886$ & 0,00002 & 0,00662 \\
\hline ENSRNOT00000051185 & ENS̄RNOT00000051185 & 0,79533 & 0,00002 & 0,00662 \\
\hline Col5a2 & NM 053488 & 0,91890 & 0,00002 & 0,00662 \\
\hline Ypel3 & NM 001135698 & $-0,80290$ & 0,00002 & 0,00662 \\
\hline Mylk2 & NM 057209 & $-0,77771$ & 0,00002 & 0,00664 \\
\hline Lmod2 & NM 001100964 & $-1,92227$ & 0,00002 & 0,00670 \\
\hline C1qa & NM 001008515 & 0,79746 & 0,00002 & 0,00670 \\
\hline Tob2 & NM_001007146 & 0,94150 & 0,00002 & 0,00670 \\
\hline Ppp1r14b & NM 172045 & 0,80905 & 0,00002 & 0,00670 \\
\hline Ppap2b & NM 138905 & 0,93531 & 0,00002 & 0,00677 \\
\hline Asb2 & NM 001011984 & $-1,41262$ & 0,00002 & 0,00701 \\
\hline Abhd4 & NM 001108866 & $-0,75356$ & 0,00002 & 0,00804 \\
\hline Cryab & NM 012935 & 0,83348 & 0,00002 & 0,00830 \\
\hline A_64_P110996 & A 64 P110996 & 1,04808 & 0,00002 & 0,00834 \\
\hline Ḡprc $\overline{5} c$ & EN'SRNNOT00000004256 & 0,78674 & 0,00002 & 0,00834 \\
\hline St3gal6 & NM 207602 & $-0,83326$ & 0,00002 & 0,00834 \\
\hline A_64_P033230 & A 64 P 033230 & 0,79335 & 0,00003 & 0,00834 \\
\hline A_64_P163812 & A 64 P 163812 & 0,82850 & 0,00003 & 0,00859 \\
\hline $\mathrm{C} \overline{\mathrm{d}} 24$ & NM $\overline{012752}$ & $-0,85739$ & 0,00003 & 0,00864 \\
\hline Srebf1 & ENS̄RNOT00000047053 & 0,85954 & 0,00003 & 0,00887 \\
\hline Dynll1 & NM 053319 & 0,82904 & 0,00003 & 0,00924 \\
\hline Slc13a3 & NM 022866 & 1,01409 & 0,00003 & 0,00940 \\
\hline Pde4d & NM 017032 & $-0,79303$ & 0,00003 & 0,00961 \\
\hline A_64_P157693 & A 64 P157693 & 1,03326 & 0,00003 & 0,00982 \\
\hline Nme 1 & NM $\overline{138548}$ & 0,94002 & 0,00003 & 0,00983 \\
\hline Acly & NM_016987 & 0,84064 & 0,00003 & 0,01041 \\
\hline Slk & NM 019349 & 0,72491 & 0,00004 & 0,01085 \\
\hline Gabarapl1 & NM- 001044294 & $-0,77687$ & 0,00004 & 0,01089 \\
\hline Ankrd54 & NM- 001025285 & $-0,73501$ & 0,00004 & 0,01089 \\
\hline LOC680810 & XM 001058983 & $-0,79061$ & 0,00004 & 0,01140 \\
\hline Cd248 & NM ${ }^{-} 001106325$ & 0,78557 & 0,00004 & 0,01196 \\
\hline Rbl2 & NM 031094 & $-1,02917$ & 0,00004 & 0,01217 \\
\hline Cnppd1 & NM 199112 & $-0,71033$ & 0,00004 & 0,01217 \\
\hline Gapdh-ps1 & NR 003722 & $-0,79808$ & 0,00004 & 0,01217 \\
\hline Pgf & NM 053595 & 0,79607 & 0,00004 & 0,01217 \\
\hline Postn & NM 001108550 & 0,72792 & 0,00005 & 0,01244 \\
\hline Plcd4 & NM 080688 & 1,15712 & 0,00005 & 0,01244 \\
\hline
\end{tabular}




\begin{tabular}{|c|c|c|c|c|}
\hline Zbtb38 & NM_001012471 & $-0,69389$ & 0,00005 & 0,01253 \\
\hline Pnp & NM 001106031 & 0.84356 & 0.00005 & 0.01262 \\
\hline Jph2 & NM_001037974 & 0,69789 & 0,00005 & 0,01271 \\
\hline Ptprf & NM_019249 & 0,71288 & 0,00005 & 0,01330 \\
\hline A_64_P115772 & A_64_P115772 & 0,78012 & 0,00005 & 0,01341 \\
\hline ENSRNOT00000043148 & ENSRNOT00000043148 & $-0,75353$ & 0,00005 & 0,01341 \\
\hline ENSRNOT00000013159 & ENSRNOT00000013159 & 0,74366 & 0,00005 & 0,01341 \\
\hline Tbx1 & NM 001108322 & $-0,71321$ & 0,00005 & 0,01341 \\
\hline Mkrn2 & NM 001008314 & $-0,78101$ & 0,00006 & 0,01361 \\
\hline Tspan8 & NM 133526 & $-0,74024$ & 0,00006 & 0,01440 \\
\hline Prkca & NM 001105713 & 0,67194 & 0,00006 & 0,01445 \\
\hline Trim63 & NM 080903 & $-0,95440$ & 0,00006 & 0,01468 \\
\hline ENSRNOT00000001785 & ENS̄RNOT00000001785 & 0,80574 & 0,00006 & 0,01494 \\
\hline Crim1 & NM 001169103 & $-0,86266$ & 0,00007 & 0,01546 \\
\hline Sypl2 & NM 001108563 & 0,79625 & 0,00007 & 0,01619 \\
\hline Gas5 & NR 002704 & $-0,77728$ & 0,00007 & 0,01629 \\
\hline Rab20 & NM 001109535 & $-0,75728$ & 0,00007 & 0,01649 \\
\hline Fst & NM 012561 & 0,83431 & 0,00007 & 0,01649 \\
\hline Crym & NM 053955 & 0,72802 & 0,00007 & 0,01649 \\
\hline ENSRNOT00000048816 & ENS̄RNOT00000048816 & 0,82698 & 0,00008 & 0,01663 \\
\hline Spon1 & NM 172067 & 0,76029 & 0,00008 & 0,01663 \\
\hline Srxn1 & NM 001047858 & $-0,77407$ & 0,00008 & 0,01668 \\
\hline Scn4b & NM 001008880 & $-0,66904$ & 0,00008 & 0,01668 \\
\hline A_64_P139203 & A $\overline{64}$ P139203 & 0,66083 & 0,00008 & 0,01669 \\
\hline Arrdc3 & NM 001007797 & $-1,13619$ & 0,00008 & 0,01672 \\
\hline Abra & NM 175844 & $-1,13873$ & 0,00008 & 0,01729 \\
\hline Jun & NM 021835 & $-0,85151$ & 0,00008 & 0,01729 \\
\hline Myl6 & NM 001109484 & 0,76460 & 0,00008 & 0,01729 \\
\hline Actg1 & NM_001127449 & 0,67032 & 0,00008 & 0,01735 \\
\hline Rbp7 & NM_001108693 & 0,67248 & 0,00009 & 0,01817 \\
\hline Mat2a & NM 134351 & 0,83156 & 0,00009 & 0,01847 \\
\hline Cep85 & NM_001080151 & $-0,81683$ & 0,00009 & 0,01847 \\
\hline G0s2 & NM_001009632 & 1,93387 & 0,00009 & 0,01863 \\
\hline ENSRNOT00000014537 & ENS̄RNOT00000014537 & $-0,68901$ & 0,00009 & 0,01875 \\
\hline mrpl9 & NM 001007696 & $-0,75084$ & 0,00010 & 0,01902 \\
\hline Atpaf2 & NM_001107006 & 0,64769 & 0,00010 & 0,01932 \\
\hline Ccrn4l & NM 138526 & 1,01162 & 0,00010 & 0,01974 \\
\hline Tnxa-ps1 & NR 024118 & 0,86728 & 0,00010 & 0,01974 \\
\hline FIcn & NM̄̄199390 & $-0,69939$ & 0,00011 & 0,01988 \\
\hline A_64_P058274 & A 64 P058274 & 0,66985 & 0,00011 & 0,01988 \\
\hline Hȳoū̄ & NM $\overline{138867}$ & 0,68420 & 0,00011 & 0,01988 \\
\hline Emp3 & NM 030847 & 0,71109 & 0,00011 & 0,01994 \\
\hline Cox6a1 & NM 012814 & 0,65589 & 0,00011 & 0,01995 \\
\hline Tmem86a & NM 001135016 & $-0,70638$ & 0,00011 & 0,01995 \\
\hline Pgam1 & NM 053290 & 0,69999 & 0,00011 & 0,02005 \\
\hline Tnxb & BC168189 & 1,13213 & 0,00011 & 0,02005 \\
\hline Cd163 & NM 001107887 & 0,64246 & 0,00011 & 0,02005 \\
\hline RGD1566369 & ENS̄RNOT00000006662 & 0,78593 & 0,00011 & 0,02005 \\
\hline SIc7a6 & NM 001107424 & 0,67578 & 0,00011 & 0,02005 \\
\hline Higd1 b & NM 001105844 & 0,82990 & 0,00011 & 0,02005 \\
\hline Omd & NM 031817 & $-0,62341$ & 0,00012 & 0,02068 \\
\hline Mob2 & NM 001109159 & $-0,61530$ & 0,00012 & 0,02071 \\
\hline Arhgap28 & NM 001191815 & $-0,68947$ & 0,00012 & 0,02118 \\
\hline Ppp1r15a & NM_133546 & $-0,92134$ & 0,00012 & 0,02118 \\
\hline
\end{tabular}




\begin{tabular}{|c|c|c|c|c|}
\hline Cmbl & NM_001008770 & $-0,70446$ & 0,00012 & 0,02123 \\
\hline Creg1 & NM 001105966 & $-0,70810$ & 0,00013 & 0,02189 \\
\hline A_64_P036335 & A_64_P036335 & 0,65055 & 0,00013 & 0,02214 \\
\hline Map1s & NM_E_o01106070 & 0,72756 & 0,00013 & 0,02214 \\
\hline A_64_P101678 & A_64_P101678 & 0,74350 & 0,00013 & 0,02214 \\
\hline Stat5 $\bar{b}$ & NM_ō22380 & $-0,60977$ & 0,00013 & 0,02214 \\
\hline Calr & NM_022399 & 0,61387 & 0,00014 & 0,02250 \\
\hline Spryd7 & NM_001009635 & $-0,72619$ & 0,00014 & 0,02250 \\
\hline Anxa10 & NM_001109110 & 0,76841 & 0,00014 & 0,02250 \\
\hline A_64_P085462 & A_64_P085462 & 0,69629 & 0,00014 & 0,02250 \\
\hline A_64_P025222 & A_64_P025222 & $-0,79196$ & 0,00014 & 0,02261 \\
\hline Efna1 & NM_o53599 & $-0,85786$ & 0,00014 & 0,02262 \\
\hline Lsm12 & NM 001105843 & 0,62257 & 0,00015 & 0,02335 \\
\hline Nfe2l1 & NM 001108293 & $-0,61957$ & 0,00015 & 0,02353 \\
\hline Cxcl13 & NM_001017496 & 0,85100 & 0,00015 & 0,02415 \\
\hline Pes1 & NM_001044228 & $-0,67965$ & 0,00016 & 0,02535 \\
\hline Akap13 & NM_001106271 & $-0,65979$ & 0,00016 & 0,02543 \\
\hline XM_345356 & XM_345356 & 0,68593 & 0,00017 & 0,02606 \\
\hline Pf4 & NM_001007729 & 0,67144 & 0,00017 & 0,02606 \\
\hline Surf4 & NM_001033868 & 0,73766 & 0,00017 & 0,02606 \\
\hline Cd302 & NM_001013916 & $-0,75823$ & 0,00017 & 0,02606 \\
\hline Fabp4 & NM_053365 & 0,60750 & 0,00018 & 0,02688 \\
\hline Bcorl1 & NM_001191587 & $-0,62981$ & 0,00018 & 0,02764 \\
\hline A_64_P149316 & A_64_P149316 & 0,62785 & 0,00019 & 0,02858 \\
\hline HIx & NM_001077674 & $-0,69443$ & 0,00020 & 0,02895 \\
\hline Zfp503 & NM_001107250 & $-0,71396$ & 0,00020 & 0,02906 \\
\hline A_64_P053237 & A_64_P053237 & 0,69325 & 0,00020 & 0,02915 \\
\hline Bmper & NM_001135799 & 0,66638 & 0,00020 & 0,02915 \\
\hline Chac1 & NM_001173437 & $-0,60653$ & 0,00020 & 0,02946 \\
\hline A_64_P042056 & A_64_P042056 & 0,89047 & 0,00020 & 0,02949 \\
\hline A_64_P141709 & A_64_P141709 & 0,67184 & 0,00021 & 0,03025 \\
\hline Sgk1 & NM_019232 & $-0,71438$ & 0,00022 & 0,03044 \\
\hline Vegfa & NM_031836 & 0,68597 & 0,00022 & 0,03062 \\
\hline Mgp & NM_012862 & 0,84650 & 0,00023 & 0,03176 \\
\hline C1qc & NM_001008524 & 0,61287 & 0,00023 & 0,03209 \\
\hline S100a4 & NM_012618 & 0,62895 & 0,00023 & 0,03223 \\
\hline Pi15 & NM_001106917 & 0,64194 & 0,00024 & 0,03299 \\
\hline Tubb2a & NM_001109119 & 0,64753 & 0,00025 & 0,03350 \\
\hline Lyz2 & NM_012771 & 0,68577 & 0,00025 & 0,03350 \\
\hline Hmgn1 & NM_001013184 & 0,64126 & 0,00025 & 0,03391 \\
\hline Abtb1 & NM_001005902 & $-0,64847$ & 0,00026 & 0,03406 \\
\hline Ctps & NM_001134873 & 0,59741 & 0,00027 & 0,03496 \\
\hline Ccdc28a & NM_001037789 & $-0,72442$ & 0,00027 & 0,03496 \\
\hline Mrpl44 & NM_001031650 & $-0,63474$ & 0,00027 & 0,03556 \\
\hline Limk1 & NM_031727 & 0,62480 & 0,00028 & 0,03556 \\
\hline Dnajc25 & NM_001025021 & 0,63194 & 0,00028 & 0,03573 \\
\hline Taf9b & NM_133615 & 0,67004 & 0,00028 & 0,03575 \\
\hline Sparc & NM_012656 & 0,82873 & 0,00028 & 0,03602 \\
\hline Sept8 & NM_001107002 & 0,62038 & 0,00029 & 0,03618 \\
\hline ENSRNOT00000029281 & ENSRNOT00000029281 & $-0,59874$ & 0,00029 & 0,03618 \\
\hline LOC684327 & XM_001069890 & $-0,58622$ & 0,00029 & 0,03623 \\
\hline A_64_P150064 & A $\overline{64}$ P 150064 & $-0,65792$ & 0,00029 & 0,03625 \\
\hline Assb15 & EÑSRNOT00000008917 & $-0,60135$ & 0,00030 & 0,03652 \\
\hline Sod3 & NM_012880 & $-0,85238$ & 0,00030 & 0,03653 \\
\hline
\end{tabular}




\begin{tabular}{llrrr}
\hline Pnrc1 & NM_173322 & $-0,69618$ & 0,00030 & 0,03671 \\
KIhI21 & NM_001107996 & $-0,61601$ & 0,00031 & 0,03815 \\
A_64_P087796 & A_64_P087796 & $-0,69958$ & 0,00032 & 0,03832 \\
\hline Lman2 & NM_001115024 & 0,67014 & 0,00033 & 0,03878 \\
Acss1 & NM_001106524 & $-0,66277$ & 0,00033 & 0,03878 \\
A_64_P111963 & A_64_P111963 & 0,65838 & 0,00033 & 0,03878 \\
EgIn3 & NM_019371 & $-0,59314$ & 0,00033 & 0,03878 \\
Ttc30b & NM_001127607 & $-0,61973$ & 0,00034 & 0,04032 \\
Usp10 & NM_001034146 & 0,59294 & 0,00036 & 0,04157 \\
II1r2 & NM_053953 & 0,68716 & 0,00036 & 0,04157 \\
A_64_P147586 & A_64_P147586 & 0,59990 & 0,00036 & 0,04157 \\
Fabp5 & NM_145878 & 0,71748 & 0,00037 & 0,04232 \\
A_64_P106707 & A_64_P106707 & 0,66047 & 0,00038 & 0,04232 \\
Dusp26 & NM_001012352 & $-0,61859$ & 0,00038 & 0,04284 \\
Mn1 & NM_001191928 & $-0,60775$ & 0,00039 & 0,04317 \\
Tgm2 & NM_019386 & 0,66414 & 0,00039 & 0,04343 \\
Fam65a & ENSRNOT00000023710 & $-0,67655$ & 0,00040 & 0,04359 \\
DV714996 & DV714996 & 0,67424 & 0,00040 & 0,04381 \\
Myoc & NM_030865 & $-0,65735$ & 0,00040 & 0,04389 \\
Usp3 & NM_001025424 & $-0,67152$ & 0,00041 & 0,04415 \\
RT1-A2 & NM_001008829 & $-0,70263$ & 0,00043 & 0,04500 \\
A_64_P069236 & A_64_P069236 & $-0,59370$ & 0,00043 & 0,04518 \\
Ankrd23 & NM_001108211 & $-0,60264$ & 0,00044 & 0,04605 \\
CtsI1 & NM_013156 & $-0,94422$ & 0,00044 & 0,04607 \\
LOC687797 & XM_001080179 & 0,63891 & 0,00045 & 0,04651 \\
\hline Pcgf5 & NM_001129882 & $-0,63103$ & 0,00046 & 0,04707 \\
ENSRNOT00000041811 & ENSRNOT00000041811 & $-0,76984$ & 0,00047 & 0,04767 \\
ENSRNOT00000058522 & ENSRNOT00000058522 & $-0,77847$ & 0,00047 & 0,04767 \\
Fdx1I & NM_001108002 & 0,60614 & 0,00047 & 0,04767 \\
Ssr3 & NM_031120 & 0,71134 & 0,00048 & 0,04776 \\
A_64_P123387 & A_64_P123387 & 0,61003 & 0,00048 & 0,04776 \\
A_64_P120936 & A_64_P120936 & $-0,72988$ & 0,00048 & 0,04796 \\
ENSRNOT00000058516 & ENSRNOT00000058516 & 0,63639 & 0,00049 & 0,04840 \\
A_64_P028255 & A_64_P028255 & 0,59827 & 0,00050 & 0,04913 \\
\hline & & & & \\
\hline
\end{tabular}




\section{APÊNDICE B. Análise funcional DAVID.}

\begin{tabular}{|c|c|c|c|c|c|c|c|c|c|c|}
\hline Category & Term & Count & $\%$ & $\begin{array}{l}\text { List } \\
\text { Total }\end{array}$ & $\begin{array}{l}\text { Pop } \\
\text { Hits }\end{array}$ & $\begin{array}{l}\text { Pop } \\
\text { Total }\end{array}$ & $\begin{array}{c}\text { Fold } \\
\text { Enrichment }\end{array}$ & PValue & $\begin{array}{c}\text { Benjami } \\
n i\end{array}$ & $-\log 10$ (pvalue) \\
\hline GOTERM_CC_DIRECT & GO:0070062 extracellular exosome & 62 & 28,8372093 & 195 & 2646 & 18520 & 2,225400702 & 0,000 & 0,000 & 6,731939351 \\
\hline GOTERM_CC_DIRECT & GO:0031012 extracellular matrix & 15 & 6,976744186 & 195 & 254 & 18520 & 5,608721987 & 0,000 & 0,000 & 4,215147315 \\
\hline GOTERM_CC_DIRECT & GO:0043209 myelin sheath & 13 & 6,046511628 & 195 & 191 & 18520 & 6,464223386 & 0,000 & 0,000 & 4,161193106 \\
\hline GOTERM_CC_DIRECT & GO:0005615 extracellular space & 34 & 15,81395349 & 195 & 1316 & 18520 & 2,453744837 & 0,000 & 0,000 & 3,926468602 \\
\hline GOTERM_CC_DIRECT & GO:0005737 cytoplasm & 86 & 40 & 195 & 5227 & 18520 & 1,562616199 & 0,000 & 0,000 & 3,85336081 \\
\hline GOTERM_CC_DIRECT & GO:0005829 cytosol & 35 & 16,27906977 & 195 & 1590 & 18520 & 2,090630543 & 0,000 & 0,002 & 2,704304014 \\
\hline GOTERM_CC_DIRECT & $\begin{array}{l}\text { GO:0005578 proteinaceous } \\
\text { extracellular matrix }\end{array}$ & 12 & 5,581395349 & 195 & 253 & 18520 & 4,504712679 & 0,000 & 0,003 & 2,574253662 \\
\hline GOTERM_BP_DIRECT & $\begin{array}{l}\text { GO:0009612 response to } \\
\text { mechanical stimulus }\end{array}$ & 10 & 4,651162791 & 191 & 104 & 17535 & 8,827527185 & 0,000 & 0,003 & 2,571746939 \\
\hline GOTERM_CC_DIRECT & GO:0005581 collagen trimer & 6 & 2,790697674 & 195 & 60 & 18520 & 9,497435897 & 0,000 & 0,013 & 1,900173122 \\
\hline GOTERM_CC_DIRECT & GO:0030016 myofibril & 5 & 2,325581395 & 195 & 40 & 18520 & 11,87179487 & 0,001 & 0,022 & 1,666109768 \\
\hline
\end{tabular}




\section{APÊNDICE C. Membranas de nitrocelulose para Western blotting.}

Exemplos de membranas de nitrocelulose feitas para os experimentos de validação com amostras de músculo Elevador do ânus de ratos machos adultos.
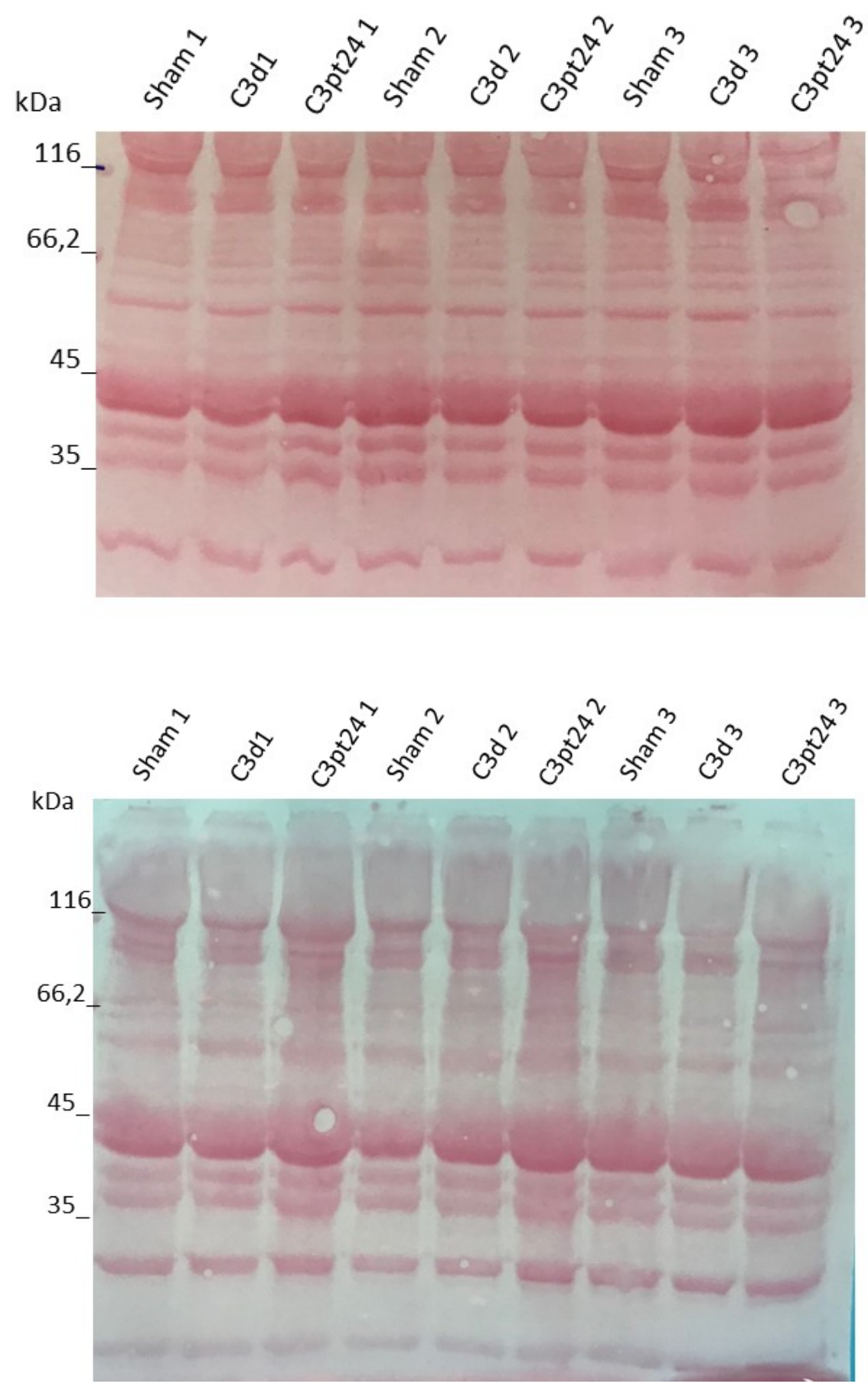

Apêndice C. Exemplos de membranas de nitrocelulose coradas com Ponceau utilizadas para incubação de anticorpos anti proteínas-alvo dos experimentos de validação de RT-PCR (Sham, C3 e C3pt24). As membranas foram incubadas com os anticorpos já listados previamente. 

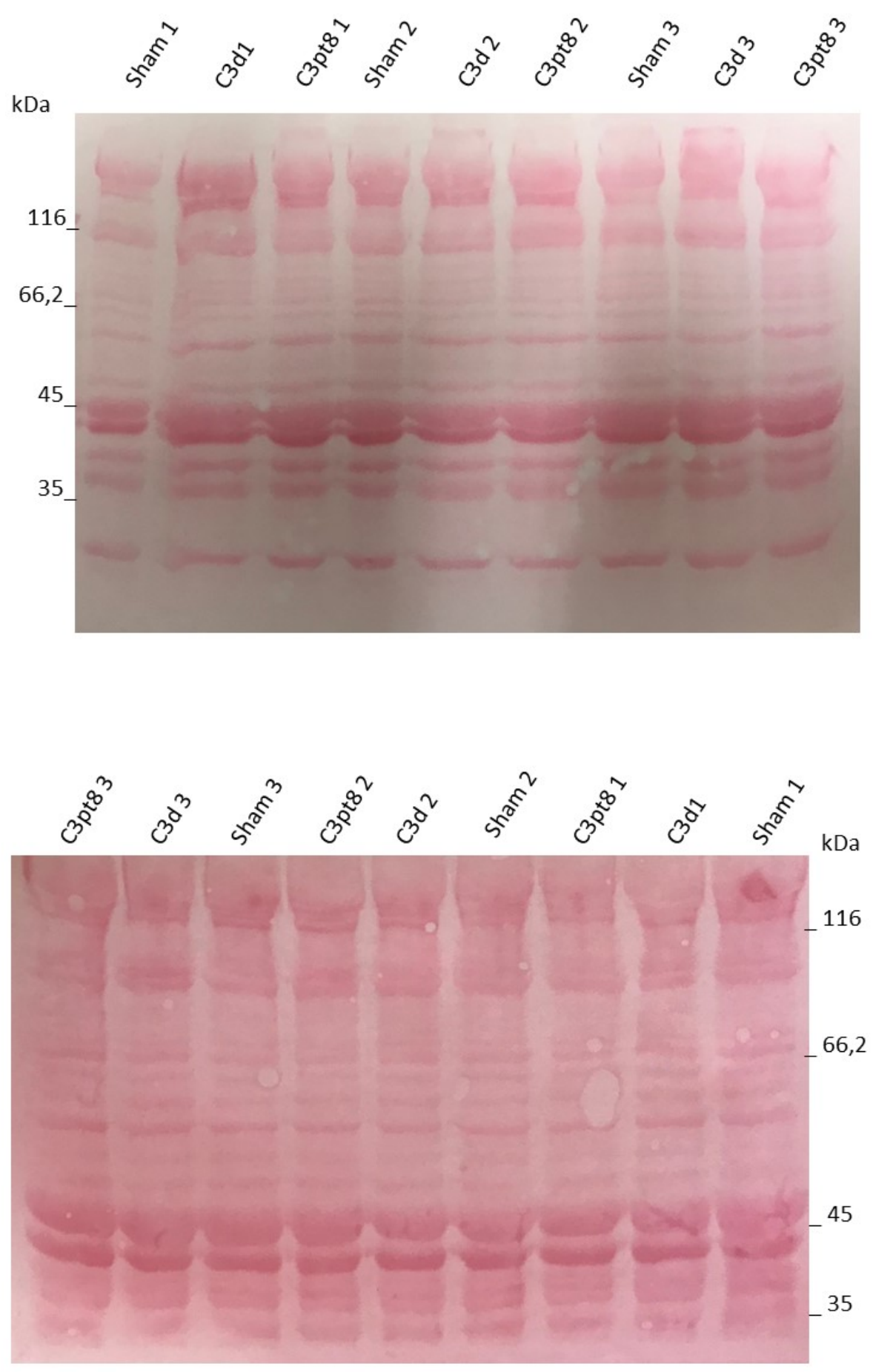

Apêndice C. Exemplo de membranas de nitrocelulose coradas com Ponceau utilizadas para incubação de anticorpos anti proteínas-alvo dos experimentos de validação do array de anticorpos anti-fosfoquinases (Sham, C3 e C3pt8). As membranas foram incubadas com os anticorpos já listados previamente. 
ANEXOS 


\section{ANEXO 1. Documentação CEUA.}

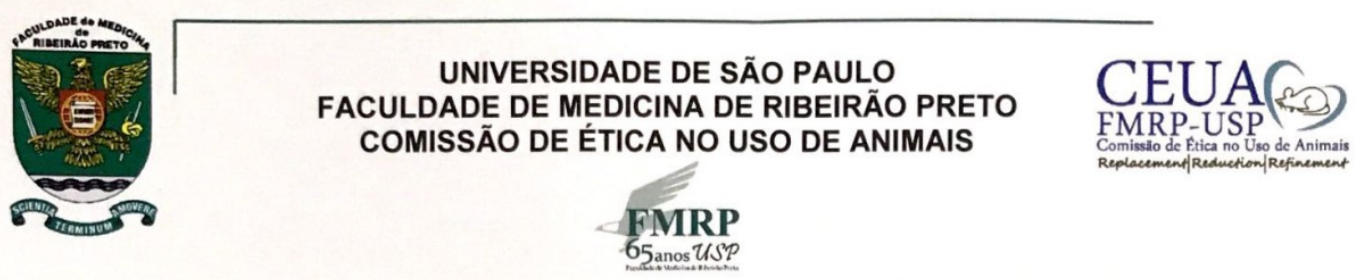

\section{E R T I F I C A D O}

Certificamos que o Protocolo intitulado "Análise dos genes diferencialmente expressos durante o processo de reversão da atrofia muscular", registrado com o número 161/2017, sob a responsabilidade do Prof. Dr. Marcelo Damario Gomes, envolvendo a produção, manutenção ou utilização de animais pertencentes ao filo Chordata, subfilo Vertebrata (exceto humanos) para fins de pesquisa científica, encontra-se de acordo com os preceitos da Lei $\mathrm{n}^{\circ} 11.794$ de 8 de outubro de 2008, do Decreto $\mathrm{n}^{\circ} 6.899$ de 15 de julho de 2009 e com as normas editadas pelo Conselho Nacional de Controle de Experimentação Animal (CONCEA), e foi APROVADO pela Comissão de Ética no Uso de Animais da Faculdade de Medicina de Ribeirão Preto da Universidade de São Paulo em reunião de 28 de agosto de 2017.

Este Protocolo prevê a utilização de 12 camundongos C57Bl 6 machos pesando $30 \mathrm{~g}$, oriundos do Serviço de Biotério da Prefeitura do Campus de Ribeirão Preto da Universidade de São Paulo. Vigência da autorização: 28/08/2017 a 30/03/2019.

We certify that the Protocol $n^{\circ} 161 / 2017$, entitled "Analysis of differentially expressed genes in the process of reversal of muscle atrophy", is in accordance with the Ethical Principles in Animal Research adopted by the National Council for the Control of Animal Experimentation (CONCEA) and was approved by the Local Animal Ethical Committee from Ribeirão Preto Medical School of the University of São Paulo in 08/28/2017. This protocol involves the production, maintenance or use of animals from phylum Chordata, subphylum Vertebrata (except humans) for research purposes, and includes the use of 12 male C57Bl 6 mice weighing $30 \mathrm{~g}$ from the Central Animal House of Ribeirao Preto Medical School, University of São Paulo. This certificate is valid until 03/30/2019.

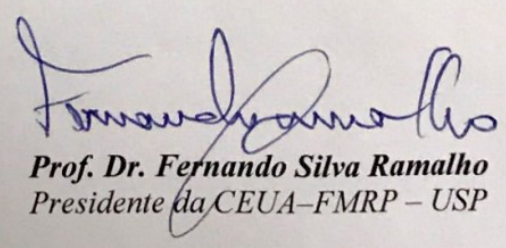




\section{ANEXO 2. Fosfoquinases e sítios de fosforilação.}

Relação das 43 quinases presentes nas membranas A e B do array de anticorpos anti-fosfoquinases. Coordenadas, descrição da respectiva fosfoquinase e seus sítios de fosforilação. Também estão listados os controles do ensaio.

\begin{tabular}{|c|c|c|}
\hline $\begin{array}{l}\text { Membrane/ } \\
\text { Coordinate }\end{array}$ & Target/Control & $\begin{array}{l}\text { Phosphorylation } \\
\text { Site }\end{array}$ \\
\hline $\mathrm{A}-\mathrm{A} 1, \mathrm{~A} 2$ & Reference Spot & - \\
\hline $\mathrm{A}-\mathrm{A} 3, \mathrm{~A} 4$ & p38a & $\mathrm{T} 180 / \mathrm{Y} 182$ \\
\hline A-A5, A6 & ERK $1 / 2$ & $\begin{array}{l}\text { T202/Y204, T185/ } \\
\text { Y187 }\end{array}$ \\
\hline A-A7, A8 & JNK $1 / 2 / 3$ & $\begin{array}{l}\mathrm{T} 183 / \mathrm{Y} 185, \mathrm{~T} 221 / \\
\text { Y223 }\end{array}$ \\
\hline $\mathrm{A}-\mathrm{A} 9 \mathrm{9}, \mathrm{A} 10$ & GSK-3a/B & $S 21 / 59$ \\
\hline B-A13,A14 & p53 & S392 \\
\hline B-A17, A18 & Reference Spot & - \\
\hline$A-B 3, B 4$ & EGF R & Y1086 \\
\hline$A-B 5, B 6$ & MSK $1 / 2$ & $S 376 / 5360$ \\
\hline$A-B 7, B 8$ & AMPKa1 & T183 \\
\hline$A-B 9, B 10$ & Akt $1 / 2 / 3$ & $\$ 473$ \\
\hline$B-B 11, B 12$ & Akt $1 / 2 / 3$ & T308 \\
\hline B-B13, B14 & p53 & $\$ 46$ \\
\hline $\mathrm{A}-\mathrm{C} 1, \mathrm{C} 2$ & TOR & $\mathbf{S 2 4 4 8}$ \\
\hline $\mathrm{A}-\mathrm{C} 3, \mathrm{C} 4$ & CREB & $\$ 133$ \\
\hline $\mathrm{A}-\mathrm{C} 5, \mathrm{C} 6$ & HSP27 & $578 / 582$ \\
\hline $\mathrm{A}-\mathrm{C} 7, \mathrm{C} 8$ & AMPKa2 & $\mathrm{T} 172$ \\
\hline A-C9, C10 & $\beta$-Catenin & - \\
\hline $\mathrm{B}-\mathrm{C} 11, \mathrm{C} 12$ & p70 S6 Kinase & T389 \\
\hline $\mathrm{B}-\mathrm{C} 13, \mathrm{C} 14$ & p53 & S15 \\
\hline $\mathrm{B}-\mathrm{C} 15, \mathrm{C} 16$ & C-Jun & $\$ 63$ \\
\hline$A-D 1, D 2$ & Sic & Y419 \\
\hline$A-D 3, D 4$ & Lyn & Y397 \\
\hline$A-D 5, D 6$ & Lck & Y394 \\
\hline$A-D 7, D 8$ & STAT2 & Y689 \\
\hline $\mathrm{A}-\mathrm{D9}, \mathrm{D} 10$ & STAISa & Y694 \\
\hline B-D11, D12 & p70 56 Kinase & $\mathrm{T} 421 / \mathrm{S} 424$ \\
\hline B-D13, D14 & $\mathrm{RSK} 1 / 2 / 3$ & S380/S386/S377 \\
\hline B-D15, D16 & eNOS & $\$ 1177$ \\
\hline
\end{tabular}

\begin{tabular}{|l|l|l|}
\hline $\begin{array}{l}\text { Membrane/ } \\
\text { Coordinate }\end{array}$ & Target/Control & $\begin{array}{l}\text { Phosphorylation } \\
\text { Site }\end{array}$ \\
\hline A-E1, E2 & Fyn & Y420 \\
\hline A-E3, E4 & Yes & Y426 \\
\hline A-ES, E6 & Fgr & Y412 \\
\hline A-E7, E8 & STAT6 & Y641 \\
\hline A-E9, E10 & STAT5b & Y699 \\
\hline B-E11, E12 & STAT3 & Y705 \\
\hline B-E13, E14 & P27 & T198 \\
\hline B-E15, E16 & PLC-Y1 & Y783 \\
\hline A-F1, F2 & Hdk & Y411 \\
\hline A-F3, F4 & Chk-2 & T68 \\
\hline A-F5, F6 & FAK & Y397 \\
\hline A-F7, F8 & PDGF RB & Y751 \\
\hline A-F9, F10 & STAT5a/b & Y694/ 6999 \\
\hline B-F11, F12 & STAT3 & S727 \\
\hline B-F13, F14 & WNK1 & T60 \\
\hline B-F15, F16 & PYK2 & Y402 \\
\hline A-G1, G2 & Reference Spot & - \\
\hline A-G3, G4 & PRAS40 & T246 \\
\hline A-G9, G10 & PBS (Negative Control) & - \\
\hline B-G11, G12 & HSP60 & - \\
\hline B-G17, G18 & PBS (Negative Control) & - \\
\hline & & \\
\hline
\end{tabular}

